\title{
DISTRIBUIÇÃO DE RENDA E POBREZA NO ESTADO DE MINAS GERAIS
}

\section{ROSYCLER CRISTINA SANTOS SIMÃO}

\author{
Dissertação apresentada à Escola Superior de \\ Agricultura "Luiz de Queiroz", Universidade de \\ São Paulo, para obtenção do título de mestre em \\ Ciências, Área de Concentração: Economia \\ Aplicada.
}

P I R A C I C A B A

Estado de São Paulo - Brasil

Abril - 2004 


\title{
DISTRIBUIÇÃO DE RENDA E POBREZA NO ESTADO DE MINAS GERAIS
}

\section{ROSYCLER CRISTINA SANTOS SIMÃo}

Bacharel em Ciências Econômicas

\section{Orientador: Prof. Dr. RODOLFO HOFFMANN}

\author{
Dissertação apresentada à Escola Superior de \\ Agricultura "Luiz de Queiroz", Universidade de \\ São Paulo, para obtenção do título de mestre em \\ Ciências, Área de Concentração: Economia \\ Aplicada.
}

P I R A C I C A B A

Estado de São Paulo - Brasil

Abril - 2004 


\section{Dados Internacionais de Catalogação na Publicação (CIP) DIVISÃO DE BIBLIOTECA E DOCUMENTAÇÃO - ESALQ/USP}

\section{Simão, Rosycler Cristina Santos}

Distribuição de renda e pobreza no Estado de Minas Gerais / Rosycler Cristina

Santos Simão. - - Piracicaba, 2004.

$112 \mathrm{p}$.

Dissertação (mestrado) - - Escola Superior de Agricultura Luiz de Queiroz, 2004.

Bibliografia.

1. Desigualdade de renda 2. Distribuição de renda 3. Minas Gerais 4. Pobreza Título

CDD 339.2

"Permitida a cópia total ou parcial deste documento, desde que citada a fonte - O autor" 


\section{OFEREÇO}

A Lourdes Barbosa

A Marcelo Barbosa 


\section{SUMÁRIO}

Página

LISTA DE FIGURAS........................................................................... vii

LISTA DE TABELAS.............................................................................. viii

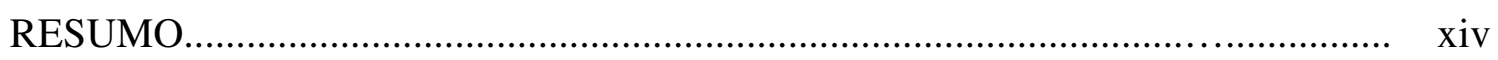

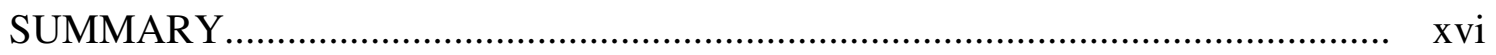

1 INTRODUÇÃO

1.1 O problema e sua importância ............................................................ 1

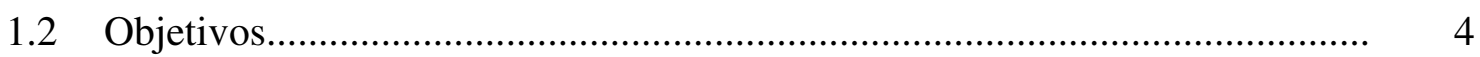

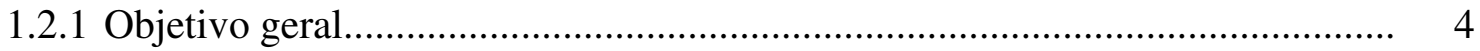

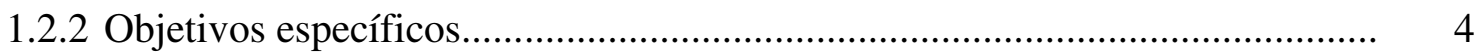

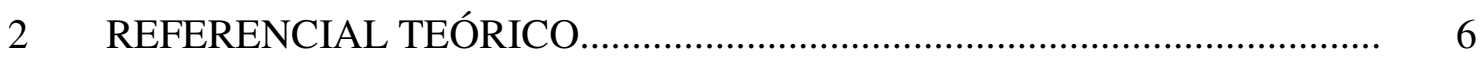

2.1 A história da desigualdade brasileira......................................................... 6

2.2 O estado de Minas Gerais........................................................................ 11

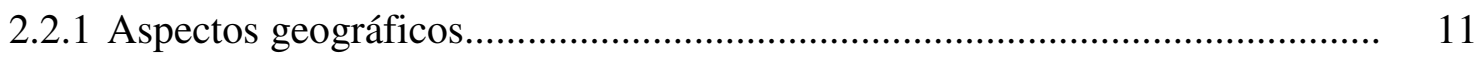

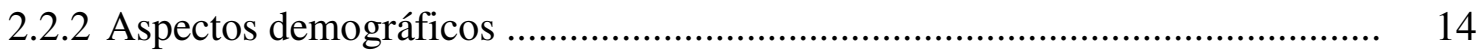

2.2.3 Aspectos socioeconômicos.............................................................. 15

2.2.4 Índice de Desenvolvimento Humano de Minas Gerais................................. 20

2.2.5 Caracterização das regiões mineiras......................................................... 23

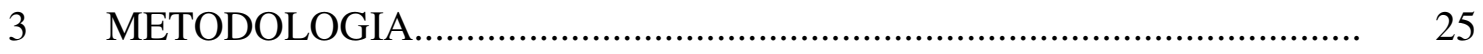

3.1 Medidas de desigualdade ................................................................ 25

3.1.1 Curva de Lorenz e o índice de Gini........................................................... 25

3.1.2 Curvas de concentração e decomposição do índice de Gini......................... 27 
3.1.3 Medidas de desigualdade de Theil......................................................... $\quad 30$

3.1.4 As separatrizes e outras medidas de desigualdade.......................................... 31

3.2 Medidas de pobreza …………............................................................... 32

3.2.1 Proporção de pobres ............................................................................. 33

3.2.2 Razão de insuficiência de renda ................................................................ 33

3.2.3 Índice de Foster, Greer e Thorbecke (FGT).............................................. 33

3.3 Equações de rendimento........................................................................... 34

$3.4 \quad$ Base de dados ................................................................................. 36

$3.5 \quad$ As variáveis................................................................................. 38

$4 \quad$ RESULTADOS E DISCUSSÃO................................................................ 42

4.1 A distribuição do rendimento domiciliar per capita........................................... 43

4.2 A contribuição dos componentes do rendimento domiciliar per capita para a desigualdade......................................................................................... 52

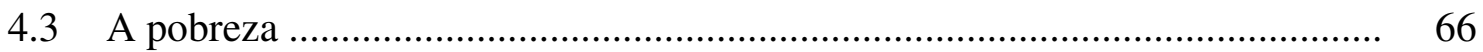

4.4 A distribuição do rendimento das pessoas ocupadas......................................... 69

4.5 As equações de rendimento ........................................................................ 75

4.6 Comparações da amostra do censo com os dados da PNAD de 2001............. 86

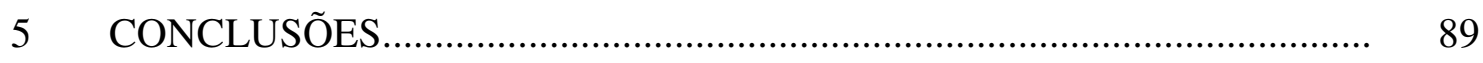

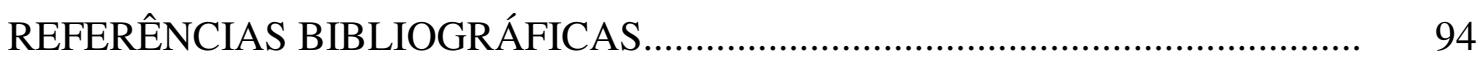

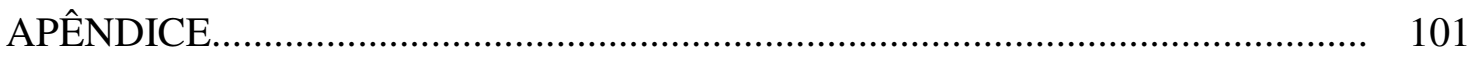




\section{LISTA DE FIGURAS}

\section{Página}

1 Mesorregiões geográficas de Minas Gerais.

2 Regiões de planejamento de Minas Gerais .................................................... 14

3 Classificação dos 10 estados brasileiros de maior PIB per capita....................... 19

4 Curva de Lorenz e curva de concentração do componente aluguel da renda domiciliar per capita, Minas Gerais............................................................. 26

5 A participação das mesorregiões no total da renda declarada .......................... 45

6 A renda domiciliar per capita média e o IDH-M das mesorregiões

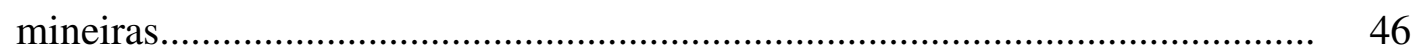

7 As curvas de concentração para os componentes do rendimento domiciliar per capita, em Minas Gerais, 2000 ............................................................ $\quad 66$

8 Coeficientes estimados para as variáveis binárias "anos de estudo", e o "threshold effect". 


\section{LISTA DE TABELAS}

\section{Página}

1 Índice de Gini da distribuição do rendimento domiciliar per capita nas unidades federativas brasileiras, 2000 .............................................................. 9

$2 \quad$ As 12 mesorregiões mineiras e suas 66 microrregiões........................................ 13

3 A população e sua participação nas 12 mesorregiões mineiras............................ 15

4 Taxas de crescimento médio anual do PIB: Brasil e algumas unidades da

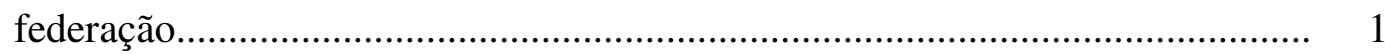

5 PIB dos cinco mais importantes estados brasileiros e a sua participação no PIB do Brasil, no ano de 2000....................................................................... 18

6 Produto Interno Bruto a preços correntes, segundo os setores de atividade econômica em Minas Gerais, 2000.................................................................. 18

7 Índice de Desenvolvimento Humano nas unidades da federação brasileira, $1991 / 2000$

8 Dados para exemplo numérico para a decomposição do índice de

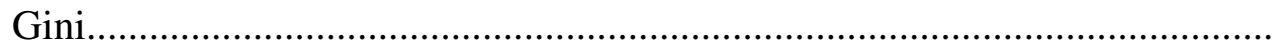

9 Número de domicílios e pessoas, na amostra e na população, de acordo com os dados da amostra do censo de 2000 . 
10 Distribuição das pessoas com 10 anos ou mais de idade em estratos de rendimento de todos os trabalhos

11 Índice de Desenvolvimento Humano (IDH-M) nas 12 mesorregiões mineiras, em 2000

12 Número de domicílios particulares permanentes e de pessoas, na amostra e na população, em Minas Gerais e nas 12 mesorregiões mineiras, de acordo com os dados da amostra do censo de 2000

13 Principais características da distribuição do rendimento domiciliar per capita em Minas Gerais e nas 12 mesorregiões mineiras, de acordo com a amostra do censo de 2000

14 Distribuição dos domicílios e das pessoas em 9 estratos de rendimento domiciliar per capita, na população de acordo com a amostra do censo de 2000 .

15 Proporção de pessoas em domicílios com rendimento per capita igual a zero, em Minas Gerais e nas 12 mesorregiões mineiras, de acordo com dados da amostra do censo de 2000

16 Participação percentual dos componentes do rendimento domiciliar per capita em Minas Gerais e nas 12 mesorregiões mineiras, de acordo com dados da amostra do censo de 2000

17 Decomposição do índice de Gini do rendimento domiciliar per capita em Minas e nas mesorregiões mineiras, em 2000: razão de concentração $\left(C_{h}\right)$, parcela do componente no índice de Gini global $\left(\varphi_{h} C_{h}\right)$ e contribuição

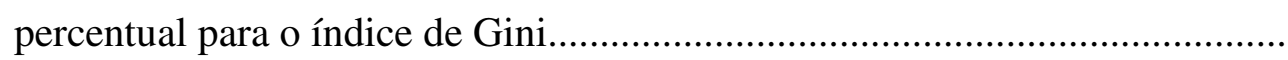


18 Correlação simples entre o IDH-M e a razão de concentração das mesorregiões mineiras, em 2000 e probabilidade caudal do teste da hipótese de ausência de correlação

19 Número de pessoas com rendimento positivo para aposentadorias e pensões na amostra, $n^{0}$ de pessoas com rendimento positivo para aposentadoria e pensões na população, a participação percentual de aposentados e pensionistas $\left(\%_{\mathrm{A}}\right)$, participação de aposentados e pensionistas na população das mesorregiões $\left(\%_{\mathrm{B}}\right)$ e o valor médio das aposentadorias e pensões pagas, em 2000 .

20 Número de pessoas pobres na população, a proporção de pessoas pobres, índice de Foster, Greer e Thorbecke (FGT) e a razão de insuficiência (I) da renda domiciliar per capita, adotando uma linha de pobreza com valor real igual a $\mathrm{R} \$ 76,00$, de acordo com a amostra do censo de 2000

21 Pessoas ocupadas em Minas Gerais e nas 12 mesorregiões com declaração do rendimento de todos os trabalhos: tamanho da amostra e da população, porcentagem sem rendimento e número de pessoas com rendimento positivo, em 2000

22 Principais características da distribuição do rendimento de todos os trabalhos de pessoas ocupadas (somente pessoas com rendimento positivo, utilizadas na estimação das equações de rendimento), em Minas Gerais e nas 12 mesorregiões mineiras, de acordo com dos dados da amostra do censo de 2000

23 Equações de rendimento para pessoas ocupadas em Minas Gerais, considerando o rendimento de todos os trabalhos, de acordo com os dados da amostra do censo de 2000 . 
24 A contribuição marginal de cada fator para a soma dos quadrados de regressão das equações de rendimento ajustadas.........................................

25 Equações de rendimento para pessoas ocupadas em Minas Gerais, considerando o rendimento de todos os trabalhos, incluindo variáveis de interação, de acordo com os dados da amostra do censo de 2000 .

26 Principais características da distribuição do rendimento domiciliar per capita, em Minas Gerais, de acordo com dados da PNAD de 2001 e do Censo Demográfico 2000.

27 Número de pessoas na amostra e na população com rendimento positivo para aposentadorias e pensões que residem na zona rural das mesoregiões e a sua participação, em 2000

28 Distribuição dos domicílios e das pessoas em estratos de rendimento de aposentadorias e pensões em Minas Gerais, em 2000

29 Distribuição dos domicílios e das pessoas em estratos de rendimento de aposentadorias e pensões no Noroeste de Minas, em 2000.

30 Distribuição dos domicílios e das pessoas em estratos de rendimento de aposentadorias e pensões no Norte de Minas, em 2000.

31 Distribuição dos domicílios e das pessoas em estratos de rendimento de aposentadorias e pensões no Vale do Jequitinhonha, em 2000........

32 Distribuição dos domicílios e das pessoas em estratos de rendimento de aposentadorias e pensões no Vale do Mucuri, em 2000.

33 Distribuição dos domicílios e das pessoas em estratos de rendimento de aposentadorias e pensões no Triângulo Mineiro/Alto Paranaíba, em 2000 . 
34 Distribuição dos domicílios e das pessoas em estratos de rendimento de aposentadorias e pensões na Central Mineira, em 2000.

35 Distribuição dos domicílios e das pessoas em estratos de rendimento de aposentadorias e pensões na Metropolitana de Belo Horizonte, em 2000

36 Distribuição dos domicílios e das pessoas em estratos de rendimento de aposentadorias e pensões no Vale do Rio Doce, em 2000

37 Distribuição dos domicílios e das pessoas em estratos do rendimento de aposentadorias e pensões no Oeste de Minas, em 2000

38 Distribuição dos domicílios e das pessoas em estratos de rendimento de aposentadorias e pensões no Sul/Sudoeste de Minas, em 2000

39 Distribuição dos domicílios e das pessoas em estratos de rendimento de aposentadorias e pensões no Campo das Vertentes, em 2000

40 Distribuição dos domicílios e das pessoas em estratos do rendimento de aposentadorias e pensões na Zona da Mata, em 2000

41 Número de pessoas beneficiárias do rendimento renda mínima, bolsa escola seguro desemprego de valor $\leq \mathrm{R} \$ 151,00$ e que residem em domicílios com renda domiciliar per capita $\leq \mathrm{R} \$ 760,00$, conforme dados da amostra do censo de 2000

42 Equações de rendimento para pessoas ocupadas em Minas Gerais, considerando o rendimento de todos os trabalhos, incluindo o "threshold effect", de acordo com a amostra do censo de 2000. 
43 Equações de rendimento para pessoas ocupadas em Minas Gerais, considerando o rendimento de todos os trabalhos, conforme setor de ocupação, de acordo com a amostra do censo de 2000 ...................................

44 Correlação simples entre a taxa de retorno da educação, o IDH-M, renda média das pessoas ocupadas e participação do setor de serviços nas mesorregiões mineiras e probabilidade caudal do teste de hipótese de

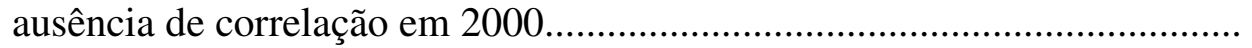




\title{
DISTRIBUIÇÃO DE RENDA E POBREZA NO ESTADO DE MINAS GERAIS
}

\author{
Autora: ROSYCLER CRISTINA SANTOS SIMÃO \\ Orientador: Prof. Dr. RODOLFO HOFFMANN
}

\section{RESUMO}

Minas Gerais é um dos estados que mais se destaca pelas disparidades regionais. Coexistem no estado regiões dinâmicas e modernas em contraste com regiões atrasadas e estagnadas. Neste contexto, o objetivo deste trabalho foi de analisar a distribuição de renda e pobreza em Minas Gerais, destacando as desigualdades regionais do estado, considerando a divisão do estado em 12 mesorregiões. Cada mesorregião apresenta um nível de desenvolvimento medido pelo Índice de Desenvolvimento Humano Municipal (IDH-M). Para a análise foram usadas medidas de desigualdade, medidas de posição e modelos de regressão múltipla. A principal base de dados utilizada é o Censo Demográfico de 2000 do Instituto Brasileiro de Geografia e Estatística. Para o cumprimento dos objetivos, foram analisados dois tipos de distribuição: do rendimento domiciliar per capita e das pessoas ocupadas com rendimento. Verificou-se que a desigualdade da distribuição da renda domiciliar per capita tende a ser menor nas mesorregiões mais desenvolvidas do que nas mesorregiões menos desenvolvidas. $\mathrm{O}$ rendimento domiciliar per capita foi dividido em 7componentes: rendimento do trabalho principal; rendimento demais trabalhos; aposentadorias e pensões; aluguéis; pensão alimentícia, mesada, doação; renda mínima, bolsa escola, seguro desemprego e outros rendimentos. Dessas 7 parcelas, 3 delas (rendimento trabalho principal, aposentadorias e pensões e renda mínima/bolsa escola e seguro desemprego) contribuem para diminuir a 
desigualdade, enquanto as 4 restantes (demais trabalhos, aluguéis, pensão alimentícia/mesada/doação e outros rendimentos) contribuem para aumentar a desigualdade. Na análise regional, constatou-se que as razões de concentração do rendimento do trabalho principal e dos aluguéis estão negativamente correlacionados com o nível de desenvolvimento das mesorregiões, medido pelo IDH-M. Por outro lado, as razões de concentração do rendimento dos demais trabalhos e de outros rendimentos estão positivamente correlacionados com o nível de desenvolvimento regional. $\mathrm{Na}$ mensuração da pobreza observou-se que as mesorregiões Jequitinhonha, Vale do Mucuri e Norte de Minas estão em situação crítica de pobreza, sendo que mais da metade da população é considerada pobre. O número de pessoas pobres atendidas pelos programas de renda mínima, bolsa escola e seguro desemprego nessas mesorregiões é ainda pequeno, sugerindo a expansão desses benefícios. Analisando a distribuição do rendimento das pessoas ocupadas, observou-se que a educação se destaca como o principal condicionante da desigualdade entre elas. Também foi destacado que a taxa de retorno da educação não é constante para todos os níveis de escolaridade. Notou-se que, além da taxa de retorno da educação ter acréscimos maiores com a obtenção de um diploma, há um nítido aumento nessa taxa a partir dos 10 anos, devido ao "threshold effect". Observou-se que a taxa de retorno da educação está relacionada com a participação do setor de serviços nas mesorregiões, mas não se constatou a existência de uma relação monotônica entre essa taxa e o nível de desenvolvimento das mesorregiões. 


\title{
INCOME DISTRIBUTION AND POVERTY IN THE STATE OF MINAS GERIAS
}

\author{
Author: ROSYCLER CRISTINA SANTOS SIMÃO \\ Advisor: Prof. Dr. RODOLFO HOFFMANN
}

\section{SUMMARY}

Minas Gerais is one of the states that shows large differences among regions. On the one hand, there are dinamic and modern regions; on the other hand, backward and stagnated ones. In this context, the aim of this study was to analyze income distribution and povety in Minas Gerais, focusing on the regional inequalities in the state, dividing the state into 12 regions. The level of development of each region was measured by the Municipal Human Development Index. To carry out the analysis, measures of inequality, measures of position and multiple regression models were used. The main database used is the Demographic Census of 2000 from the Brazilian Institute of Geography and Statistics. Two types of income were considered: per capita household income and earnings of employed workers. It was noticed that the inequality of the per capita household income distribution tends to be smaller in more developed regions than in the less developed ones. The household income was divided into 7 components: earnings from the main job; earnings from other jobs; pensions; rents; alimony and donations; government income transfers and other incomes. Out of these 7 components, three of them ( earnings from the main job, pensions and government income transfer) contribute to reduce inequality, while the other 4 (earnings from other jobs, rents, 
alimony/donations and other incomes) contribute to increase inequality. In the regional analysis, it was observed that the concentration ratios of earnings from the main job and rents are negatively related to the level of development of the regions, measured by IDH-M. On the other hand, concentration ratios of earnings from other jobs and from other incomes are positively related to the level of regional development. In measuring poverty, it was noticed that the regions of Jequitinhonha, Vale do Mucuri and North of Minas Gerais are in a critical condition of poverty, with the majority of the population considered poor. The number of poor people assisted by the government income transfers programs in these regions is still too small, suggesting the expansion of such benefits. Analysing income distribution of employed people, it was observed that education is as the main determinant inequality. It was also highlighted that the education return rate is not constant for all levels of education. It was observed that, besides being higher at levels that correspond to a diploma, the education return rate shows an expressive increase from 10 years on, due to a "threshold effect". It was noticed that the education return rate is related to the participation of the service sector in the regions, but the dada did not show the existence of a monotonic relation between this rate and the level of development of the regions. 


\section{INTRODUÇÃO}

\subsection{O problema e sua importância}

O mundo moderno mostra que cada vez mais torna-se utópico imaginar uma sociedade onde reina a igualdade. Mas no caso brasileiro é assustador o grau da desigualdade ao longo destes mais de 500 anos de história de desenvolvimento. De acordo com Barros et al. (2000), a desigualdade de renda é tão parte da história brasileira que adquire status de coisa natural.

Mesmo que a maioria dos cidadãos deste país não sejam capazes de entender os estudos e as estatísticas relacionados ao tema, ainda assim, são visíveis aos olhos de todos as disparidades na distribuição da renda e sua contribuição na geração da pobreza. Barros et al. (2000, p.21) colocam que:

“... o Brasil não é um país pobre, mas um país com muitos pobres... os elevados níveis de pobreza que afligem a sociedade encontram seu principal determinante na estrutura da desigualdade brasileira, uma perversa desigualdade na distribuição da renda e das oportunidades de inclusão econômica e social".

A literatura indica uma relação muito estreita entre a pobreza e a desigualdade de renda. Para analisar essa relação cabe distinguir duas situações. A primeira é quando a desigualdade se faz presente nos países nos quais a renda nacional é insuficiente para garantir o mínimo considerado indispensável a cada um de seus cidadãos. Neste caso a renda per capita é baixa e a pobreza absoluta é inevitável. A segunda situação é a existência da desigualdade nos países onde o produto nacional é suficientemente elevado para garantir o mínimo necessário a todos, de modo que a pobreza resulta da má distribuição de renda (Rocha, 2001). 
A pobreza brasileira é determinada principalmente pela elevada desigualdade na distribuição dos recursos. As contas nacionais mostram que o PIB per capita ou Renda per capita no Brasil no ano 2000 foi de $\mathrm{R} \$ 6.473,00$, sendo que mais de $75 \%$ da população mundial vive em países com renda per capita inferior à brasileira (Barros \& Foguel, 2000).

Nas comparações internacionais, o Brasil é classificado no grupo de países que apresentam os maiores índices de desigualdade, considerando somente países que apresentam dados confiáveis de renda (Barros \& Medonça, 1995).

Um dos objetivos dos estudos sobre a distribuição de renda é ajudar na identificação das origens das desigualdades, servindo de subsidio para combatê-las. Os estudos empíricos, com abrangência nacional, iniciaram-se a partir da divulgação dos dados do Censo Demográfico de 1960. Desde então, uma vasta literatura vem sendo publicada dedicando-se a analisar os dados produzidos pelo Instituto Brasileiro de Geografia e Estatística (IBGE).

As principais bases de dados usadas nos estudos sobre a distribuição são o Censo Demográfico e a Pesquisa Nacional por Amostra de Domicílios (PNAD).

O Censo Demográfico Brasileiro tem periodicidade decenal desde 1890, mas somente no ano 1960 que a variável rendimento passa a ser investigada. O último Censo Demográfico no Brasil foi realizado em 2000, sendo coletadas informações básicas de toda a população brasileira e por técnica de amostragem, de maneira mais detalhada, características dos domicílios e seus moradores, incluindo o rendimento. Os dados são represetantivos para grandes regiões, unidades da federação, mesorregiões, microrregiões e municípios (IBGE, 2002a).

A PNAD foi criada em 1967 e ao longo de seus mais de 30 anos de existência o quesito rendimento sempre tem sido pesquisado. A PNAD apresenta periodicidade anual, com interrupções em anos censitários. Os seus dados são representativos para grandes regiões, unidades da federação e regiões metropolitanas (IBGE, 2001a).

As pesquisas sobre distribuição de renda do Brasil apontam os contrates do desenvolvimento entre regiões como um dos fatores que contribuem para que o quadro de disparidades de renda entre indivíduos e famílias dentro do país permaneça sem 
alterações substanciais. Geralmente, mencionam-se as diferenças de desigualdade dos estados das regiões sul e sudeste em comparação com os estados das regiões norte e nordeste (Kageyma \& Hoffmann, 2000).

Como o Brasil é um país continental, os desequilíbrios regionais não se limitam às diferenças entre os estados brasileiros, mas ocorrem também dentro dos estados. Porém, ainda há certa carência de estudos sobre a desigualdade de renda voltados mais diretamente para os estados brasileiros. Sendo assim, uma análise regional pode ser realizada para os estados. Para isso, basta adotar uma divisão regional e ter informações, a ser trabalhadas. Como o Censo Demográfico têm informações mais desagregadas para os estados do que a PNAD, ele é uma base de dados apropriada para o tipo de estudo pretendido.

No presente estudo desenvolve-se uma análise da desigualdade de renda e da pobreza no estado de Minas Gerais. Para isso, considera-se a divisão do estado em mesorregiões, adotada na metodologia do Censo Demográfico de 2000.

A escolha de Minas Gerais deve-se ao fato de que, dentre os estados brasileiros, ele é um dos que mais se destaca pelas grandes disparidades regionais.

Segundo Queiroz (2001, p.66), "o Estado de Minas Gerais é, provavelmente, uma das regiões mais heterogêneas do país; coexistem no estado regiões dinâmicas, modernas e com indicadores sócio-econômicos de alto nível com localidades atrasadas, estagnadas, que não oferecem a mínima condição de vida para a sua população".

Neste sentido, na realização de um detalhado estudo sobre a distribuição da renda em Minas Gerais, pretende-se contribuir, em plano estadual, para a compreensão da desigualdade de renda regional mineira.

Na seção 2.2 são mostrados mais detalhes a respeito das características do estado mineiro, destacando algumas das disparidades regionais. 


\subsection{Objetivos}

\subsubsection{Objetivo geral}

O objetivo geral do trabalho é analisar a distribuição de renda e a pobreza no estado de Minas Gerais (MG), utilizando os dados da amostra do censo demográfico de 2000.

\subsubsection{Objetivos específicos}

- Conhecer a distribuição da renda domiciliar per capita em Minas Gerais e nas mesorregiões mineiras, mostrando as relações do desenvolvimento das mesorregiões com as medidas de desigualdade;

- Examinar a contribuição das parcelas do rendimento ${ }^{1}$ domiciliar per capita para a desigualdade, verificando se há associação com o nível de desenvolvimento da mesorregião;

- Analisar o nível de pobreza nas mesorregiões mineiras, de acordo com rendimento domiciliar per capita;

- Conhecer a distribuição do rendimento da população economicamente ativa ocupada em Minas Gerais e nas mesorregiões mineiras;

- Analisar os determinantes dos rendimentos das pessoas ocupadas em Minas Gerais (equações de rendimento), verificando se o efeito da variável escolaridade está associado ao nível de desenvolvimento das mesorregiões;

\footnotetext{
${ }^{1} \mathrm{Na}$ amostra do censo 7 parcelas de rendimento formam o rendimento total e estão listadas na seção 3.5 .
} 
- Comparar os resultados sobre a desigualdade de distribuição de renda em Minas Gerais obtidos na amostra do censo de 2000 com os da PNAD de 2001, pois acredita-se que há diferenças nos resultados, conforme a base de dados utilizada, PNAD ou amostra do censo. Uma razão possível para isso é que os dados do censo, por constituírem uma amostra muito maior, captam melhor os rendimentos extremamente elevados; 


\section{REFERENCIAL TEÓRICO}

\subsection{A história da desigualdade brasileira}

A desigualdade da distribuição da renda no Brasil é um tema que tem sido intensamente debatido por diversos acadêmicos (sociólogos, historiadores, antropólogos e economistas), gerando controvérsias por sua complexidade e pela elevada carga de julgamentos éticos envolvidos na questão.

No conjunto das explicações para essa desigualdade, não se pode deixar de levar em conta os aspectos históricos e institucionais do período colonial brasileiro, que influenciaram o perfil distributivo da renda na época, cujos efeitos perduram até hoje. ${ }^{2}$

Um aspecto fundamental desse período refere-se à distribuição da posse de terra em grandes latifúndios, associada ao desenvolvimento do modelo agrário exportador de produtos primários. Essa opção política pela grande propriedade rural no período colonial acarretou ao Brasil do século XXI uma estrutura fundiária altamente concentrada, caracterizada pela coexistência de latifúndios e minifúndios. Um outro aspecto, também de fundamental importância, foi o processo de escravismo e a maneira como ocorreu o processo abolicionista dos negros, relegando-os a uma situação marginal na sociedade brasileira (Gremaud et al., 2002 e Furtado, 1967).

Logo após a divulgação dos dados do censo de 1970, dois estudos mostraram um grande crescimento da desigualdade da distribuição da renda no Brasil entre 1960 e 1970: os de Fishlow (1972) e Hoffmann \& Duarte (1972). Dada a conjuntura da época, esse aumento de desigualdade transformou-se em elemento importante na crítica da política econômica e social dos governos militares (Hoffmann, 2001c).

\footnotetext{
${ }^{2}$ Está fora do âmbito deste trabalho fazer uma discussão completa dessa literatura.
} 
Posteriormente, em 1973, Langoni publica um livro descrevendo a distribuição da renda no Brasil, distinguindo-se dos demais trabalhos já realizados pelo fato de ser apoiado pelo ministro da fazenda da época, Antônio Delfim Neto. Langoni confirma o aumento da desigualdade entre 1960 e 1970. A partir daí, criou-se um consenso sobre o aumento da desigualdade, concentrando a polêmica na interpretação do fenômeno.

$\mathrm{Na}$ argumentação de Langoni (1973), o aumento da desigualdade era conseqüência das profundas modificações que acompanharam o processo de desenvolvimento econômico brasileiro entre 1960 e 1970. Para ele, grande parcela do aumento de desigualdade observado estava intimamente ligada às mudanças qualitativas (nível de educação, idade e sexo) e alocativas (setorial e regional) da força de trabalho. Assim, o aumento de concentração da renda no período era transitório e corrigível no longo prazo.

De forma alternativa, alguns autores enfatizaram as políticas adotadas pelo governo militar no período pós-64 de combate à inflação, que incluíam uma série de medidas desfavoráveis à manutenção dos salários reais como, por exemplo, a intervenção nos sindicatos trabalhistas e repressão aos movimentos sociais (Ramos \& Reis, 1991).

Para Hoffmann (2002b), de acordo com essas duas interpretações seria de se esperar que terminada a fase de crescimento rápido ou encerrada a ditadura haveria uma redução na desigualdade. No entanto, os resultados empíricos recentes mostram que isso não ocorreu.

Segundo Mendonça e Barros (1995), as curvas de Lorenz para os anos de 1960, 1970, 1980 e 1990 revelam que as desigualdades de renda apresentaram um crescimento contínuo ao longo desses 30 anos analisados.

Com a divulgação dos dados do censo de 1980 constatou-se que a distribuição de renda havia se tornado ainda mais concentrada nos anos 70, embora o aumento da desigualdade tenha sido muito menor do que nos anos 60 (Bonelli, 1993).

Novamente, na "década perdida" dos anos 80, as medidas de desigualdade voltaram a aumentar substancialmente, alcançando um pico em 1989. Fatores 
conjunturais como inflação e o baixo valor do salário mínimo foram responsabilizados por tais resultados.

O estudo de Hoffmann (1998b), analisando o período de 1979-97, mostrou que a desigualdade da distribuição da renda aumenta com a inflação e está negativamente relacionada com o valor do salário mínimo.

A tendência crescente da desigualdade da renda se manteve até o início da década de 90. Somente com o advento do Plano Real, em julho de 1994, houve uma recuperação expressiva do nível de rendimentos, acompanhada de progressos distributivos também importantes (Coelho \& Corseuil, 2002).

Mas cabe ressaltar que deve-se ter uma certa cautela ao relacionar as mudanças ocorridas entre 1993 a 1995 ao plano Real, uma vez que o crescimento econômico tem determinantes mais complexos. Nota-se que entre 1993 e 2001 houve uma substancial redução da desigualdade da distribuição do rendimento das pessoas economicamente ativas. Entretanto, a redução da desigualdade no período torna-se quase desprezível quando analisada a distribuição do rendimento familiar per capita Hoffmann (2002b).

Passados já 30 anos dos trabalhos pioneiros de Fishlow e Hoffmann \& Duarte, o Brasil do século XXI ainda tem uma distribuição de renda muito concentrada. O índice de Gini para o Brasil nesse início de século, mesmo com a tendência declinante na década de 90 é ainda maior do que o apresentado 3 décadas antes.

A título de exemplo, a Tabela 1 mostra as diferenças de desigualdade de renda entre as unidades federativas do país. O índice de Gini da tabela está medindo o grau de desigualdade existente na distribuição de indivíduos segundo a renda domiciliar per capita nos anos de 1991 e 2000. ${ }^{3}$ Em 2000, dentre os estados do país, o estado com o menor valor para o Gini é Santa Catarina $(\mathrm{G}=0,560)$, e o estado com o pior valor para o Gini é Alagoas $(\mathrm{G}=0,691)$.

\footnotetext{
${ }^{3}$ Essa tabela foi extraída do software Atlas de Desenvolvimento Humano do Brasil. Os dados do censo demográfico são utilizados no Atlas. Na seção 2.2.4 há uma explicação mais detalhada a respeito do Atlas de Desenvolvimento Humano do Brasil.
} 
Tabela 1. Índice de Gini da distribuição do rendimento domiciliar per capita nas unidades federativas brasileiras, 2000.

\begin{tabular}{|c|c|c|}
\hline \multirow[t]{2}{*}{ Estados } & \multicolumn{2}{|c|}{ Ano } \\
\hline & 1991 & 2000 \\
\hline \multicolumn{3}{|l|}{ Norte } \\
\hline Rondônia & 0,612 & 0,614 \\
\hline Acre & 0,623 & 0,648 \\
\hline Amazonas & 0,623 & 0,683 \\
\hline Roraima & 0,647 & 0,622 \\
\hline Pará & 0,619 & 0,655 \\
\hline Amapá & 0,582 & 0,637 \\
\hline Tocantins & 0,627 & 0,662 \\
\hline \multicolumn{3}{|l|}{ Nordeste } \\
\hline Maranhão & 0,599 & 0,659 \\
\hline Piauí & 0,636 & 0,661 \\
\hline Ceará & 0,654 & 0,675 \\
\hline Rio Grande do Norte & 0,628 & 0,657 \\
\hline Paraíba & 0,634 & 0,646 \\
\hline Pernambuco & 0,654 & 0,673 \\
\hline Alagoas & 0,625 & 0,691 \\
\hline Sergipe & 0,627 & 0,658 \\
\hline Bahia & 0,664 & 0,669 \\
\hline \multicolumn{3}{|l|}{ Sudeste } \\
\hline Minas Gerais & 0,614 & 0,615 \\
\hline Espírito Santo & 0,598 & 0,608 \\
\hline Rio de Janeiro & 0,609 & 0,614 \\
\hline São Paulo & 0,555 & 0,592 \\
\hline \multicolumn{3}{|l|}{ Sul } \\
\hline Paraná & 0,597 & 0,607 \\
\hline Santa Catarina & 0,546 & 0,560 \\
\hline Rio Grande do Sul & 0,585 & 0,586 \\
\hline \multicolumn{3}{|l|}{ Centro-Oeste } \\
\hline Mato Grosso do Sul & 0,604 & 0,627 \\
\hline Mato Grosso & 0,598 & 0,630 \\
\hline Goiás & 0,585 & 0,611 \\
\hline Distrito Federal & 0,614 & 0,640 \\
\hline
\end{tabular}

Fonte: PNUD, IPEA \& FJP (2003) 
De acordo com a tabela 1 , no ano 2000 , as 27 unidades federativas brasileiras estão distribuídas nos seguintes intervalos de índice de Gini: entre 0,55 e 0,58 (3,7\%), entre 0,58 e $0,60(7,4 \%)$, entre 0,60 e $0,63(25,9 \%)$, entre 0,63 e $0,65(22,2 \%)$ e entre 0,65 e $0,68(40,7 \%)$, mostrando como é elevada a desigualdade de renda nas unidades federativas brasileiras. Particularmente, Minas Gerais é o estado que apresenta maior valor para o índice de Gini entre os estados da região sul e sudeste.

Nos estudos sobre distribuição de renda com abrangência nacional, o estado de Minas Gerais é apenas citado. Além disso, o Banco de Desenvolvimento de Minas Gerais (BDMG) publicou em 2002 um amplo estudo a respeito de Minas Gerais no século XXI incluindo os mais variados temas, mas com carência de informações sobre a desigualdade de renda. Neste sentido esse trabalho vem preencher essa lacuna. 


\subsection{O estado de Minas Gerais}

Como a área de estudo limita-se ao estado de Minas, nesta seção são delineados os perfis geográficos, demográficos e socioeconômicos do estado.

\subsubsection{Aspectos geográficos}

Minas Gerais pertence, juntamente com os Estados do Rio de Janeiro, Espírito Santo e São Paulo, à região Sudeste do Brasil. Os $588384 \mathrm{~km}^{2}$ de área total conduzem Minas Gerais a participações de 6,9 \% no total territorial do Brasil e de 63,5\% no total da região Sudeste, ocupando, assim a $4^{\circ}$ posição em extensão territorial brasileira (Anuário Estatístico de Minas Gerais, 2001).

Nesta vasta e diversificada porção territorial estão distribuídos 853 municípios. ${ }^{4}$ As disparidades mineiras já começam em relação ao tamanho desses municípios. Em média, um município mineiro apresenta uma extensão territorial de $690 \mathrm{~km}^{2}$. No entanto, quarenta e um municípios apresentam menos de $100 \mathrm{~km}^{2}$ de extensão e apenas sete apresentam áreas superiores $5000 \mathrm{~km}^{2}$.

$\mathrm{Na}$ organização da divisão territorial brasileira, a metodologia aplicada pelo IBGE trabalha com os conceitos de microrregião e mesorregião. Segundo IBGE (2002a, p.16),

“As microrregiões são um conjunto de municípios, contíguos e contidos na mesma unidade da federação, agrupados com base em características do quadro natural, da organização da produção e de sua integração. As mesorregiões são um conjunto de microrregiões também agrupadas com base no quadro natural, no processo social e na rede de comunicações e de lugares".

\footnotetext{
${ }^{4}$ Minas Gerais ocupa a posição de estado com maior número de municípios, entre todos os estados brasileiros.
} 
De acordo com essas classificações, há em Minas Gerais 12 mesorregiões e 66 microrregiões. As mesorregiões mineiras são: Noroeste de Minas, Norte de Minas, Jequitinhonha, Vale do Mucuri, Triângulo Mineiro/Alto do Paranaíba, Central Mineira, Metropolitana de Belo Horizonte (sede da capital mineira), Vale do Rio Doce, Oeste de Minas, Sul/Sudoeste de Minas, Campo das Vertentes e Zona da Mata. A Figura 1 mostra a distribuição geográfica das 12 mesorregiões.

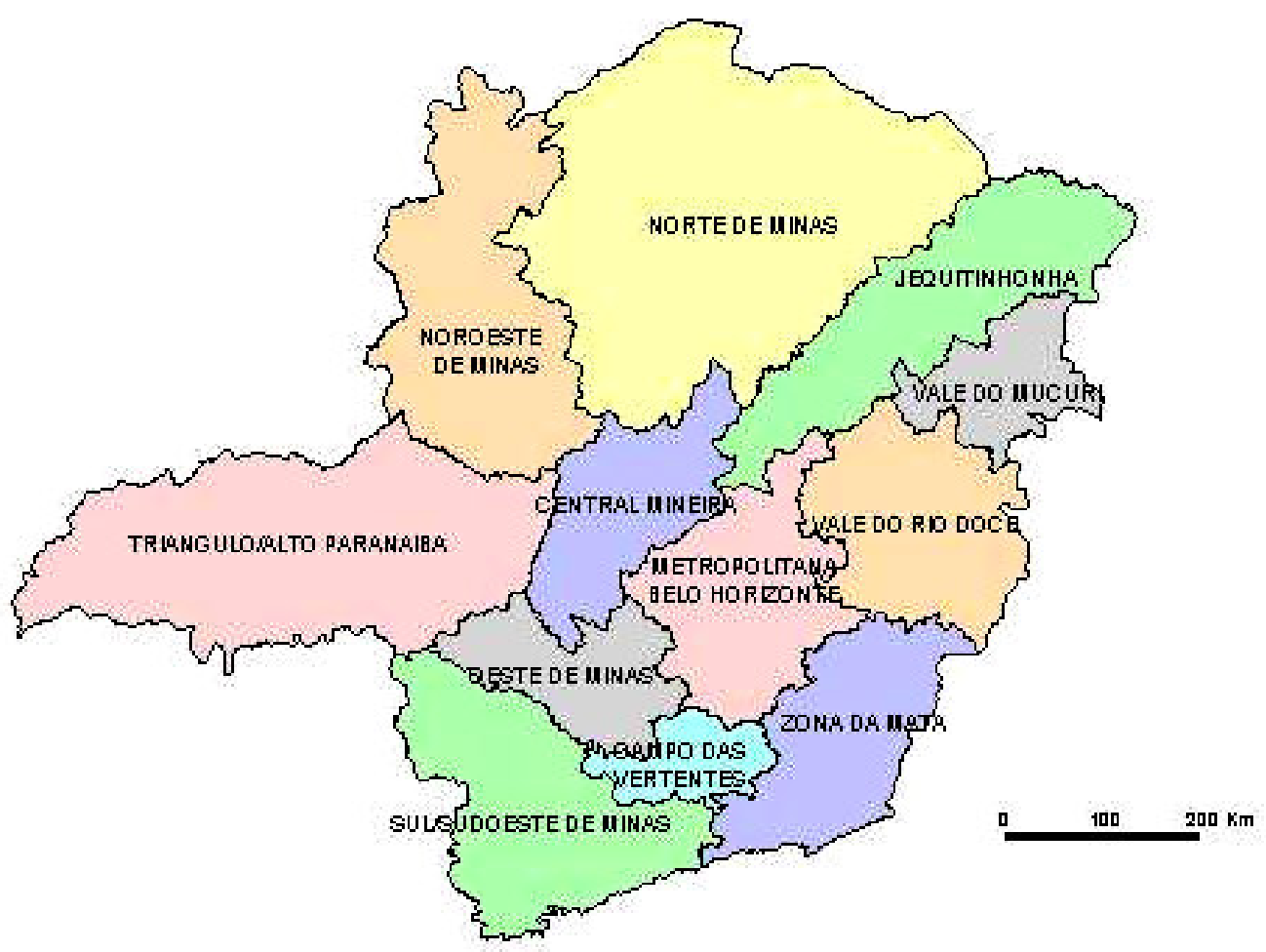

Figura 1 - Mesorregiões geográficas de Minas Gerais.

Fonte: Minas Gerais (2003)

A Tabela 2 mostra como as 66 microrregiões estão agregadas nas mesorregiões. O número de microrregiões em cada mesorregião é: Noroeste de Minas (2), Norte de Minas (7), Jequitinhonha (5), Vale do Mucuri (2), Triângulo Mineiro/Alto Paranaíba (7), Central Mineira (3), Metropolitana de Belo Horizonte (8), Vale do Rio Doce (7), Oeste de Minas (6), Sul/Sudoeste de Minas (9), Campo das Vertentes (3) e Zona da Mata (7).

Além dessa divisão regional feita pelo o IBGE, o governo estadual mineiro promove uma divisão regional para fins de planejamento, dividindo o estado mineiro em 10 regiões de planejamento (Zona da Mata, Noroeste de Minas, Norte de Minas, Rio 
Doce, Sul de Minas, Centro Oeste de Minas, Triângulo Mineiro, Alto Paranaíba, Jequitinhonha/Mucuri e Central Mineira), como mostra a Figura 2.

Tabela 2. As 12 mesorregiões mineiras e suas 66 microrregiões.

\begin{tabular}{|c|c|}
\hline Mesorregiões & Microrregiões \\
\hline Noroeste de Minas & Unaí e Paracatu \\
\hline Norte de Minas & $\begin{array}{l}\text { Januária, Janaúba, Salinas, Pirapora, } \\
\text { Montes Claros, Grão Mogol e Bocaiúva. }\end{array}$ \\
\hline Jequitinhonha & $\begin{array}{l}\text { Almenara, Araçuaí, Capelinha, Pedra } \\
\text { Azul e Diamantina. }\end{array}$ \\
\hline Vale do Mucuri & Teófilo Otoni e Nanuque \\
\hline Triângulo Mineiro/ Alto Paranaíba & $\begin{array}{l}\text { Ituiutaba, Uberlândia, Patrocínio, Patos de } \\
\text { Minas, Frutal, Uberaba e Araxá. }\end{array}$ \\
\hline Central Mineira & Três Marias, Curvelo e Bom Despacho. \\
\hline Metropolitana de Belo Horizonte & $\begin{array}{l}\text { Sete Lagoas, Conceição do Mato Dentro, } \\
\text { Pará de Minas, Belo Horizonte, Itabira, } \\
\text { Itaguara, Ouro Preto e Conselheiro } \\
\text { Lafaiete. }\end{array}$ \\
\hline Vale do Rio Doce & $\begin{array}{l}\text { Guanhães, Peçanha, Governador } \\
\text { Valadares, Mantena, Ipatinga, Caratinga e } \\
\text { Aimorés. }\end{array}$ \\
\hline Oeste de Minas & $\begin{array}{l}\text { Piui, Campo Belo, Oliveira, Divinópolis e } \\
\text { Formiga. }\end{array}$ \\
\hline Sul/ Sudoeste de Minas & $\begin{array}{l}\text { São Sebastião do Paraíso, Alfenas, } \\
\text { Varginha, Poços de Caldas, Pouso Alegre, } \\
\text { Santa Rita do Sapucaí, São Lourenço, } \\
\text { Andrelândia, Itajubá e Passos. }\end{array}$ \\
\hline Campo das Vertentes & Lavras, São João Del Rei e Barbacena. \\
\hline Zona da Mata & $\begin{array}{l}\text { Ponte Nova, Manhuaçu, Viçosa, Muriaé, } \\
\text { Ubá, Juiz de Fora e Cataguases. }\end{array}$ \\
\hline
\end{tabular}

Fonte: IBGE (2002a) 


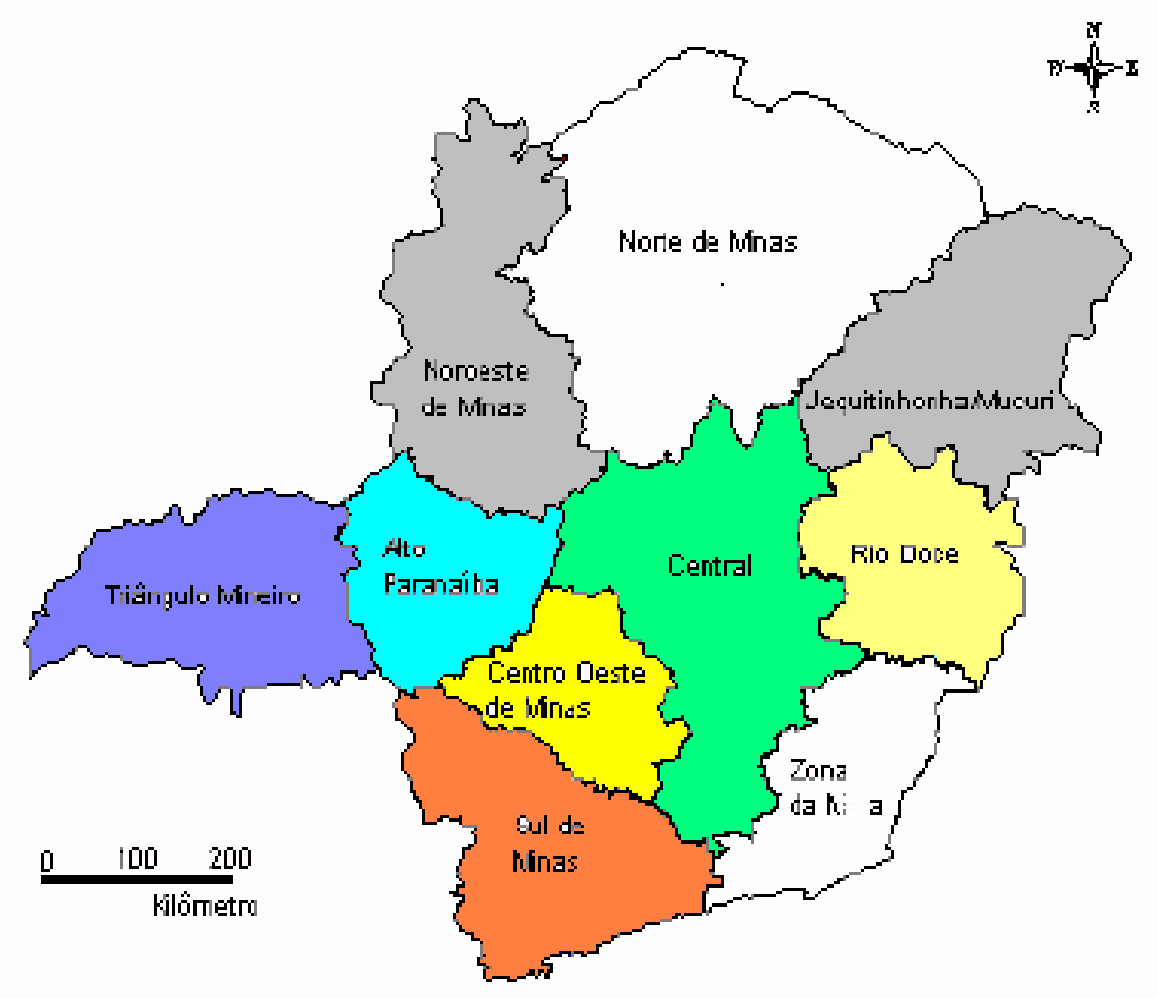

Figura 2 - Regiões de planejamento de Minas Gerais.

Fonte: Santana (2002)

Conforme ilustram os dois mapas das figuras 1 e 2, as duas divisões regionais são muito parecidas. As regiões de planejamento diferem das mesorregiões basicamente em três aspectos: há uma separação do Triângulo e Alto Paranaíba; o Vale do Mucuri e o Jequitinhonha estão agregados e as regiões Central e Oeste têm uma demarcação territorial diferente.

\subsubsection{Aspectos demográficos}

Segundo o censo do IBGE para o ano 2000, a população mineira é de 17.891.494 habitantes, que o torna o segundo maior estado do Brasil em número de habitantes, perdendo apenas para São Paulo. Essa população, que corresponde a 10,54\% da população nacional, está localizada, em sua maioria (82\%) em áreas urbanas e apenas 
$18 \%$ em áreas rurais. A proporção de homens e mulheres é respectivamente de 49,47\% e $50,53 \%$, ou seja, há 8.851.587 homens e 9.039.907 mulheres.

A Tabela 3 mostra a distribuição da população nas doze mesorregiões mineiras. Há uma concentração populacional na região metropolitana de Belo Horizonte (RMBH), abrigando $31,23 \%$ do número total de habitantes do estado.

Segundo Prates et al. (2002a), uma das disparidades regionais, em Minas Gerais, está relacionada ao número de habitantes por município. No ano de 2000, existia um grande número de municípios (60,3\%) que tinham menos de 10 mil habitantes e um pequeno número de municípios $(2,7 \%)$ com uma população acima de 100 mil habitantes.

Tabela 3. A população e sua participação nas 12 mesorregiões mineiras.

\begin{tabular}{lrc}
\hline \multicolumn{1}{c}{ Mesorregiões } & População & Participação (\%) \\
\hline Noroeste de Minas & 334.509 & 1,87 \\
Norte de Minas & 1.492 .715 & 8,34 \\
Jequitinhonha & 678.872 & 3,79 \\
Vale do Mucuri & 380.735 & 2,13 \\
Triângulo Mineiro/Alto Paranaíba & 1.869 .886 & 10,45 \\
Central Mineira & 380.992 & 2,13 \\
Metropolitana de Belo Horizonte & 5.587 .808 & 31,23 \\
Vale do Rio Doce & 1.534 .268 & 8,58 \\
Oeste de Minas & 839.104 & 4,69 \\
Sul/Sudoeste de Minas & 2.250 .178 & 12,58 \\
Campo das Vertentes & 511.571 & 2,86 \\
Zona da Mata & 2.030 .856 & 11,35 \\
\hline
\end{tabular}

Fonte: IBGE (2001b)

\subsubsection{Aspectos socioeconômicos}

A formação econômica de Minas Gerais iniciou-se a partir da exploração e povoamento do interior brasileiro no período colonial, com as famosas expedições que desejavam encontrar metais preciosos. No século XVII, ocorreram as descobertas de grandes jazidas mineiras que atraíram um contingente de exploradores, induzindo o aparecimento de povoados e vilas, e criando condições para a definitiva ocupação de toda a região. 
No final do século XVIII, a atividade mineradora (exploração do ouro) entrou numa fase declinante, a maioria das minas economicamente viáveis já se haviam esgotado, não gerando nenhuma significativa expansão econômica para o estado. Somente no século XIX surge uma nova dinâmica: a atividade agrário exportadora baseada na cultura do café, que predominou até 1950, aproximadamente, quando o estado passa a se destacar na produção siderúrgica e há um crescente aproveitamento dos recursos naturais (FJP, 2002).

Até o final da década de 60, no entanto, a performance econômica da região estava muito aquém da nacional devido, principalmente, à concentração do processo industrial em São Paulo e no Rio de Janeiro. Em outras palavras, pode-se dizer que a economia mineira estava inserida perifericamente no processo de desenvolvimento do país.

No decorrer dos anos 70, Minas Gerais passou a ser atrativa para diversos tipos de investimentos. Sendo que, foram vários os fatores responsáveis pelo processo de desenvolvimento mineiro, tais como: uma reversão da tendência concentradora das indústrias na região metropolitana de São Paulo, a decadência econômica do Rio de Janeiro, a existência de recursos naturais abundantes, a disponibilidade de infra-estrutura econômica, a existência de indústria básica (metalúrgica e cimento) e extrativa mineral gerando externalidades e mercado para a indústria de bens de capital, a privilegiada posição geográfica do Estado, o esquema de incentivos fiscais e o aparato institucional de apoio à industrialização aliada a uma ativa liderança política. Segundo Santos (2002, p.20), 
"Minas Gerais, nos anos 70, será lembrada como uma das experiências estaduais de industrialização mais exitosas do país. Essa foi uma época de dramáticas mudanças estruturais, quando um grande surto de investimentos veio a reverter a perda de posição relativa do Estado no contexto nacional, dando início a um processo de diversificação e adensamento da estrutura industrial, de consolidação de novos setores industriais, e de ampliação da inserção nacional e internacional. Simultaneamente, a decadência histórica da agricultura mineira foi revertida, com a expansão e incorporação de novas áreas de cultivo. Atrelado ao crescimento industrial e agrícola, houve grande expansão dos serviços produtivos".

A partir daí, Minas Gerais foi conquistando o seu espaço no cenário nacional. As taxas de crescimento do PIB mineiro ao longo das décadas de 70, 80 e 90 ficaram acima da média nacional, conforme mostra a Tabela 4.

Tabela 4. Taxas de crescimento médio anual do PIB: Brasil e algumas unidades da federação.

\begin{tabular}{lccc}
\hline & \multicolumn{3}{c}{ Taxa de Crescimento Médio Anual (\%) } \\
\cline { 2 - 4 } Unidades da Federação & $1970-1980$ & $1980-1990$ & $1990-1999$ \\
\hline Minas Gerais & 11,67 & 2,40 & 2,86 \\
São Paulo & 9,71 & 2,30 & 1,81 \\
Rio de Janeiro & 8,12 & 0,16 & 3,37 \\
Paraná & 10,88 & 3,54 & 2,45 \\
Rio Grande do Sul & 9,33 & 2,81 & 1,91 \\
Brasil & 8,56 & 2,16 & 2,46 \\
\hline
\end{tabular}

Fonte: Santos (2002)

Hoje, a economia mineira é a $3^{\circ}$ mais importante do país, ficando atrás, somente, de São Paulo e do Rio de Janeiro. Em 2000, O PIB de Minas, segundo as estimativas do IBGE, atingiu 106.169 bilhões, correspondendo a 9,64\% do PIB brasileiro. De acordo com a Tabela 5, os estados de Minas Gerais, São Paulo, Rio de Janeiro, Paraná e Rio Grande do Sul concentram mais de dois terços da produção nacional. 
Tabela 5. PIB dos cinco mais importantes estados brasileiros e a sua participação no PIB do Brasil, no ano de 2000.

\begin{tabular}{lrc}
\hline \multicolumn{1}{c}{ Estados } & R\$ milhão & Participação $(\%)$ \\
\hline Minas Gerais & 106.169 & 9,64 \\
São Paulo & 137.877 & 33,67 \\
Rio de Janeiro & 370.819 & 12,52 \\
Paraná & 65.969 & 5,99 \\
Rio Grande do Sul & 85.138 & 7,73 \\
Brasil & 1.101 .255 & 100,00 \\
\hline
\end{tabular}

Fonte: IBGE (2001c)

Em Minas Gerais, os setores de atividade serviço, indústria e agropecuária contribuem, respectivamente, com $48,66 \%, 42,84 \%$ e $8,51 \%$ no PIB, conforme indica a Tabela 6. O setor de serviços é o de maior peso para a economia mineira.

Tabela 6. Produto Interno Bruto a preços correntes, segundo os setores de atividade econômica em Minas Gerais, 2000. ${ }^{1}$

\begin{tabular}{lcc}
\hline \multicolumn{1}{c}{ Setores } & Valores em R\$ & Participação (\%) \\
\hline Indústria & 43.168 .418 & 42,84 \\
Agropecuária & 8.571 .678 & 8,51 \\
Serviços & 49.031 .410 & 48,66 \\
\hline
\end{tabular}

Fonte: FJP (2002)

${ }^{1}$ resultados preliminares

A agropecuária, um setor importante na história econômica do estado, conquistou certa projeção na fase de decadência do ouro, mas ao longo do processo de industrialização sua contribuição na geração de riqueza para o estado caiu. Mesmo assim, ainda hoje, o setor é bastante representativo. No PIB agropecuário mineiro, o café desponta como o principal produto agrícola. Na pecuária, Minas Gerais se destaca como o maior produtor de leite do país e detém um vasto rebanho de bovinos, suínos e aves (Prates et al., 2002b).

Segundo Abreu et al. (2002), o PIB industrial mineiro é distribuído de maneira pouco uniforme, apresentando amplas diferenças regionais. Dos 14 municípios com PIB industrial superior a R $\$ 500$ milhões por ano, apenas um se encontra na região norte, o município de Montes Claros. Os outros estão localizados no Sul de Minas (Pouso Alegre 
e Poços de Caldas), na Zona da Mata (Juiz de Fora), no Triângulo Mineiro (Uberlândia e Uberaba), na RMBH e no Vale do Rio Doce (somente os municípios da região do Vale do Aço).

Apesar desse quadro comparativo com a situação nacional sugerir uma posição favorável a Minas Gerais, tal avaliação não se sustenta quando considerados outros indicadores. Os aspectos mais evidentes das condições desfavoráveis do estado mineiro são o PIB per capita, que é quase $10 \%$ inferior à média nacional, e sua posição relativa na classificação do índice de desenvolvimento humano estadual (BDMG/DPE, 2002).

Conforme ilustra a Figura 3, Minas Gerais ocupa a oitava posição em termos de PIB per capita, mesmo encontrando-se entre os cinco estados (Rio Grande do Sul, Rio de Janeiro, São Paulo, Paraná e Minas Gerais) de maior importância para a riqueza do país.

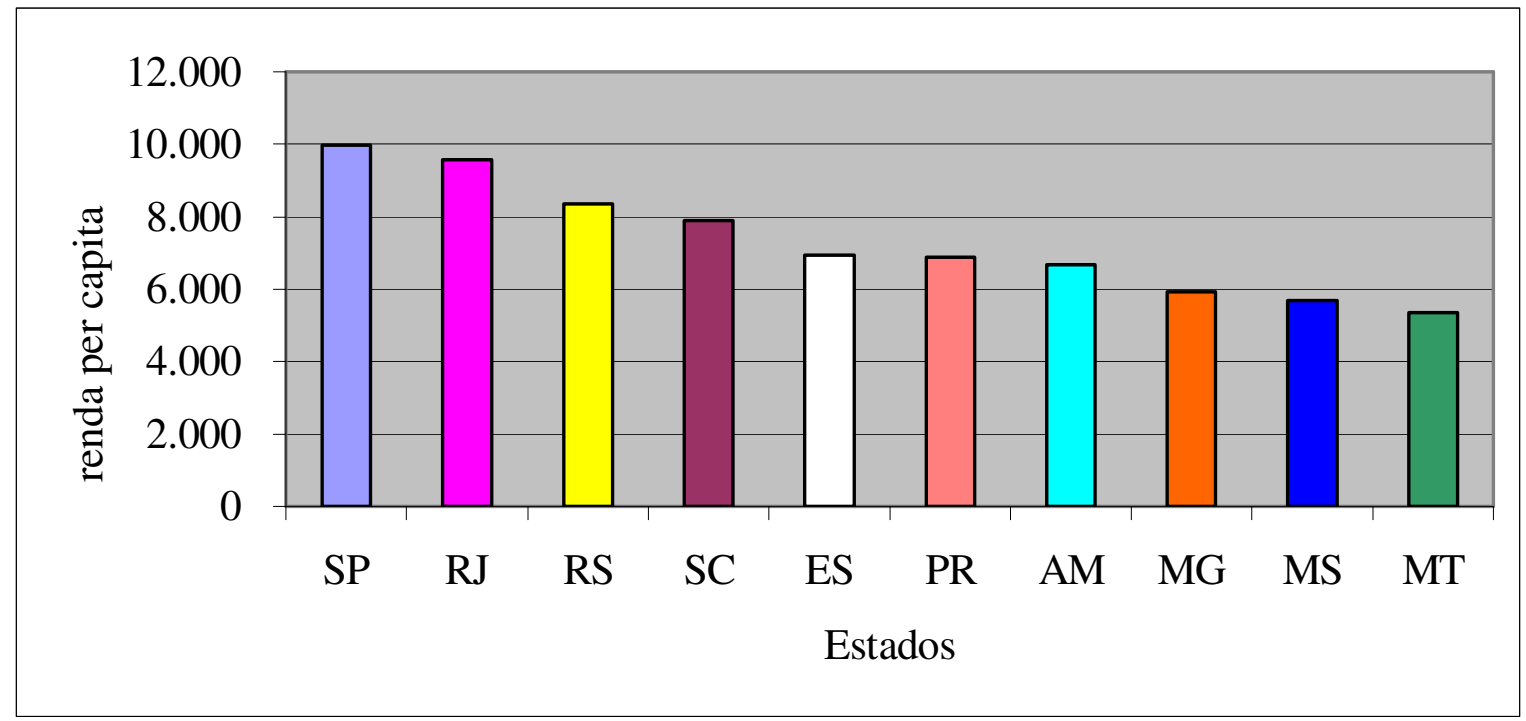

Figura 3 - Classificação dos 10 estados brasileiros de maior PIB per capita.

Fonte: IBGE (2001c) 


\subsection{4 Índice de Desenvolvimento Humano de Minas Gerais}

Desde 1990, o Programa das Nações Unidas para o Desenvolvimento (PNUD), publica o Relatório sobre o Desenvolvimento Humano (RDH). No RDH, é apresentado um indicador chamado Índice de Desenvolvimento Humano (IDH) que tem como finalidade medir a qualidade de vida e o progresso humano em âmbito mundial, incorporando dimensões que ultrapassem a abordagem meramente econômica. Sendo assim, o IDH busca combinar três componentes básicos do desenvolvimento humano: longevidade, educação e renda (PNUD, 2002).

Em 1998, os Institutos de Pesquisa da Fundação João Pinheiro (FJP) e o Instituto de Pesquisa Econômica Aplicada (IPEA), juntamente com o PNUD, uniram-se para desenvolver um projeto que tinha como objetivo adaptar a metodologia do IDH, a fim de que fosse possível a aplicação dos conceitos e medidas do desenvolvimento humano a unidades geo-político-administrativas mais desagregadas. $\mathrm{O}$ resultado desse trabalho foi a criação do Atlas de Desenvolvimento Humano do Brasil que além de apresentar o IDH-M, um índice de desenvolvimento humano adaptado para os estados e municípios brasileiros, conta com dados e indicadores sobre população, renda, educação, habitação, saúde e outros. ${ }^{5}$

O lançamento do Atlas de Desenvolvimento do Brasil, em 1998, foi feito utilizando dados do censo de 1991. Em 2003, novamente as três instituições (IPEA, FJP e PNUD) lançaram o novo Atlas do Desenvolvimento Humano do Brasil, atualizado pelos dados do Censo Demográfico de 2000. O IDH Municipal é formado por três índices:

\footnotetext{
${ }^{5}$ O novo índice foi denominado Índice Municipal de Desenvolvimento Humano e é designado pela sigla IDH-M, reservando a denominação Índice de Desenvolvimento Humano e a sigla IDH exclusivamente para os índices calculados segundo a metodologia padrão do PNUD.
} 
a) Um indicador de renda, medido pela renda familiar per capita média do município. No IDH a renda é baseada no PIB per capita;

b) Um indicador das condições de saúde (longevidade), obtido a partir da esperança de vida ao nascer;

c) Um indicador das condições de educação é obtido a partir da taxa de alfabetização de adultos e da taxa bruta de freqüência à escola, que é o somatório da quantidade de pessoas (todas as idades) que freqüentam os cursos fundamental, secundário e superior dividido pelo total de pessoas na faixa etária de 7 a 22 anos, sendo ambos convertidos em índices. O IDH-M Educação é a média desses dois índices, com peso 2 para a taxa de alfabetização e peso 1 para a taxa bruta de freqüência;

O que está por trás dessa combinação é a idéia de que o crescimento material de um país, refletido na renda per capita, deve vir acompanhado de um aumento na esperança de vida de seus habitantes e de uma expansão nas condições de educação. Depois de uma série de manipulações estatísticas, cada um desses três indicadores transforma-se num número que varia entre zero e um, sendo efetuada posteriormente uma média aritmética simples entre eles.

A Tabela 7 mostra a classificação do IDH-M de todas as unidades federativas brasileiras. Os maiores IDH-M no Brasil são respectivamente, Distrito Federal, Santa Catarina, São Paulo, Rio Grande do Sul e Rio de Janeiro, situando-se na faixa de alto desenvolvimento humano. Todos os demais estados, inclusive Minas Gerais, encontramse na categoria de médio desenvolvimento humano. Particularmente, o estado de Minas Gerais encontra-se na $9^{\circ}$ posição na classificação do IDH-M nos dois períodos analisados, mas, empatado com Mato Grosso em 2000. 
Tabela 7. Índice de Desenvolvimento Humano (IDH-M) ${ }^{6}$ nas unidades da federação brasileira, 1991/2000.

\begin{tabular}{|c|c|c|c|c|}
\hline & \multicolumn{2}{|c|}{ Ano } & \multicolumn{2}{|c|}{ Posição de ordem } \\
\hline & 1991 & 2000 & 1991 & 2000 \\
\hline Distrito Federal & 0,799 & 0,844 & 1 & 1 \\
\hline Santa Catarina & 0,748 & 0,822 & 5 & 2 \\
\hline São Paulo & 0,778 & 0,820 & 2 & 3 \\
\hline Rio Grande do Sul & 0,753 & 0,814 & 3 & 4 \\
\hline Rio de Janeiro & 0,753 & 0,807 & 3 & 5 \\
\hline Paraná & 0,711 & 0,787 & 7 & 6 \\
\hline Mato Grosso do Sul & 0,716 & 0,778 & 6 & 7 \\
\hline Goiás & 0,700 & 0,776 & 8 & 8 \\
\hline Mato Grosso & 0,685 & 0,773 & 13 & 9 \\
\hline Minas Gerais & 0,697 & 0,773 & 9 & 9 \\
\hline Espírito Santo & 0,690 & 0,765 & 12 & 11 \\
\hline Amapá & 0,691 & 0,753 & 11 & 12 \\
\hline Roraima & 0,692 & 0,746 & 10 & 13 \\
\hline Rondônia & 0,660 & 0,735 & 15 & 14 \\
\hline Pará & 0,650 & 0,723 & 16 & 15 \\
\hline Amazonas & 0,664 & 0,713 & 14 & 16 \\
\hline Tocantins & 0,611 & 0,710 & 19 & 17 \\
\hline Pernambuco & 0,620 & 0,705 & 18 & 18 \\
\hline Rio Grande do Norte & 0,604 & 0,705 & 20 & 19 \\
\hline Ceará & 0,593 & 0,700 & 22 & 20 \\
\hline Acre & 0,624 & 0,697 & 17 & 21 \\
\hline Bahia & 0,590 & 0,688 & 23 & 22 \\
\hline Sergipe & 0,597 & 0,682 & 21 & 23 \\
\hline Paraíba & 0,561 & 0,661 & 25 & 24 \\
\hline Piauí & 0,566 & 0,656 & 24 & 25 \\
\hline Alagoas & 0,548 & 0,649 & 26 & 26 \\
\hline Maranhão & 0,543 & 0,636 & 27 & 27 \\
\hline
\end{tabular}

Fonte: PNUD, IPEA \& FJP (2003)

\footnotetext{
${ }^{6}$ A classificação do nível de desenvolvimento humano é feita de acordo com os seguintes intervalos: $0 \leq \mathrm{IDH}-\mathrm{M}<0,5$, baixo desenvolvimento humano; $0,5 \leq \mathrm{IDH}-\mathrm{M}<0,8$, médio desenvolvimento $\mathrm{e}$ $0,8 \leq \mathrm{IDH}-\mathrm{M}<1$, alto desenvolvimento humano.
} 


\subsubsection{Caracterização das regiões mineiras}

Ferreira (1996) e Santana (2002) caracterizam as regiões mineiras de planejamento, da seguinte forma:

a) Triângulo Mineiro e Alto Paranaíba - O Alto Paranaíba possui base econômica sedimentada na pecuária bovina, agricultura e extração mineral. Já o triângulo Mineiro, historicamente ligado a São Paulo, tem sua economia baseada na agropecuária, com grandes projetos agroindustriais. Segundo a Federação das Indústrias de Minas Gerais (FIEMG), essa foi a segunda região que mais recebeu investimento $(9,78 \%)$ no ano de 2002.

b) Noroeste de Minas - Essa região sofre influência de Brasília e Goiânia. Embora ocupe mais de $25 \%$ do território mineiro, possui densidade demográfica bastante reduzida. A base econômica é formada pela atividade primária e extrativa mineral.

c) Norte de Minas - é caracterizada pela elevada aridez do solo, baixa incorporação de tecnologia e graves deficiências na sua infra-estrutura social. Essa região conseguiu atrair somente $0,35 \%$ dos investimentos totais feitos em Minas Gerais em 2002.

d) Zona da Mata - é influenciada pelo Estado do Rio de Janeiro. A base econômica é tradicionalmente voltada para a pecuária, a cafeicultura e a indústria. A desenvolvida microrregião de Juiz de Fora, localizada nessa região, se destaca por sua infra-estrutura urbana, qualidade de mão-de-obra e posição geográfica.

e) A região Vale do Rio Doce - tem uma grande importância para o estado devido à presença do complexo siderúrgico (Vale do Aço), mas se excluirmos os municípios que compõem o Vale do Aço, a região Vale do Rio Doce torna-se uma região problemática, pois os demais municípios, que não se localizam no complexo, não são dinâmicos economicamente.

f) A região Sul de Minas - tem sua economia baseada na produção de leite, café e na indústria. As microrregiões que compõem o Sul de Minas mostram um 
comportamento bem homogêneo entre elas. Em 2002, o Sul de Minas foi a terceira região que mais atraiu investimentos $(8,40 \%)$.

g) A região do Vale Jequitinhonha e Mucuri - a economia dessa região é baseada na bonivicultura de corte e na agricultura de subsistência. Essa região é considerada uma das mais pobres de Minas Gerais. De acordo com Relatório da FIEMG, não ocorreu nenhum investimento nesta região em 2002.

h) Centro-Oeste de Minas - conseguiu se beneficiar do processo de desconcentração industrial paulista, devido principalmente a sua localização geográfica. A atividade industrial da região iniciou-se com a instalação de indústrias têxteis, siderúrgicas e de alimentos. Outras atividades industriais da região que merecem destaque são a construção civil, móveis e produção de grafite natural.

i) Região central - é a mais desenvolvida do Estado e corresponde, também, a uma das primeiras regiões que foram ocupadas para mineração do ouro e diamante. A presença da capital do Estado, bem como a centralização das atividades econômicas nessa região fortalecem o papel da mesma como centro polarizador capaz de exercer influência sobre todo o Estado, particularmente nas regiões que não são afetadas por outros pólos como São Paulo, Rio de Janeiro e Brasília. A região concentra a maior densidade de indústrias do Estado. Segundo FIEMG (2002), a região Central foi a mais atrativa para investimentos no ano de 2002 (67,91\%).

Como a divisão das regiões de planejamento assemelha-se à divisão em mesorregiões, as características apresentadas para as regiões de planejamento ajudam a caracterizar as mesorregiões. 


\section{METODOLOGIA}

\subsection{Medidas de desigualdade}

Os índices de Gini $(G)$, T de Theil $(T)$ e L de Theil $(L)$ são as medidas de desigualdade mais comumente usadas nos estudos sobre distribuição de renda. ${ }^{7}$ Não há como apontar entre as três medidas a melhor a ser usada, pois o emprego de cada uma delas dependerá da natureza da análise. No presente trabalho, há espaço para a aplicação de qualquer uma delas.

\subsubsection{Curva de Lorenz e o índice de Gini}

O índice de Gini deriva-se da curva de Lorenz. A Curva de Lorenz mostra graficamente como a proporção acumulada da renda aumenta em função da proporção acumulada da população, considerando que as rendas estejam em ordem crescente.

Na Figura 4 a curva preta é a curva de Lorenz da distribuição da renda domiciliar per capita de Minas Gerais. ${ }^{8}$ Quanto mais afastada a curva estiver do segmento OB, maior o grau de desigualdade da distribuição.

\footnotetext{
7 Estas medidas podem ser utilizadas para medir o grau de desigualdade de qualquer distribuição estatística.

${ }^{8}$ Nessa figura está sendo representada a curva de Lorenz e a curva de concentração do rendimento de aluguel em Minas Gerais. Ao longo do trabalho, explicações mais detalhadas são fornecidas a respeito delas.
} 


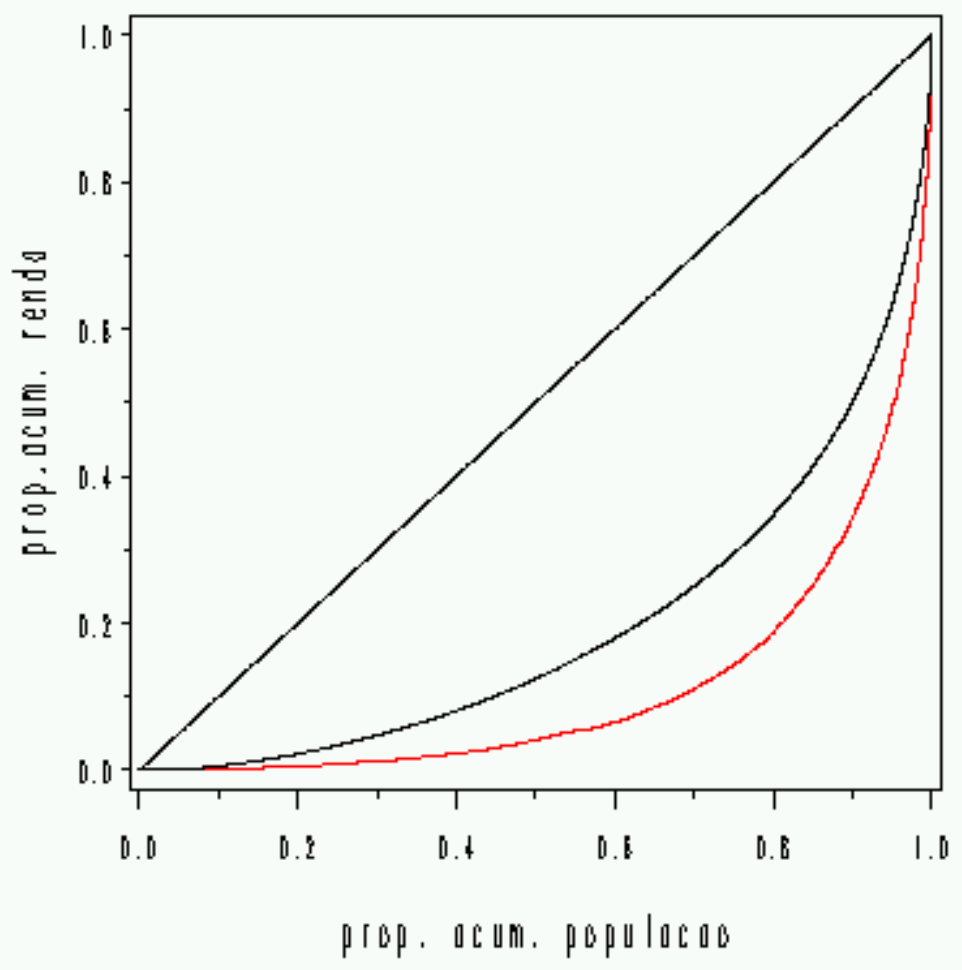

Figura 4 - Curva de Lorenz e curva de concentração do componente aluguel da renda domiciliar per capita, Minas Gerais.

Fonte: dados da pesquisa.

No eixo das abscissas, $p_{i}$ é a porcentagem acumulada da população até a $i$-ésima pessoa, sendo $i=1,2 \ldots, n$ e $n$ o número de pessoas da população:

$$
p_{i}=\frac{i}{n}
$$

Nas ordenadas, $\Phi_{i}$ é a proporção de todas as rendas recebidas por essas pessoas em um determinado período do tempo. Considerando que $x_{i}$ é a renda da $i$-ésima pessoa em uma população de $n$ pessoas e $\mu$ esteja indicando a renda média,

$$
\Phi_{i}=\frac{1}{n \mu} \sum_{j=1}^{i} x_{j}
$$

Imagine que todas as pessoas têm exatamente a mesma renda; então a proporção acumulada da renda será sempre igual à proporção acumulada da população. Neste caso 
particular, a curva de Lorenz seria o segmento $\mathrm{OB}$, denominado linha de perfeita igualdade.

A área compreendida entre a linha de perfeita igualdade e a Curva de Lorenz recebe o nome de área de desigualdade, sendo indicada por $\alpha$. Como a área do triângulo OBC é igual a 0,5 verifica-se que $\alpha$ está no intervalo de 0 até 0,5 .

Por definição, o índice de Gini $(G)$ é a relação entre a área de desigualdade $(\alpha)$ e a área do triângulo $\mathrm{OBC}$, isto é:

$$
G=\frac{\alpha}{0,5}=2 \alpha
$$

Esse índice foi proposto em 1914 por Corrado Gini e quanto mais próximo de 1 o seu valor, maior é o grau de desigualdade.

\subsubsection{Curvas de concentração e decomposição do índice de Gini}

Há várias maneiras de decompor a desigualdade da distribuição da renda no Brasil. Uma destas formas consiste em determinar a contribuição de cada parcela do rendimento para a desigualdade total.

As curvas de concentração permitem que seja graficamente visualizada a decomposição da desigualdade total conforme parcelas do rendimento domiciliar per capita. Elas são definidas de maneira análoga à curva de Lorenz. Na verdade, a curva de Lorenz da distribuição do rendimento total é uma espécie de média ponderada das curvas de concentração das parcelas desse rendimento.

Se a curva de concentração de uma parcela do rendimento ficar sempre abaixo da curva de Lorenz, pode-se dizer que essa parcela está contribuindo para aumentar a desigualdade da distribuição do rendimento domiciliar per capita .

Considerando que o rendimento domiciliar per capita $X_{i}$ seja formado por $k$ parcelas, temos que:

$$
X_{i}=\sum_{h=1}^{k} X_{h i}
$$

Se as pessoas estão ordenadas de acordo com o seu rendimento, temos $X_{1} \leq X_{2} \leq \ldots \leq X_{n}$ 
Pode-se calcular, para qualquer ponto da seqüência ordenada, a proporção acumulada do rendimento da $h$-ésima parcela, dada por:

$$
\Phi_{h i}=\frac{1}{n \mu_{h}} \sum_{j=1}^{i} X_{h j}
$$

Onde $\mu_{h}$ é a média dos $n$ valores de $X_{h \mathrm{i}}$

A curva de concentração da parcela $\mathrm{X}_{h i}$ mostra como $\Phi_{h i}$ cresce em função de $p_{i}$ (a proporção acumulada da população). Na figura 4 a curva vermelha está representando a curva de concentração do componente rendimento de aluguéis em Minas gerais.

A decomposição do índice de Gini depende do conhecimento das razões de concentração $\left(\mathrm{C}_{h}\right)$ das $k$ parcelas que compõem o rendimento e das participações de cada parcela na renda total $\left(\varphi_{h}\right)$.

Cada parcela do rendimento tem uma razão de concentração, que é definida de maneira análoga ao índice de Gini, a partir de sua correspondente curva de concentração.

A razão de concentração de $X_{h i}$ é definida como:

$$
C_{h}=1-2 \beta_{h}
$$

sendo $\beta_{h}$ a área localizada entre a curva de concentração (linha vermelha da Figura 4) e o eixo das abscissas.

O índice de Gini de uma distribuição é uma média ponderada das razões de concentração das $k$ parcelas que compõem o rendimento domiciliar per capita, de acordo com a seguinte equação:

$$
G=\sum_{h=1}^{k} \varphi_{h} C_{h}
$$

Quando a razão de concentração de qualquer parcela do rendimento é maior do que o índice de Gini, sua participação na desigualdade é maior do que sua participação no rendimento total.

Ferreira (2003) apresenta um exemplo numérico de decomposição bastante simples, onde considera que existe uma população formada por apenas cinco pessoas, com rendas $1,1,2,6$ e 30. Isso é equivalente a considerar apenas quatro rendas $\left(X_{i}\right)$ distintas $\left(1,2,6\right.$ e 30) e fatores de expansão $\left(w_{i}\right)$ iguais a 2, 1, 1 e 1 . Admite-se ainda 
que a renda $X_{i}$ é formada por 3 parcelas $\left(x_{1}, x_{2}\right.$ e $\left.x_{3}\right)$. Todos os dados do exemplo estão na Tabela 8 e são usados para os cálculos.

Tabela 8. Dados para exemplo numérico para a decomposição do índice de Gini.

\begin{tabular}{ccccccc}
\hline $\begin{array}{c}\text { Ordem } \\
(i)\end{array}$ & $w_{i}$ & $X_{i}$ & $w_{i} X_{i}$ & $x_{i 1}$ & $x_{i 2}$ & $x_{i 3}$ \\
\hline 1 & 2 & 1 & 2 & 1 & 0 & 0 \\
2 & 1 & 2 & 2 & 0 & 2 & 0 \\
3 & 1 & 6 & 6 & 0 & 2 & 4 \\
4 & 1 & 30 & 30 & 0 & 2 & 28 \\
\hline
\end{tabular}

Fonte: Ferreira (2003)

O total dos fatores de expansão, indicando o número de pessoas na população, é

$$
\begin{aligned}
& N=\sum w_{i} \\
& N=5
\end{aligned}
$$

A renda total da população é

$$
\begin{aligned}
& S=\sum w_{i} X_{i} \\
& S=40
\end{aligned}
$$

O total da renda para cada uma das três parcelas do rendimento

$$
\begin{aligned}
& S_{h}=\sum w_{i} x_{i h} \\
& S_{1}=2 \\
& S_{2}=6 \\
& S_{3}=32
\end{aligned}
$$

A média da renda total

$$
\begin{aligned}
& \mu=\frac{1}{N} \sum w_{i} X_{i}=\frac{S}{N} \\
& \mu=8
\end{aligned}
$$

A renda média das três parcela que compõem o rendimento total

$$
\begin{aligned}
& \mu_{h}=\frac{1}{N} \sum w_{i} x_{i h}=\frac{S_{h}}{N} \\
& \mu_{1}=0,4 \\
& \mu_{2}=1,2 \\
& \mu_{3}=6,4
\end{aligned}
$$


A participação de cada parcela do rendimento na renda total

$$
\begin{aligned}
\phi_{k} & =\frac{\sum w_{i} x_{i h}}{\sum w_{i} X_{i}}=\frac{\mu_{h}}{\mu} \\
\phi_{1} & =0,05 \\
\phi_{2} & =0,15 \\
\phi_{3} & =0,8
\end{aligned}
$$

Abaixo das curvas de concentração $x_{1}, x_{2}$ e $x_{3}$, há as respectivas áreas $\beta_{1}, \beta_{2}$ e $\beta_{3}$

$$
\begin{aligned}
& \beta_{h}=\frac{1}{N S_{k}} \sum_{i=1}^{n} w_{i} q_{i k}, \\
& \beta_{1}=0,8 \\
& \beta_{2}=0,30 \\
& \beta_{3}=0,125
\end{aligned}
$$

\section{Onde}

$q_{i h}=\sum_{j=1}^{i-1} w_{j} x_{i h}+\frac{1}{2} w_{i} x_{i h}$

Utilizando a equação (6), calcula-se a razão de concentração para as três parcelas, que são $C_{1}=-0,6 ; C_{2}=0,4$ e $C_{3}=0,75$.

Por fim, o calculo do índice de Gini global, conforme a equação (7) é,

$$
\begin{aligned}
& G=0,05(-0,6)+0,15 \cdot 0,4+0,8 \cdot 0,75 \\
& G=-0,03+0,06+0,60 \\
& G=0,63
\end{aligned}
$$

\subsubsection{Medidas de desigualdade de Theil}

As medidas de desigualdade $T$ e $L$ de Theil foram propostas por Henry Theil em 1967.

O cálculo do $T$ de Theil é dado pela fórmula:

$$
T=\sum_{i=1}^{n} y_{i} \ln n y_{i}
$$


Considera-se uma população de $n$ pessoas, onde cada uma receba uma fração não negativa da renda, e $y_{i}$ represente a participação da $i$-ésima pessoa na renda total $\left(y_{i}=x_{i} / n \mu\right)$.O valor de $T$ varia de zero (no caso de perfeita igualdade) a $\ln n$ (quando uma única pessoa se apropria de toda renda).

Já o $L$ de Theil é obtido pela equação:

$$
L=\sum_{i=1}^{n} \frac{1}{n} \ln \frac{\frac{1}{n}}{y_{i}}=\frac{1}{n} \sum \ln \frac{1}{n y_{i}}
$$

Se o $L$ de Theil assume o valor mínimo de zero, a distribuição da renda é perfeitamente igualitária $\left(y_{i}=1 / n\right.$ para todo $i$ ). Por outro lado, o valor de $L$ tende ao infinito quando qualquer $y_{i}$ tende a zero.

Ao analisar a distribuição das pessoas de acordo com seu rendimento domiciliar, são incluídas as famílias com rendimento zero, não sendo possível, então, calcular o $L$ de Theil. Essa medida de desigualdade é utilizada apenas na análise da distribuição da renda entre pessoas economicamente ativas com rendimento.

\subsubsection{As separatrizes e outras medidas de desigualdade}

As separatrizes dividem a distribuição de renda em um determinado número de partes iguais. Citam-se, como exemplo, a mediana, os três quartis, os quatro quintis, os nove decis e os percentis, que dividem a distribuição em duas, quatro, cinco, dez e cem partes iguais, respectivamente.

Outras medidas de desigualdade de renda utilizadas são as proporções da renda total apropriada por certos grupos, tal como a proporção da renda apropriada pelos $50 \%$ mais pobres $\left(50^{-}\right)$, ou pelos $10 \%$ mais ricos $\left(10^{+}\right)$, ou $5 \%$ mais ricos $\left(5^{+}\right)$, ou $1 \%$ mais $\operatorname{ricos}\left(1^{+}\right)$.

Essas medidas de desigualdade não atendem ao princípio de Pigou-Dalton; o contrário acontece nos três índices expostos anteriormente. Segundo o critério de Pigou-Dalton, as medidas de desigualdade devem ter seus valores aumentados quando há transferência regressiva de renda, que consiste em subtrair um montante da renda de 
uma pessoa e acrescentá-lo à de uma outra pessoa que, anteriormente, tinha renda igual ou maior do que a primeira.

\subsection{Medidas de pobreza}

A pobreza absoluta ocorre quando são estabelecidos padrões mínimos de suficiência de renda para a população e quando uma proporção dessa não atinge aquele mínimo e, conseqüentemente, é considerada pobre. Um problema fundamental para a obtenção das medidas de pobreza com base em dados sobre a renda está na dificuldade de estabelecer critérios para fixar as linhas de pobreza. Mas se os critérios utilizados para determinar as linhas de pobreza são consistentes, então pode-se comparar os graus de pobreza de diferentes regiões.

No Brasil é relativamente comum a utilização de múltiplos do salário mínimo na construção das linhas de pobreza. É razoável, então, adotar uma linha de pobreza de R\$ 76,00 (valor que aproximadamente corresponde a 1/2 salário mínimo na semana de referência para o censo) para as mesorregiões mineiras e compará-las. A limitação da análise é admitir que não há diferenças substancias de custo de vida entre as mesorregiões.

\subsubsection{Proporção de pobres}

Dada uma população com $n$ indivíduos, seja $x_{i}(\operatorname{com} i=1, \ldots, n)$ a renda do $i$-ésimo indivíduo. Admitindo que os indivíduos estão ordenados conforme os valores crescentes de renda, são considerados pobres os indivíduos com a renda menor ou igual a $z$. O valor de $z$ é denominado linha de pobreza. Admitindo que há $k$ ndivíduos pobres, tem-se

$$
\begin{gathered}
X_{k} \leq z \\
\mathrm{e} \\
X_{k+1}>z
\end{gathered}
$$

A proporção de pobres na população é dada por:

$$
H=\frac{k}{n}
$$


Verifica-se que $0 \leq H \leq 1$. O valor de $H$ é um indicador da incidência ou extensão da pobreza da população. Essa medida do grau de pobreza é, entretanto, totalmente insensível a variações na intensidade da pobreza, uma vez que o valor de $H$ não é afetado se a renda dos pobres for reduzida, ou seja, se acontecer uma situação em que as rendas de todos os pobres sejam reduzidas e as rendas dos não-pobres permaneçam as mesmas.

\subsubsection{Razão de insuficiência de renda}

Uma outra medida do grau de pobreza é a razão de insuficiência de renda dada por

$$
I=\frac{1}{k z} \sum_{i=1}^{k}\left(z-x_{i}\right)
$$

A diferença $z-x_{i}($ com $i \leq k)$ é a insuficiência de renda de um pobre, isto é, mostra o quanto deveria crescer a renda de um pobre para atingir a linha de pobreza, já o $k z$ é o valor máximo dessa insuficiência de renda, quando os $k$ pobres tivessem uma renda nula. A medida $I$ é a razão entre a insuficiência de renda e o seu valor máximo, fixado o número de pobres.

As medidas $H$ e $I$ apresentam, portanto defeitos e qualidade complementares: enquanto $H$ é insensível à intensidade da pobreza de cada indivíduo (medida pela insuficiência de renda), I é insensível ao número de pobres (Hoffmann, 1998a).

\subsection{3 Índice de Foster, Greer e Thorbecke (FGT)}

O índice de Foster, Greer e Thorbecke (TGT) é dado pela expressão (12), quando $\alpha$ for igual a 2 .

$$
\varphi(\alpha)=\frac{1}{n_{z}^{\alpha}} \sum_{i=1}\left(z-x_{i}\right)^{\alpha}
$$

Pode-se verificar que o valor de $\varphi(\alpha)$ varia de zero a um. Quando $\varphi(\alpha)=0$ todas as pessoas têm renda maior do que $z$ e quando $\varphi(\alpha)=1$ todas as rendas são iguais a zero. 


\subsection{Equações de rendimento}

A desigualdade encontra-se, em grande parte, associada às diferenças de rendimento do mercado de trabalho. A investigação dos fatores que determinam os rendimentos das pessoas ocupadas no mercado de trabalho ajudam no conhecimento da desigualdade de renda.

A análise de regressão é uma ferramenta econométrica, que tem sido usada para a estimação das equações de rendimento, procurando mostrar os efeitos de algumas variáveis econômicas e sócio-demográficas sobre o rendimento. A análise, utiliza como base de dados a distribuição das pessoas economicamente ativas ocupadas, de acordo com os dados da amostra do censo.

O ajustamento das equações é feito pelo método dos mínimos quadrados ponderados, usando o peso ou fator de expansão associado a cada pessoa da amostra, fornecido pelo IBGE, como fator de ponderação. A variável dependente $(y)$ é o logaritmo neperiano do rendimento por hora de todos os trabalhos das pessoas ocupadas. A função logarítmica é justificada pela forte assimetria da distribuição da renda. As variáveis explanatórias usadas são, em grande parte, variáveis binárias que assumem o valor 1 se o indivíduo pertence a determinado grupo, ou 0 , caso não pertença. $\mathrm{O}$ modelo de equação estimado é:

$$
y_{j}=\alpha+\sum \beta_{i} x_{i j}+u_{j}
$$

onde $\alpha$ e $\beta_{i}$ são parâmetros e $u_{j}$ são erros aleatórios heterocedásticos com as propriedades usuais. Considera-se para análise o seguinte conjunto de variáveis explanatórias:

a) Variável binária para sexo, que assume valor 1 para as mulheres;

b) A idade da pessoa, medida em dezenas de anos, e também o quadrado dessa variável, tendo em vista que y não varia linearmente com a idade. A idade é medida em dezenas de anos apenas para evitar que os coeficientes sejam muito pequenos. Se os parâmetros para a idade e idade ao quadrado forem indicados por $\beta_{1}$ e $\beta_{2}$, 
respectivamente, deve-se ter $\beta_{1}>0$ e $\beta_{2}<0$ e então o valor esperado de $y$ será máximo quando a idade da pessoa for igual a $-\beta_{1} /\left(2 \beta_{2}\right)$;

c) Escolaridade, variando de 0 (no caso de pessoa sem instrução ou com menos de um ano de estudo) a 16 e assumindo um valor 18 para a pessoa com 17 anos ou mais de estudo;

d) Duas variáveis binárias para distinguir três posições na ocupação: empregado (tomado como base), empregador e conta própria;

e) Quatro variáveis binárias para distinguir cor: branca (tomada como base), preta, amarela, parda e indígena;

f) Duas variáveis binárias para distinguir os setores de atividade (agricultura, indústria e serviços). O setor agrícola é tomado como base.

g) Uma variável binária que assume valor 1 quando o domicílio é urbano, e valor zero quando é rural;

h) Uma variável binária que é igual a 1 quando a observação se refere a pessoa de referência da família e é igual a zero nos demais casos;

i) Onze variáveis binárias para distinguir 12 mesorregiões: RMBH (tomada como base), Norte de Minas, Noroeste de Minas, Triângulo/Alto Paranaíba, Central Mineira, Vale do Rio Doce, Vale do Mucuri, Jequitinhonha, Oeste de Minas, Campo das Vertentes, Zona da Mata e Sul/Sudoeste de Minas;

j) Em uma das equações estimadas são incluídas variáveis binárias para captar o efeito de interações entre o nível de escolaridade e a mesorregião em que o indivíduo reside.

Uma das razões pela escolha dessas variáveis como fatores relevantes para o rendimento pessoal fundamenta-se no fato delas poderem ser consideradas como proxies razoáveis para captar a contribuição de treinamento e experiência das pessoas (idade, escolaridade), as discriminações e segmentações do mercado (cor, sexo, setor de atividade), a diferença de posse de propriedade e riqueza (posição na ocupação) (Corrêa, 1998). 


\subsection{Base de dados}

Para a obtenção dos resultados, a principal base de dados utilizada é a amostra do

censo demográfico de 2000. ${ }^{9}$ Mas também usam-se dados da PNAD de 2001, com o objetivo de fazer comparações entre os resultados obtidos entre as duas bases de dados.

A PNAD tem sido usada como a principal base de dados nos estudos de distribuição de renda. Ao longo dos seus mais de 30 anos de existência, a investigação dos quesitos referentes ao rendimento tem passado por transformações com o objetivo de captar, de forma mais abrangente, o valor do rendimento das pessoas. Em 1980, a PNAD passou a ser realizada regularmente todos os anos, exceto em 1994 e nos anos censitários de 1980, 1991 e 2000 (Rocha, 2002).

Cabe ressaltar que o desenho amostral da pesquisa visa possibilitar a expansão dos resultados para Brasil, Grandes Regiões, Unidades da Federação e Regiões Metropolitanas. Portanto, não está garantida a representatividade da amostra para níveis geográficos menores (município, distrito e setor) (IBGE, 2001a).

Conforme IBGE (2002a, p.21), a técnica de amostragem na coleta do Censo Demográfico vem sendo utilizada desde 1960. O desenho amostral adotado compreende a seleção sistemática e com eqüiprobabilidade, dentro de cada setor censitário. O setor censitário é a unidade territorial de coleta e controle cadastral, percorrida por um único recenseador, contínua e situada em área urbana ou rural de um mesmo distrito, em função do perímetro urbano. A investigação dos domicílios e das pessoas neles residentes teve como data de referência o dia primeiro de agosto de 2000. Afirma-se que:

\footnotetext{
${ }^{9}$ O IBGE publicou em 2002 o CD-ROM dos microdados da amostra do censo de 2000 para todos os Estados.
} 
"No Censo Demográfico do Brasil de 2000, a técnica de amostragem aplicada foi definida de acordo com duas frações amostrais distintas, sendo: 10\% para os municípios com população estimada superior a 15.000 habitantes e $20 \%$ para os demais municípios. Dois modelos de questionário foram aplicados: 1) um questionário básico aplicado nas unidades não selecionadas para a amostra e contendo perguntas referentes às características que foram investigadas para 100\% da população, 2) um segundo questionário aplicado somente nos domicílios selecionados para a amostra contendo, além das perguntas que também constam do questionário básico, outras perguntas mais detalhadas sobre características do domicílio e de seus moradores, referentes aos temas religião, cor ou raça, deficiência, migração, escolaridade, fecundidade, nupcialidade, trabalho e rendimento".

Para a expansão dos dados coletados na amostra do censo, o IBGE calcula pesos para cada um dos domicílios pesquisados, sendo tais pesos atribuídos ao próprio domicilio e a cada um de seus moradores. O questionário da amostra aplicado no censo de 2000 está com um maior número de informações do que os aplicados em censos anteriores. Cita-se como exemplo, a variável rendimento. No questionário ${ }^{10}$ aplicado no censo de 1991 havia quatro quesitos para o rendimento: rendimento na ocupação declarada, rendimento de outras ocupações, rendimento de aposentadorias ou pensões, outros rendimentos. No questionário da amostra do censo 2000, há sete quesitos para a variável rendimento e são semelhantes aos extraídos nas PNADs.

Os dados sobre renda nas PNADs e na amostra do censo apresentam certas limitações, tais como: o questionário procura captar tanto os rendimentos em dinheiro como os pagamentos em espécies, mas não considera o valor da produção para autoconsumo, que pode ser um componente importante da renda real de pequenos produtores agrícolas; desconsidera um rendimento implícito que é o valor do aluguel da casa própria usada pela famílias; há uma subdeclaração dos rendimentos, especialmente dos mais elevados. Assim, no exame das várias medidas de posição da distribuição da

\footnotetext{
${ }^{10}$ Essas informações foram verificadas no próprio questionário aplicado em 1991.
} 
renda, é necessário admitir que o valor verdadeiro possa ser $50 \%$ ou $100 \%$ maior (Hoffmann, 2001a).

Deve-se ressaltar também que os rendimentos de capital em pesquisas individuais, tais como a PNAD e o Censo Demográfico, possuem uma captação que é reconhecidamente deficiente pela própria natureza desse tipo de rendimento (Rocha, 2002).

\subsection{As variáveis}

Para a mensuração da desigualdade da distribuição da renda é necessário especificar qual será a variável renda considerada e qual é a população analisada. Assim, nessa seção estão definidas as variáveis:

a) A renda domiciliar per capita é construída por meio das várias fontes de rendimentos recebidas pelos indivíduos pertencentes ao domicilio. ${ }^{11}$ De acordo com o questionário da amostra do censo, há sete quesitos para a variável rendimento: 1) trabalho principal, 2) demais trabalhos, 3) aposentadorias ou pensões, 4) aluguel, 5) pensão alimentícia, mesada, doação, 6) renda mínima, bolsa escola, seguro desemprego e 7) outros rendimentos. ${ }^{12} \mathrm{O}$ rendimento domiciliar é formado pelo somatório desses sete rendimentos. O rendimento domiciliar per capita é obtido pela divisão do rendimento domiciliar pelo número de pessoas residentes no domicílio, excluindo pensionistas, empregados domésticos e seus parentes. Esse rendimento é expresso em valor nominal mensal obtido no mês de julho de 2000.

b) O rendimento de todos os trabalhos é a soma dos rendimentos nominais mensais do mês de julho de 2000 do trabalho principal e dos demais trabalhos, considerando somente as pessoas com idade de 10 anos ou mais. Esse rendimento é definido para a análise da distribuição da população economicamente ativa ocupada.

c) A população economicamente ativa (PEA), é formada pelas pessoas ocupadas e desocupadas, na semana de referência do censo. As pessoas consideradas ocupadas são aquelas que tinham trabalho durante todo ou parte do período da semana de

${ }^{11}$ Considera-se somente os domicílios classificados como particulares permanentes.

${ }^{12}$ Abono de permanência em serviço, juros de aplicações financeiras, dividendos, juros de renda fixa etc. 
referência, ou aquelas que não exerceram trabalho remunerado por motivo de férias, licença, greve, etc. As pessoas desocupadas são aquelas que não tinham trabalho, na semana de referência, mas tomaram alguma providencia efetiva de procurar trabalho. Para a finalidade do censo demográfico de 2000, trabalho em atividade econômica é o exercício do trabalho remunerado, trabalho sem remuneração e trabalho na produção para o próprio consumo, na semana de referencia de 23 a 29 de julho.

A Tabela 9 mostra o número de domicílios e pessoas na amostra e o correspondente número de domicílios e pessoas na população nas mesorregiões e em Minas Gerais como um todo.

Tabela 9. Número de domicílios e pessoas, na amostra e na população, de acordo com os dados da amostra do censo de 2000.

\begin{tabular}{lrrrr}
\hline $\begin{array}{c}\text { Minas Gerais } \\
\text { Mesorregiões }\end{array}$ & $\begin{array}{c}\mathrm{N}^{\mathrm{o}} \text { de domicílios } \\
\text { na amostra }\end{array}$ & $\begin{array}{c}\mathrm{N}^{0} \text { de domicílios } \\
\text { na população }\end{array}$ & $\begin{array}{r}\mathrm{N}^{\mathrm{o}} \text { de pessoas } \\
\text { da amostra }\end{array}$ & $\begin{array}{c}\mathrm{N}^{0} \text { de pessoas } \\
\text { na população }\end{array}$ \\
\hline Minas Gerais & 615.101 & 4.837 .296 & 2.347 .758 & 17.905 .134 \\
Noroeste & 11.446 & 89.404 & 44.156 & 334.534 \\
Norte & 47.556 & 349.452 & 214.143 & 1.495 .284 \\
Jequitinhonha & 24.050 & 160.277 & 107.271 & 679.850 \\
Vale do Mucuri & 14.112 & 96.353 & 60.385 & 382.977 \\
Triângulo/ Alto & & & & \\
Paranaíba & 64.594 & 546.611 & 226.104 & 1.871 .237 \\
Central Mineira & 14.411 & 106.600 & 53.816 & 381.600 \\
RMBH & 165.509 & 1.510 .025 & 620.251 & 5.588 .300 \\
Vale do Rio Doce & 55.516 & 405.160 & 215.865 & 1.535 .177 \\
Oeste de Minas & 29.837 & 237.381 & 107.437 & 839.112 \\
Sul/Sudoeste & 89.439 & 630.155 & 326.817 & 2.251 .629 \\
Campo das & & & & \\
Vertentes & 19.450 & 140.463 & 73.705 & 511.956 \\
Zona da Mata & 79.181 & 565.415 & 297.808 & 2.033 .478 \\
\hline
\end{tabular}

Fonte: dados da pesquisa.

${ }^{1}$ Região Metropolitana de Belo Horizonte 
Dos 615.101 domicílios da amostra, 606.120 (98,54\%) pertencem à categoria dos particulares permanentes, onde residem 2.330.135 pessoas da amostra. Os particulares improvisados são $2.912(0,47 \%)$ e os restantes 6.069 são os domicílios coletivos. Somente os domicílios particulares permanentes são considerados para o cálculo da renda domiciliar per capita.

No arquivo de dados referente a pessoas, das 2.347 .758 pesquisadas, há 7.188 classificadas no grupo de pensionistas, empregados domésticos e parentes de empregado doméstico. Dessas 7.188 classificadas nesse grupo, há 7171 em domicílios particulares permanentes, que são excluídas na contagem da renda domiciliar per capita.

A Tabela 10 mostra que há 45 pessoas que possuem um rendimento total no valor de $\mathrm{R} \$ 100.000,00$ ou mais. Esses rendimentos excepcionalmente elevados são provenientes principalmente, dos rendimentos dos trabalhos (principal e outros), ou seja, 39 pessoas declararam ter rendimentos de todos os trabalhos de $\mathrm{R} \$ 100.000$ ou mais. Ao relacionar essas rendas com a posição na ocupação observa-se que 11 pessoas disseram serem dirigentes de empresa, 7 pessoas exercem atividade agrícola ou pecuária e o restante fazem parte de um conjunto variado de profissões. Nesse conjunto variado há trabalhadores no serviço de higiene e embelezamento, garçons e vendedores, colocando em dúvida o valor do rendimento declarado. Assim, na análise do rendimento domiciliar per capita opta-se em excluir 42 domicílios particulares permanentes que abrigam as 45 pessoas com rendimento total no valor de $\mathrm{R} \$ 100.000,00$ ou mais. Na análise da PEA ocupada, uma vez que a variável definida para análise é o rendimento de todos os trabalhos, são excluídas as 39 pessoas com declaração de rendimento no valor de $\mathrm{R} \$ 100.000,00$ ou mais.

$\mathrm{Na}$ amostra do censo, o número de pessoas consideradas ocupadas e desocupadas para a PEA é respectivamente 925.970 e 141.589 pessoas, contabilizando uma PEA amostral de 1.067.559. 
Tabela 10. Distribuição das pessoas com 10 anos ou mais de idade em estratos de rendimento de todos os trabalhos.

\begin{tabular}{lc}
\hline Faixa de renda $(\mathrm{R} \$)$ & Número de pessoas \\
\hline Renda nula & 771.134 \\
Até 151 & 418.890 \\
De 151 a 500 & 472.473 \\
De 500 a 1.000 & 132.169 \\
De 1.000 a 5.000 & 95.064 \\
De 5.000 a 10.000 & 6.683 \\
De 10.000 a 50.000 & 1.923 \\
De 50.000 a 100.000 & 68 \\
100.000 ou mais & 45 \\
Total & 1.898 .449 \\
\hline
\end{tabular}

Fonte: dados da pesquisa. 


\section{RESULTADOS E DISCUSSÃO}

Nesse capítulo são apresentados os resultados da análise da distribuição da renda e da pobreza em Minas Gerais e nas suas doze mesorregiões.

Uma maneira interessante de expor os resultados é mostrar as relações entre a desigualdade de renda e pobreza das mesorregiões com o seu nível de desenvolvimento.

Para saber o nível de desenvolvimento de cada mesorregião é usado o Atlas de Desenvolvimento do Brasil com dados para 2000. Como as informações no Atlas são por município, é construído um IDH-M para as mesorregiões mineiras. Considerando os municípios que formam cada mesorregião, calcula-se uma média ponderada dos IDH-M, usando a população de cada município como fator de ponderação. Essa média ponderada passa a ser utilizada como IDH-M da mesorregião.

A Tabela 11 apresenta o IDH-M das mesorregiões mineiras. O IDH-M de Minas Gerais é 0,773. Segundo a classificação do PNUD, o Estado está entre as regiões consideradas de médio desenvolvimento humano. Apesar dessa classificação, a mesorregião Triângulo Mineiro/Alto Paranaíba está situada na faixa de alto desenvolvimento (IDH entre 0,8 e 1 ).

Com o objetivo de facilitar a discussão dos resultados, as mesorregiões são separadas em dois blocos: mesorregiões mais desenvolvidas e menos desenvolvidas. São consideradas mesorregiões mais desenvolvidas aquelas que têm o IDH-M superior ao do estado $(0,773)$ e menos desenvolvidas aquelas com IDH-M inferior ao do estado. Sendo assim, as mesorregiões mais desenvolvidas do estado são cinco: Triângulo Mineiro/Alto Paranaíba, Metropolitana de Belo Horizonte (RMBH), Oeste de Minas, Sul e Sudoeste de Minas e Campo das Vertentes. Por outro lado as menos desenvolvidas são as que possuem os menores valores para o IDH-M: Jequitinhonha, 
Vale do Mucuri, Norte de Minas, Vale do Rio Doce, Central Mineira, Noroeste de Minas e Zona da Mata.

Tabela 11. Índice de Desenvolvimento Humano (IDH-M) nas 12 mesorregiões mineiras, em 2000.

\begin{tabular}{lc}
\hline $\begin{array}{l}\text { Estado e } \\
\text { mesorregiões }\end{array}$ & IDH -M \\
\hline Minas Gerais & 0,773 \\
Jequitinhonha & 0,659 \\
Vale do Mucuri & 0,677 \\
Norte de Minas & 0,690 \\
Vale do Rio Doce & 0,734 \\
Central Mineira & 0,754 \\
Noroeste de Minas & 0,757 \\
Zona da Mata & 0,760 \\
Campo das Vertentes & 0,774 \\
Sul/ Sudoeste de Minas & 0,785 \\
Oeste de Minas & 0,789 \\
Metropolitana de Belo Horizonte & 0,796 \\
Triângulo Mineiro/Alto Paranaíba & 0,808 \\
\hline
\end{tabular}

Fonte: elaboração a partir do PNUD, IPEA \& FJP (2003)

\subsection{A distribuição do rendimento domiciliar per capita}

O objetivo desta seção é analisar a distribuição do rendimento domiciliar per capita em Minas Gerais e nas 12 mesorregiões mineiras, no ano de 2000.

A Tabela 12 mostra que após a exclusão das pessoas cuja condição no domicílio enquadra-se na categoria de empregado doméstico, parente de empregado doméstico e pensionista e dos domicílios classificados como coletivos ou improvisados e daqueles em que residem pessoas que têm um rendimento com valor de $\mathrm{R} \$ 100.000,00$ ou mais, são analisados na amostra 606.078 domicílios e 2.322 .809 pessoas. Essa amostra representa 4,8 milhões de domicílios e 17,7 milhões de pessoas na população. 
Tabela 12. Número de domicílios particulares permanentes e de pessoas, na amostra e na população, em Minas Gerais e nas 12 mesorregiões mineiras, de acordo com os dados da amostra do censo de 2000.

\begin{tabular}{lccrrc}
\hline \multicolumn{1}{c}{ Estado e } & $\begin{array}{c}\mathrm{N}^{0} \text { de } \\
\text { Mesorregiões } \\
\text { domićlios } \\
\text { na amostra }\end{array}$ & $\begin{array}{c}\mathrm{N}^{0} \text { de domicílios } \\
\text { na população }\end{array}$ & $\begin{array}{c}\mathrm{N}^{0} \text { de } \\
\text { pessoas } \\
\text { na amostra }\end{array}$ & $\begin{array}{c}\mathrm{N}^{0} \text { de pessoas } \\
\text { na população }\end{array}$ & $\begin{array}{c}\mathrm{N}^{0} \text { de } \\
\text { pessoas por } \\
\text { domicílio }\end{array}$ \\
\hline Minas Gerais & 606.078 & 4.762 .914 & 2.322 .809 & 17.711 .995 & 3,7 \\
Noroeste & 11.117 & 86.731 & 43.105 & 327.166 & 3,8 \\
Norte de Minas & 46.847 & 344.226 & 211.165 & 1.475 .019 & 4,3 \\
Jequitinhonha & 23.690 & 157.582 & 105.938 & 670.823 & 4,3 \\
Vale do Mucuri & 13.873 & 94.604 & 59.458 & 377.158 & 4,0 \\
Triângulo/Alto & & & & & \\
Paranaíba & 63.690 & 538.619 & 223.856 & 1.851 .878 & 3,4 \\
Central Mineira & 14.114 & 104.377 & 53.080 & 376.893 & 3,6 \\
RMBH & 163.332 & 1.489 .506 & 613.420 & 5.525 .920 & 3,7 \\
Vale do Rio & & & & & \\
Doce & 54.746 & 399.535 & 213.712 & 1.520 .366 & 3,8 \\
Oeste de Minas & 29.483 & 234.283 & 106.700 & 832.676 & 3,5 \\
Sul/ Sudoeste & 87.987 & 619.328 & 323.941 & 2.231 .546 & 3,6 \\
Campo das & & & & & \\
Vertentes & 19.114 & 137.588 & 73.103 & 507.398 & 3,7 \\
Zona da Mata & 78.085 & 556.534 & 295.331 & 2.015 .152 & 3,6 \\
\hline
\end{tabular}

Fonte: dados da pesquisa.

A Figura 5 ilustra as participações das mesorregiões no total da renda declarada na amostra do censo. Nota-se que as principais regiões na geração da riqueza mineira são: RMBH, Sul/ Sudoeste de Minas e Triângulo/ Paranaíba. A RMBH detém quase $41 \%$ da renda total declarada, seguida pelo Sul/Sudoeste de Minas (13,5\%) e Triângulo Mineiro/Alto Paranaíba (12,7\%). Em conjunto essa três mesorregiões são responsáveis por $66,2 \%$ da renda domiciliar total declarada, restando para as outras nove mesorregiões $33,8 \%$ dessa renda. 


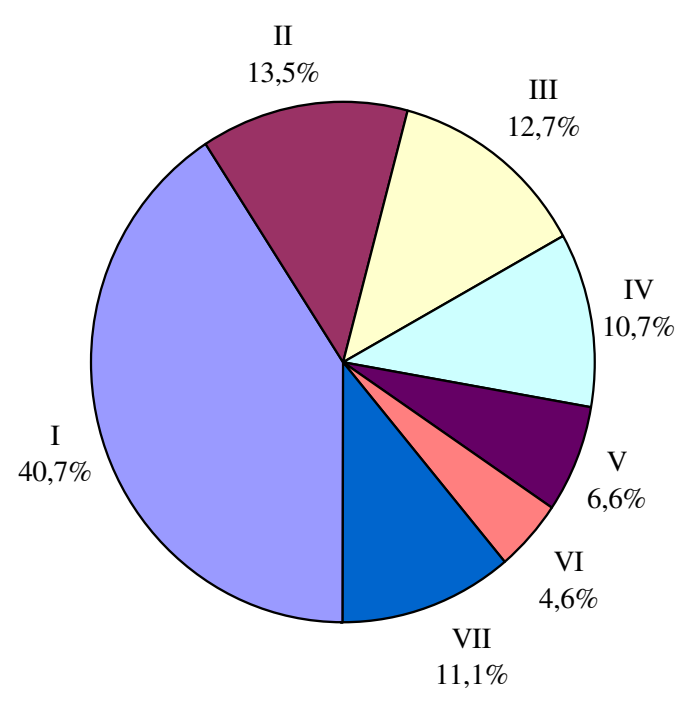

Figura 5 - A participação das mesorregiões no total da renda declarada.

Fonte: dados da pesquisa.

Nota: I. RMBH; II. Sul e Sudeste de Minas; III. Triângulo Mineiro/Paranaíba; IV. Zona da Mata; V. Vale do Rio Doce; VI. Oeste de Minas; VII. demais mesorregiões.

Contudo, a renda domiciliar per capita média é um melhor indicador para ajudar a sinalizar o nível de bem estar de uma sociedade. Quanto maior o nível de renda per capita de uma região, em geral, mais desenvolvida ela tende a ser. Cabe ressaltar que o conceito de desenvolvimento aqui adotado abrange não só a renda, mas também as condições de educação e saúde da sociedade.

A Figura 6 mostra a renda domiciliar per capita média e o nível de desenvolvimento (medido pelo IDH-M) das mesorregiões mineiras. Nota-se, pela figura, que à medida que o IDH-M das mesorregiões se eleva, as rendas domiciliares per capita médias são mais altas, mostrando assim a correlação positiva entre essas variáveis.

As mesorregiões que apresentam maiores valores para a renda domiciliar per capita média são: RMBH, Triângulo Mineiro/Alto Paranaíba, Sul/Sudoeste de Minas e Oeste de Minas. Contudo, a classificação do IDH-M nessas mesorregiões não segue essa mesma ordem. O Triângulo Mineiro/Alto do Paranaíba está à frente da RMBH e Sul e 
Sudoeste de Minas ocupa a $4^{\circ}$ posição, sendo a $3^{\circ}$ posição ocupada pela mesorregião Oeste de Minas. Essas pequenas diferenças ocorrem devido à influência das condições de educação e saúde no IDH-M.

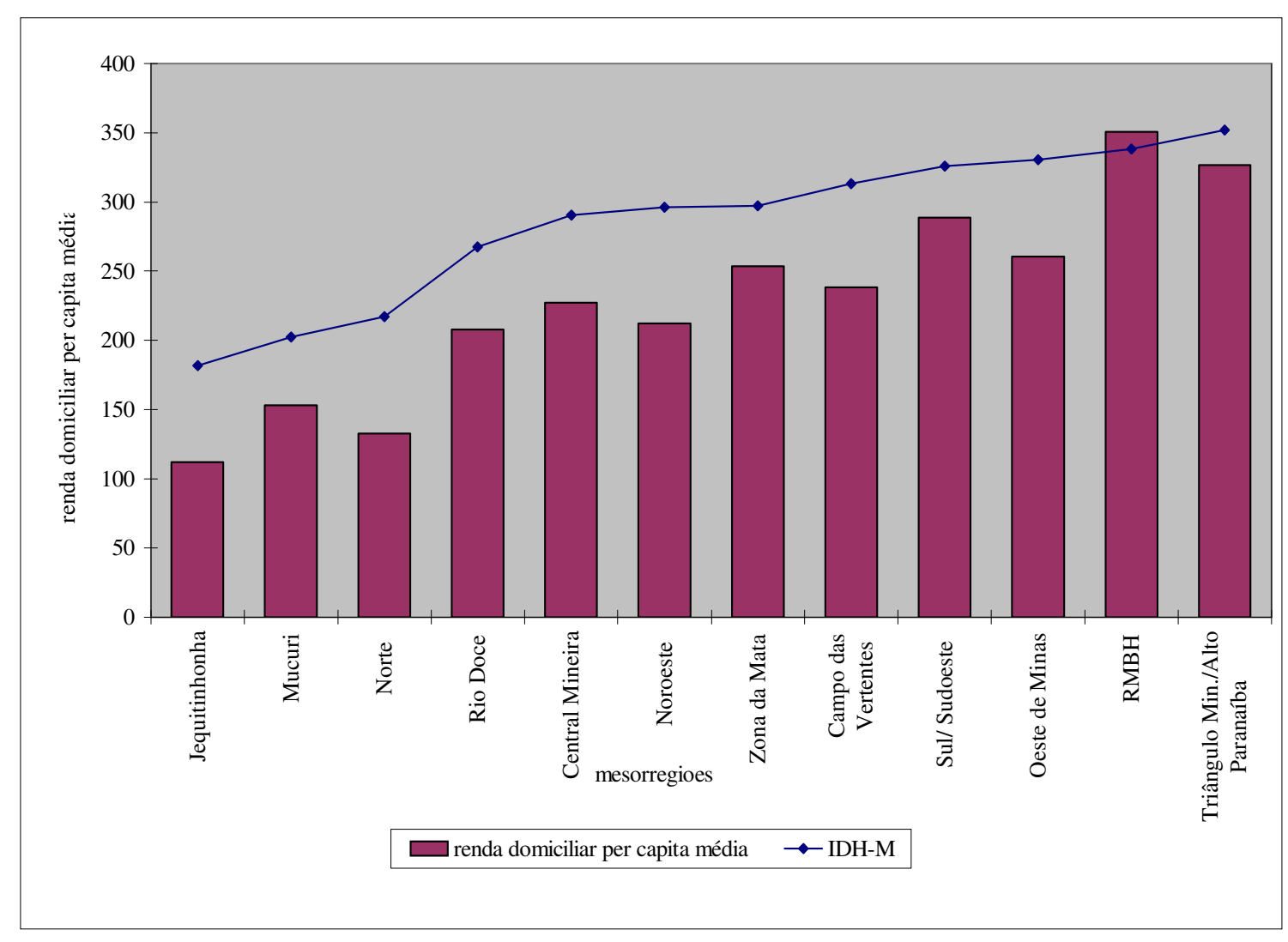

Figura 6 - A renda domiciliar per capita média e o IDH-M das mesorregiões mineiras. Fonte: dados da pesquisa.

Conforme já mencionado, há uma subdeclaração de rendimentos na amostra do censo. Uma maneira de avaliar este grau de subestimação consiste em comparar a renda domiciliar per capita mineira declarada na amostra do censo de 2000 e o PIB per capita mineiro estimado nas contas regionais. Em 2000, o PIB per capita mineiro foi de R\$ 5.925,00. Transformando esse valor em PIB per capita mensal o valor passa a ser de R $\$$ 493,75. De acordo com os dados da amostra do censo de 2000, a renda mensal domiciliar per capita média em Minas Gerais é de $\mathrm{R} \$ 272,98$. A relação entre a renda domiciliar per capita média e o PIB per capita é aproximadamente 0,55 . Esse resultado é bastante coerente com o obtido por Hoffmann (2001b). 
A Tabela 13 mostra as medidas de desigualdade no estado de Minas Gerais e nas mesorregiões mineiras. Não se apresenta o $L$ de Theil, que tende ao infinito na presença de rendimento domiciliar per capita igual a zero. O índice de Gini da distribuição do rendimento domiciliar per capita, em Minas Gerais, excluindo domicílios com pessoas com renda declarada igual ou superior a $\mathrm{R} \$ 100.000,00$ mensais, é de 0,610. Se não houvesse a exclusão desses domicílios o índice de Gini seria de 0,616. Esses valores estimados são semelhantes ao encontrado no Atlas de Desenvolvimento Humano do $\operatorname{Brasil}(G=0,615)$.

As comparações regionais mostram acentuadas diferenças de desigualdade na distribuição da renda entre as mesorregiões mineiras, com o índice de Gini variando de 0,530 (Oeste de Minas) a 0,638 (Vale do Mucuri), ou seja, o índice de Gini oscila 20,37\% dentro do estado de Minas Gerais. Vale do Mucuri, Norte de Minas, RMBH, Jequitinhonha são respectivamente as mesorregiões que possuem o maiores índices de Gini, igualando ou superando o valor encontrado para Minas Gerais como um todo.

Reafirmando a desigualdade do estado mineiro, o $T$ de Theil é de 0,830. Assim como o Gini, o índice de Theil apresenta maior valor na mesorregião Vale do Mucuri $(T=0,930)$ e menor valor no Oeste de Minas $(T=0,624)$. Na enumeração das quatro mesorregiões com os maiores valores para o índice de Theil, a mesma ordem não prevalece, passando a ser: Vale do Mucuri, Noroeste de Minas, Norte e Jequitinhonha. Essas diferenças de ordenação entre o índice de Gini e o $T$ de Theil ocorrem devido a sensibilidade desses índices a mudanças em diversas partes (estratos) da distribuição.

Segundo Hoffmann (2001d), o $T$ de Theil é mais sensível a modificações nas rendas dos relativamente ricos, enquanto, o índice de Gini é mais sensível a modificações nas rendas próximas da moda ou da mediana da distribuição.

Comparando os valores da renda mediana com os valores da renda média das mesorregiões mineiras, verifica-se que, o valor da mediana está bem próximo da metade do valor da média, evidenciado uma forte assimetria positiva da distribuição da renda nas mesorregiões. ${ }^{13}$

${ }^{13} \mathrm{O}$ segundo quartil da distribuição é a mediana da distribuição. 
Tabela 13. Principais características da distribuição do rendimento domiciliar per capita em Minas Gerais e nas 12 mesorregiões mineiras, de acordo a amostra do censo de 2000.

\begin{tabular}{|c|c|c|c|c|c|c|}
\hline Estatística & $\begin{array}{l}\text { Minas } \\
\text { Gerais }\end{array}$ & Noroeste & Norte & $\begin{array}{l}\text { Jequiti- } \\
\text { nhonha }\end{array}$ & $\begin{array}{l}\text { Vale do } \\
\text { Mucuri }\end{array}$ & $\begin{array}{c}\text { Triângulo/ } \\
\text { Alto Paranaíba }\end{array}$ \\
\hline Rdmto/pessoa & 272,98 & 212,06 & 132,76 & 112,09 & 153,07 & 326,69 \\
\hline Percentil 10 & 33,33 & 30,00 & 9,09 & 10,00 & 16,00 & 60,00 \\
\hline 20 & 56,83 & 50,00 & 25,00 & 23,59 & 30,00 & 86,29 \\
\hline 25 & 69,33 & 58,89 & 30,20 & 28,75 & 34,29 & 100,00 \\
\hline 30 & 77,50 & 68,40 & 37,50 & 33,33 & 40,00 & 112,50 \\
\hline 40 & 102,00 & 85,00 & 50,00 & 45,00 & 51,25 & 141,50 \\
\hline 50 & 134,00 & 105,00 & 65,00 & 57,50 & 70,00 & 168,89 \\
\hline 60 & 166,67 & 133,3 & 83,33 & 75,00 & 89,50 & 210,00 \\
\hline 70 & 224,83 & 166,25 & 112,17 & 98,50 & 120,00 & 270,00 \\
\hline 75 & 262,50 & 192,5 & 130,83 & 113,00 & 150,00 & 316,00 \\
\hline 80 & 320,00 & 228,00 & 151,00 & 138,40 & 166,67 & 376,00 \\
\hline 90 & 570,40 & 383,67 & 263,17 & 215,00 & 306,00 & 658,50 \\
\hline 95 & 957,00 & 630,00 & 440,00 & 351,82 & 530,25 & $1.053,25$ \\
\hline 99 & $2.400,00$ & $2.000,00$ & $1.210,00$ & $1.000,00$ & $1.397,75$ & $2.582,50$ \\
\hline \multicolumn{7}{|l|}{$\%$ da renda dos } \\
\hline $40 \%$ mais pobres & 8,09 & 8,71 & 7,01 & 7,71 & 7,14 & 10,18 \\
\hline $50 \%$ mais pobres & 12,43 & 13,23 & 11,27 & 12,25 & 11,10 & 14,92 \\
\hline $20 \%$ mais ricos & 65,25 & 65,02 & 65,86 & 64,22 & 67,69 & 62,26 \\
\hline $10 \%$ mais ricos & 49,88 & 51,25 & 51,08 & 49,37 & 53,02 & 47,21 \\
\hline $5 \%$ mais ricos & 36,57 & 39,88 & 38,48 & 37,25 & 39,63 & 34,58 \\
\hline $1 \%$ mais ricos & 15,79 & 29,46 & 17,95 & 17,16 & 18,18 & 15,72 \\
\hline \multirow{2}{*}{$\begin{array}{l}\text { Relação } \\
\text { médias } 10^{+} / 40^{-}\end{array}$} & & & & & & \\
\hline & 24,67 & 23,55 & 29,14 & 25,56 & 29,71 & 18,54 \\
\hline Índice de Gini & 0,610 & 0,609 & 0,628 & 0,610 & 0,638 & 0,571 \\
\hline T de Theil & 0,803 & 0,916 & 0,883 & 0,832 & 0,930 & 0,730 \\
\hline
\end{tabular}


Tabela 13. Principais características da distribuição do rendimento domiciliar per capita em Minas Gerais e nas 12 mesorregiões mineiras, de acordo com dados da amostra do censo de 2000.

\begin{tabular}{|c|c|c|c|c|c|c|c|}
\hline Estatística & Central & RMBH & $\begin{array}{l}\text { Vale do } \\
\text { Rio Doce }\end{array}$ & Oeste & $\begin{array}{c}\text { Sul e } \\
\text { Sudoeste }\end{array}$ & $\begin{array}{l}\text { Campo das } \\
\text { Vertentes }\end{array}$ & $\begin{array}{c}\text { Zona da } \\
\text { Mata }\end{array}$ \\
\hline $\mathrm{Rdmto}^{1} /$ pessoa & 227,23 & 350,69 & 207,70 & 260,52 & 288,62 & 238,39 & 253,44 \\
\hline Percentil 10 & 37,75 & 44,29 & 25,17 & 54,00 & 50,33 & 37,75 & 37,63 \\
\hline 20 & 60,00 & 73,40 & 42,00 & 78,20 & 75,78 & 60,00 & 58,33 \\
\hline 25 & 70,43 & 83,88 & 50,33 & 91,67 & 90,25 & 70,00 & 70,00 \\
\hline 30 & 75,50 & 100,00 & 60,00 & 100,67 & 100,50 & 75,50 & 75,50 \\
\hline 40 & 100,00 & 128,33 & 77,50 & 126,20 & 126,67 & 100,00 & 100,33 \\
\hline 50 & 120,80 & 161,78 & 100,67 & 151,00 & 151,00 & 125,00 & 127,86 \\
\hline 60 & 151,00 & 210,00 & 135,40 & 183,67 & 190,20 & 151,00 & 157,75 \\
\hline 70 & 187,50 & 285,25 & 175,00 & 228,57 & 242,20 & 200,00 & 209,00 \\
\hline 75 & 215,40 & 338,00 & 209,25 & 262,50 & 278,50 & 235,00 & 250,00 \\
\hline 80 & 253,00 & 419,00 & 253,00 & 302,00 & 333,33 & 283,33 & 300,00 \\
\hline 90 & 425,00 & 766,67 & 445,17 & 500,00 & 572,00 & 500,00 & 533,33 \\
\hline 95 & 686,00 & $1.274,80$ & 717,00 & 792,50 & 932,00 & 809,20 & 875,00 \\
\hline 99 & $1.966,67$ & $3.000,00$ & $1.725,00$ & $2.000,00$ & $2.364,00$ & $1.995,00$ & $2.170,00$ \\
\hline \multicolumn{8}{|l|}{$\%$ da renda dos } \\
\hline $40 \%$ mais pobres & 10,00 & 7,95 & 7,96 & 11,80 & 10,53 & 9,50 & 8,87 \\
\hline $50 \%$ mais pobres & 14,80 & 12,10 & 12,33 & 17,22 & 15,45 & 14,17 & 13,35 \\
\hline $20 \%$ mais ricos & 62,29 & 65,87 & 64,44 & 58,41 & 61,47 & 62,69 & 63,88 \\
\hline $10 \%$ mais ricos & 48,03 & 49,85 & 48,39 & 43,71 & 46,64 & 47,17 & 48,22 \\
\hline $5 \%$ mais ricos & 36,43 & 35,81 & 34,96 & 31,83 & 34,24 & 33,99 & 34,85 \\
\hline $1 \%$ mais ricos & 17,94 & 14,63 & 15,04 & 14,08 & 15,08 & 14,27 & 14,46 \\
\hline \multicolumn{8}{|l|}{ Relação médias } \\
\hline & 19,21 & 25,09 & 24,33 & 14,81 & 17,72 & 19,86 & 21,74 \\
\hline Índice de Gini & 0,576 & 0,613 & 0,604 & 0,530 & 0,562 & 0,578 & 0,592 \\
\hline $\mathrm{T}$ de Theil & 0,794 & 0,786 & 0,772 & 0,624 & 0,701 & 0,704 & 0,737 \\
\hline
\end{tabular}

Fonte: dados da pesquisa.

${ }^{1}$ rendimento

De acordo com os dados, em toda Minas Gerais um rendimento domiciliar per capita maior ou igual a $\mathrm{R} \$ 957,00$ classifica a pessoa no vigésimo mais rico da população, o qual se apropria de $36,57 \%$ da renda total. Nas mesorregiões, uma pessoa que vive no Vale do Jequitinhonha e possui uma renda domiciliar per capita igual ou superior a R $\$ 351,82$ está classificada no vigésimo mais rico da população. Por outro lado, se a pessoa estiver vivendo na RMBH precisa ter uma renda domiciliar per capita 
de pelo menos $R$ \$ 1.274,80 para obter essa mesma classificação. $O$ vigésimo mais rico, na primeira mesorregião, apropria-se de $37,25 \%$ da renda, e na segunda de $35,81 \%$ da renda. Observe que o Oeste de Minas é a única região mineira onde a proporção da renda apropriada pelos $50 \%$ mais pobres $(17,22 \%)$ é substancialmente superior à proporção apropriada pelos $1 \%$ mais ricos $(14,08 \%)$.

Nota-se na Tabela 13 que todos os percentis da distribuição da renda domiciliar per capita para a mesorregião Triângulo Mineiro/Alto Paranaíba são maiores que os percentis correspondentes da distribuição da renda domiciliar per capita das mesorregiões Noroeste, Norte, Jequitinhonha, Vale do Mucuri, Central, Vale do Rio Doce, Oeste de Minas, Campo das Vertentes. Nesse caso, diz-se que a distribuição da renda do Triângulo Mineiro/Alto Paranaíba domina, em primeira ordem, a distribuição da renda de todas essas regiões. ${ }^{14}$

Somente a $\mathrm{RMBH}$, não está inclusa, uma vez que a partir do $70^{\circ}$ percentil os valores dos percentis do Triângulo Mineiro ficam menores do que os da RMBH.

De maneira geral, verifica-se que as distribuições da renda das mesorregiões mais desenvolvidas do estado mineiro (Triângulo Mineiro/Alto Paranaíba, Sul/Sudoeste de Minas, Oeste de Minas e RMBH) dominam em primeira ordem as distribuições das demais regiões.

Ainda em relação à desigualdade da distribuição da renda domiciliar per capita, observa-se que as medidas de desigualdade da renda domiciliar per capita das regiões menos desenvolvidas tendem a ser maiores do que as medidas de desigualdade das regiões mais desenvolvidas, com exceção da $\mathrm{RMBH}$, que apresenta uma das mais elevadas medidas de desigualdade para a renda domiciliar per capita. Isso porquê nessa mesorregião localiza-se a capital mineira, Belo Horizonte, que por ser um grande centro polarizador, tende a incluir os mais ricos do estado, sem deixar de incluir grande número de pobres.

\footnotetext{
${ }^{14}$ A dominância de primeira ordem constitui um critério bastante simples e aceito para a ordenação de distribuições (Hoffmann, 1998a, p.233).
} 
Moreira e Moreira (1992, p.83), analisando os principais fatores explicativos da desigualdade da distribuição da renda familiar e pobreza absoluta para 332 microrregiões homogêneas do Brasil relativos a 1980, observou que o valor da renda média, assim como os indicadores de desigualdade da distribuição da renda, tendem a ser relativamente altos nas microrregiões das capitais.

A Tabela 14 ilustra a distribuição dos domicílios e das pessoas em 9 estratos de rendimento domiciliar per capita. A estratificação está baseada no valor do salário mínimo no período da coleta de dados do censo. No primeiro estrato estão incluídos os domicílios cujo rendimento declarado é igual a zero.

Verifica-se que os domicílios com rendimento per capita acima de zero até 1 salário mínimo (SM) constituem o maior percentual dos estratos, com 47,82\% do total, abrigando 53,56\% das pessoas e um rendimento médio de $\mathrm{R} \$ 81,64$. Destaca-se no último estrato, com somente $0,04 \%$ das pessoas, o valor do rendimento médio, que chega a $\mathrm{R} \$ 16.481,71$.

Tabela 14. Distribuição dos domicílios e das pessoas em 9 estratos de rendimento domiciliar per capita na população, de acordo com a amostra do censo de 2000.

\begin{tabular}{|c|c|c|c|c|c|}
\hline \multirow[b]{2}{*}{$\begin{array}{l}\text { Estrato de rendimento } \\
\text { Domiciliar per capita }\end{array}$} & \multicolumn{2}{|c|}{ Domicílios } & \multicolumn{2}{|c|}{ Pessoas } & \multirow{2}{*}{$\begin{array}{l}\text { Rdmto per } \\
\text { capita médio } \\
(\mathrm{R} \$)\end{array}$} \\
\hline & $\mathrm{N}^{\mathrm{O}}$ & $\%$ & $\mathrm{~N}^{\mathrm{O}}$ & $\%$ & \\
\hline 0 & 163.787 & 3,44 & 558.188 & 3,15 & - \\
\hline Mais de 0 a 151 & 2.277 .458 & 47,82 & 9.487 .277 & 53,56 & 81,64 \\
\hline Mais de 151 a 302 & 1.114 .129 & 23,39 & 3.948 .967 & 2,30 & 215,50 \\
\hline Mais de 302 a 453 & 421.908 & 8,86 & 1.383 .783 & 7,81 & 370,36 \\
\hline Mais de 453 a 755 & 357.761 & 7,51 & 1.124 .671 & 6,35 & 581,85 \\
\hline Mais de 755 a 1510 & 268.298 & 5,63 & 795.787 & 4,49 & $1.049,94$ \\
\hline Mais de 1510 a 3020 & 113.064 & 2,37 & 306.934 & 1,73 & $2.066,29$ \\
\hline Mais de 3020 a 10000 & 43.189 & 0,91 & 99.212 & 0,56 & $4.582,13$ \\
\hline Mais de 10000 & 3.320 & 0,07 & 7.176 & 0,04 & $16.481,71$ \\
\hline Total & 4.762 .914 & 100 & 17.711 .995 & 100 & - \\
\hline
\end{tabular}

Fonte: dados da pesquisa. 


\subsection{A contribuição dos componentes do rendimento domiciliar per capita para a desigualdade}

O objetivo dessa seção é analisar a contribuição das parcelas do rendimento para a desigualdade da renda domiciliar per capita e verificar se a participação dessas parcelas para o rendimento total e sua contribuição para a desigualdade estão associadas ao nível de desenvolvimento da mesorregião.

O rendimento domiciliar per capita está dividido em 7 componentes: a) rendimento do trabalho principal; b) demais trabalhos; c) aposentadorias e pensões; d) aluguéis; e) pensão alimentícia, mesada, doação; f) renda mínima, bolsa escola, seguro desemprego ${ }^{15} \mathrm{e}$ g) outros rendimentos. Contudo, como não são todos os domicílios que possuem os sete tipos de rendimento, a Tabela 15 mostra a proporção de pessoas que vivem em domicílios sem nenhum tipo de rendimento domiciliar per capita ou cuja determinada parcela desse rendimento é igual a zero.

Nota-se que para Minas Gerais como um todo, $3,15 \%$ da população vive em domicílios que tem rendimento domiciliar per capita igual a zero. Nas regiões menos desenvolvidas esses números ultrapassam os valores encontrados para o estado como um todo. No Norte de Minas, por exemplo, $8 \%$ das pessoas estão em domicílios sem nenhum rendimento.

\footnotetext{
${ }^{15}$ Nas tabelas que mostram os resultados obtidos, os componentes que são formados por três ou mais tipos de rendimento são identificados apenas pelo nome do primeiro tipo.
} 
Tabela 15. Proporção de pessoas em domicílios com rendimento per capita igual a zero, em Minas Gerais e nas 12 mesorregiões mineiras, de acordo com dados da amostra do censo de 2000.

\begin{tabular}{lcccccccc}
\hline $\begin{array}{l}\text { Estados e } \\
\text { mesorregiões }\end{array}$ & \multicolumn{7}{c}{ Proporção de pessoas com rendimento zero ( \% ) } \\
\cline { 2 - 9 } & $\begin{array}{c}\text { Rdmto } \\
\text { Total }\end{array}$ & $\begin{array}{c}\text { Trab. } \\
\text { princ. }\end{array}$ & $\begin{array}{c}\text { Demais } \\
\text { trab. }\end{array}$ & $\begin{array}{c}\text { Apos. } \\
\text { pensões }\end{array}$ & Alug. & $\begin{array}{c}\text { Pensão } \\
\text { aliment }\end{array}$ & $\begin{array}{c}\text { Rend. } \\
\text { mín. }\end{array}$ & $\begin{array}{c}\text { Outros } \\
\text { rend. }\end{array}$ \\
\hline Minas Gerais & 3,15 & 12,74 & 95,68 & 65,10 & 92,78 & 95,36 & 97,20 & 96,76 \\
Noroeste & 4,66 & 12,61 & 96,70 & 73,72 & 93,11 & 96,03 & 97,10 & 97,21 \\
Norte & 8,00 & 19,67 & 97,15 & 67,13 & 96,27 & 97,14 & 98,11 & 96,31 \\
Jequitinhonha & 6,95 & 21,20 & 97,36 & 65,82 & 96,60 & 96,52 & 89,93 & 95,96 \\
Mucuri & 4,69 & 17,06 & 96,99 & 65,32 & 96,16 & 96,40 & 98,31 & 96,13 \\
Triângulo/Alto & & & & & & & & \\
Paranaíba & 1,84 & 9,02 & 94,86 & 70,69 & 90,45 & 94,51 & 98,17 & 96,94 \\
Central & 2,31 & 11,31 & 95,74 & 66,00 & 93,26 & 95,72 & 98,26 & 97,80 \\
RMBH & 2,70 & 11,61 & 95,00 & 64,01 & 92,30 & 94,59 & 96,70 & 96,77 \\
Rio Doce & 4,16 & 16,72 & 96,75 & 62,35 & 93,50 & 96,13 & 97,02 & 96,47 \\
Oeste & 1,51 & 9,35 & 95,81 & 65,11 & 91,90 & 95,56 & 97,46 & 97,42 \\
Sul e Sudoeste & 1,44 & 8,92 & 95,37 & 67,43 & 91,87 & 95,82 & 98,41 & 97,12 \\
Campo das & & & & & & & & \\
Vertentes & 2,19 & 13,04 & 95,86 & 58,78 & 92,93 & 94,70 & 97,77 & 97,17 \\
Zona da Mata & 2,44 & 13,40 & 95,69 & 60,67 & 92,41 & 95,24 & 97,57 & 96,45 \\
\hline
\end{tabular}

Fonte: dados da pesquisa.

Um rendimento domiciliar per capita positivo tem a participação de pelo menos um dos 7 componentes na renda domiciliar per capita. A Tabela 16 mostra a participação percentual de cada componente no rendimento domiciliar per capita em Minas Gerais e nas suas mesorregiões. O trabalho principal é o componente de maior peso na formação do rendimento domiciliar per capita. Verifica-se, pela tabela que em Minas Gerais a participação do rendimento do trabalho na renda domiciliar per capita chega a 76,16\% (somatório do trabalho principal com demais trabalhos), as aposentadorias e pensões ocupa a $2^{\circ}$ posição com uma participação de $17,16 \%$ e os demais rendimentos têm uma participação de 6,38\%.

O Noroeste de Minas é a mesorregião que possui a maior participação do componente "rendimento do trabalho principal" na renda domiciliar. Conforme mostra a Tabela 15 esse tipo de componente é responsável por $83,09 \%$ da renda domiciliar per capita nessa mesorregião. Quanto ao rendimento proveniente de aposentadorias e 
pensões, sua maior participação na renda domiciliar é na mesorregião Campo das Vertentes, com 23,84\%.

Tabela 16. Participação percentual dos componentes no rendimento domiciliar per capita em Minas Gerais e nas 12 mesorregiões mineiras, de acordo com a amostra do censo de 2000.

\begin{tabular}{lccccccc}
\hline \multicolumn{1}{c}{$\begin{array}{c}\text { Estado } \\
\text { Mesorregiões }\end{array}$} & $\begin{array}{c}\text { Trab. } \\
\text { princ. }\end{array}$ & $\begin{array}{c}\text { Demais } \\
\text { trab. }\end{array}$ & $\begin{array}{c}\text { Aposent. } \\
\text { pensões }\end{array}$ & Aluguéis & $\begin{array}{c}\text { Pensão } \\
\text { alim. }\end{array}$ & $\begin{array}{c}\text { Renda } \\
\text { mín. }\end{array}$ & $\begin{array}{c}\text { Outros } \\
\text { rend. }\end{array}$ \\
\hline Minas Gerais & 73,41 & 2,75 & 17,46 & 3,09 & 1,27 & 0,36 & 1,66 \\
Noroeste & 83,09 & 2,37 & 9,63 & 2,43 & 0,85 & 0,31 & 1,33 \\
Norte de Minas & 73,84 & 2,70 & 18,37 & 2,00 & 1,01 & 0,36 & 1,72 \\
Jequitinhonha & 71,39 & 2,26 & 20,68 & 1,49 & 0,92 & 1,08 & 2,18 \\
Vale do Mucuri & 73,76 & 2,91 & 18,19 & 1,87 & 1,15 & 0,25 & 1,88 \\
Triângulo/ Alto & & & & & & & \\
Paranaíba & 78,22 & 3,07 & 12,02 & 3,19 & 1,35 & 0,30 & 1,85 \\
Central Mineira & 75,03 & 3,04 & 16,71 & 2,75 & 0,91 & 0,31 & 1,25 \\
RMBH & 72,68 & 2,80 & 18,01 & 3,11 & 1,46 & 0,40 & 1,54 \\
Rio Doce & 71,70 & 2,35 & 19,93 & 2,62 & 1,22 & 0,38 & 1,80 \\
Oeste de Minas & 75,45 & 2,59 & 16,01 & 3,26 & 0,99 & 0,33 & 1,37 \\
Sul/ Sudoeste & 75,35 & 2,80 & 15,19 & 3,51 & 0,98 & 0,26 & 1,90 \\
Campo das & & & & & & & \\
Vertentes & 67,39 & 2,70 & 23,84 & 3,20 & 1,27 & 0,40 & 1,20 \\
Zona da Mata & 68,21 & 2,51 & 22,55 & 3,46 & 1,24 & 0,35 & 1,68 \\
\hline
\end{tabular}

Fonte: dados da pesquisa.

Já foi mencionado que quando a razão de concentração de uma parcela do rendimento é maior (menor) do que o índice de Gini, sua participação na desigualdade é maior (menor) do que sua participação no rendimento total. Em outras palavras, isso significa que uma razão de concentração maior do que o índice de Gini global faz com que aquela parcela do rendimento contribua para aumentar a desigualdade, o contrário acontecendo com uma razão de concentração menor do que o índice de Gini.

A Tabela 17 ilustra os resultados da decomposição do índice de Gini. Pela decomposição é possível conhecer a razão de concentração de cada parcela do rendimento em Minas Gerais e nas doze mesorregiões mineiras e a contribuição percentual das parcelas do rendimento no índice de Gini. 
Em Minas Gerais, dos componentes analisados, três deles (trabalho principal, aposentadorias e pensões, renda mínima/bolsa escola/seguro desemprego) têm razão de concentração menor do que o índice de Gini global. Por outro lado, demais trabalhos, aluguéis, pensão alimentícia/mesada/doação e outros rendimentos têm a razão de concentração maior do que o índice de Gini. Todavia, é importante ressaltar que as razões de concentração dos componentes "aposentadorias e pensões" $(C=0,588)$ e "trabalho principal” ( $C=0,598)$ apresentam valores apenas ligeiramente menores do que o índice de Gini $(0,610)$.

Mais adiante, na Figura 7 é possível visualizar mais claramente a contribuição de cada uma dessas parcelas para a desigualdade de Minas Gerais, por meio das chamadas curvas de concentração.

Como o rendimento do trabalho principal é o componente de maior participação na renda domiciliar per capita, ele dá origem à maior parcela do índice de Gini global. Verifica-se que em Minas Gerais $72 \%$ da desigualdade total provém do trabalho principal.

Tabela 17. Decomposição do índice de Gini do rendimento domiciliar per capita em Minas e nas mesorregiões mineiras, em 2000: razão de concentração $\left(C_{h}\right)$, parcela do componente no índice de Gini global $\left(\varphi_{h} C_{h}\right)$ e contribuição percentual para o índice de Gini.

\begin{tabular}{lcccccc}
\hline \multirow{1}{*}{$\begin{array}{c}\text { Componente } \\
\text { do rendimento }\end{array}$} & \multicolumn{3}{c}{ Minas Gerais } & \multicolumn{3}{c}{ Noroeste } \\
\cline { 2 - 7 } & \multicolumn{1}{c}{$C_{h}$} & $C_{h} \varphi_{h}$ & $\%$ Gini & \multicolumn{1}{c}{$C_{h}$} & $C_{h} \varphi_{h}$ & $\%$ Gini \\
\hline Trabalho principal & 0,5980 & 0,4390 & 72,00 & 0,6210 & 0,5160 & 84,66 \\
Demais trabalhos & 0,8512 & 0,0234 & 3,84 & 0,8767 & 0,0208 & 3,41 \\
Aposent. e pensões & 0,5883 & 0,1027 & 16,85 & 0,4227 & 0,0407 & 6,68 \\
Aluguéis & 0,7740 & 0,0234 & 3,92 & 0,7353 & 0,0179 & 2,93 \\
Pensão alimentícia & 0,6208 & 0,0079 & 1,30 & 0,5429 & 0,0046 & 0,75 \\
Renda mínima & 0,1372 & 0,0005 & 0,08 & 0,0921 & 0,0003 & 0,05 \\
Outros rendimentos & 0,7456 & 0,0123 & 2,02 & 0,6983 & 0,0093 & 1,52 \\
Gini global & - & 0,6098 & 100 & - & 0,6095 & 100 \\
\hline
\end{tabular}


Tabela 17. Decomposição do índice de Gini do rendimento domiciliar per capita em Minas e nas mesorregiões mineiras, em 2000: razão de concentração $\left(C_{h}\right)$, parcela do componente no índice de Gini global $\left(\varphi_{h} C_{h}\right)$ e contribuição percentual para o índice de Gini.

\begin{tabular}{|c|c|c|c|c|c|c|}
\hline \multirow{2}{*}{$\begin{array}{l}\text { Componente do } \\
\text { rendimento }\end{array}$} & \multicolumn{3}{|c|}{ Norte } & \multicolumn{3}{|c|}{ Jequitinhonha } \\
\hline & $C_{h}$ & $C_{h} \varphi_{h}$ & $\%$ Gini & $C_{h}$ & $C_{h} \varphi_{h}$ & $\%$ Gini \\
\hline Trabalho principal & 0,6334 & 0,4678 & 74,42 & 0,6251 & 0,4463 & 73,13 \\
\hline Demais trabalhos & 0,9015 & 0,0243 & 3,87 & 0,8973 & 0,0203 & 3,33 \\
\hline Aposent.e pensões. & 0,5466 & 0,1004 & 15,98 & 0,5445 & 0,1126 & 18,45 \\
\hline Aluguéis & 0,8275 & 0,0165 & 2,63 & 0,7957 & 0,0118 & 1,94 \\
\hline Pensão alimentícia & 0,6584 & 0,0067 & 1,06 & 0,5317 & 0,0048 & 0,80 \\
\hline Renda mínima & 0,3313 & 0,0012 & 0,19 & $-0,0959$ & $-0,0010$ & $-0,17$ \\
\hline Outros rendimentos & 0,6753 & 0,0116 & 1,85 & 0,7088 & 0,0154 & 2,53 \\
\hline Gini Global & - & 0,6284 & 100 & - & 0,6103 & 100 \\
\hline \multirow{2}{*}{$\begin{array}{l}\text { Componente do } \\
\text { rendimento }\end{array}$} & \multicolumn{3}{|c|}{$\begin{array}{l}\text { Vale do } \\
\text { Mucuri }\end{array}$} & \multicolumn{3}{|c|}{$\begin{array}{l}\text { Triângulo Mineiro/ } \\
\text { Alto Paranaíba }\end{array}$} \\
\hline & $C_{h}$ & $C_{h} \varphi_{h}$ & $\%$ Gini & $C_{h}$ & $C_{h} \varphi_{h}$ & $\%$ Gini \\
\hline Trabalho principal & 0,6479 & 0,4779 & 74,90 & 0,5591 & 0,4373 & 76,61 \\
\hline Demais trabalhos & 0,9050 & 0,0263 & 4,12 & 0,8348 & 0,0257 & 4,49 \\
\hline Aposent. e pensões & 0,5401 & 0,0983 & 15,41 & 0,5255 & 0,0631 & 11,06 \\
\hline Aluguéis & 0,7975 & 0,0149 & 2,33 & 0,7040 & 0,0225 & 3,93 \\
\hline Pensão alimentícia & 0,6253 & 0,0072 & 1,12 & 0,5661 & 0,0077 & 1,34 \\
\hline Renda mínima & 0,2187 & 0,0005 & 0,09 & 0,1514 & 0,0005 & 0,08 \\
\hline Outros rendimentos & 0,6927 & 0,0130 & 1,59 & 0,7653 & 0,0141 & 2,48 \\
\hline Gini global & - & 0,6381 & 100 & - & 0,5709 & 100 \\
\hline \multirow[b]{2}{*}{$\begin{array}{l}\text { Componente do } \\
\text { rendimento }\end{array}$} & \multicolumn{3}{|c|}{ Central } & \multicolumn{3}{|c|}{ RMBH } \\
\hline & $C_{h}$ & $C_{h} \varphi_{h}$ & $\%$ Gini & $C_{h}$ & $C_{h} \varphi_{h}$ & $\%$ Gini \\
\hline Trabalho principal & 0,5617 & 0,4214 & 73,19 & 0,5975 & 0,4342 & 70,84 \\
\hline Demais trabalhos & 0,8737 & 0,0266 & 4,61 & 0,8318 & 0,0233 & 3,79 \\
\hline Aposent. e pensões & 0,5514 & 0,0921 & 16,00 & 0,6164 & 0,1110 & 18,11 \\
\hline Aluguéis & 0,7752 & 0,0213 & 3,71 & 0,7600 & 0,0236 & 3,85 \\
\hline Pensão alimentícia & 0,5172 & 0,0047 & 0,82 & 0,6193 & 0,0090 & 1,48 \\
\hline $\begin{array}{l}\text { Renda mín. } \\
\text { Bolsa esc. }\end{array}$ & 0,1612 & 0,0005 & 0,08 & 0,0426 & 0,0002 & 0,02 \\
\hline Outros rend. & 0,7306 & 0,0091 & 1,59 & 0,7535 & 0,0116 & 1,90 \\
\hline Gini global & - & 0,5758 & 100 & - & 0,6130 & 100 \\
\hline
\end{tabular}


Tabela 17. Decomposição do índice de Gini do rendimento domiciliar per capita em Minas e nas mesorregiões mineiras, em 2000: razão de concentração $\left(C_{h}\right)$, parcela do componente no índice de Gini global $\left(\varphi_{h} C_{h}\right)$ e contribuição percentual para o índice de Gini.

\begin{tabular}{|c|c|c|c|c|c|c|}
\hline \multirow[b]{2}{*}{$\begin{array}{l}\text { Componente do } \\
\text { rendimento }\end{array}$} & \multicolumn{3}{|c|}{ Vale do Rio Doce } & \multicolumn{3}{|c|}{ Oeste } \\
\hline & $C_{h}$ & $C_{h} \varphi_{h}$ & $\%$ Gini & $C_{h}$ & $C_{h} \varphi_{h}$ & $\%$ Gini \\
\hline Trabalho principal & 0,6088 & 0,4365 & 72,23 & 0,5110 & 0,3856 & 72,75 \\
\hline Demais trabalhos & 0,8730 & 0,0205 & 3,40 & 0,8417 & 0,0218 & 4,11 \\
\hline Aposent. pensões & 0,5377 & 0,1072 & 17,74 & 0,5129 & 0,0821 & 15,50 \\
\hline Aluguéis & 0,7580 & 0,0198 & 3,28 & 0,7530 & 0,0245 & 4,63 \\
\hline Pensão alimentícia & 0,5936 & 0,0073 & 1,20 & 0,5579 & 0,0055 & 1,04 \\
\hline Renda mínima & 0,1506 & 0,0005 & 0,09 & 0,1027 & 0,0003 & 0,06 \\
\hline Outros rendimentos & 0,6899 & 0,0124 & 2,05 & 0,7374 & 0,0101 & 1,91 \\
\hline Gini global & - & 0,6043 & 100 & - & 0,5300 & 100 \\
\hline \multirow{2}{*}{$\begin{array}{l}\text { Componente do } \\
\text { rendimento }\end{array}$} & \multicolumn{3}{|c|}{ Sul e Sudoeste de Minas } & \multicolumn{3}{|c|}{ Campo das Vertentes } \\
\hline & $C_{h}$ & $C_{h} \varphi_{h}$ & $\%$ Gini & $C_{h}$ & $C_{h} \varphi_{h}$ & $\%$ Gini \\
\hline Trabalho principal & 0,5375 & 0,4050 & 72,04 & 0,5504 & 0,3709 & 64,18 \\
\hline Demais trabalhos & 0,8371 & 0,0234 & 4,16 & 0,8463 & 0,0228 & 3,95 \\
\hline Aposent. pensões & 0,5634 & 0,0856 & 15,23 & 0,5991 & 0,1429 & 24,72 \\
\hline Aluguéis & 0,7654 & 0,0269 & 4,78 & 0,7807 & 0,0250 & 4,33 \\
\hline Pensão alimentícia & 0,5540 & 0,0054 & 0,97 & 0,5478 & 0,0070 & 1,21 \\
\hline Renda mínima & 0,2482 & 0,0006 & 0,11 & 0,2260 & 0,0008 & 0,16 \\
\hline Outros rendimentos & 0,7973 & 0,0150 & 2,71 & 0,7020 & 0,0084 & 1,45 \\
\hline \multirow[t]{2}{*}{ Gini global } & - & 0,5621 & 100 & - & 0,5779 & 100 \\
\hline & \multicolumn{6}{|c|}{ Zona da Mata } \\
\hline $\begin{array}{l}\text { Componente } \\
\text { do rendimento }\end{array}$ & \multicolumn{2}{|c|}{$C_{h}$} & \multicolumn{2}{|c|}{$C_{h} \varphi_{h}$} & \multicolumn{2}{|c|}{$\%$ Gini } \\
\hline Trabalho principal & \multicolumn{2}{|c|}{0,5666} & \multicolumn{2}{|c|}{0,3865} & \multicolumn{2}{|c|}{62,56} \\
\hline Demais trabalhos & \multicolumn{2}{|c|}{0,8376} & \multicolumn{2}{|c|}{0,0211} & \multicolumn{2}{|c|}{3,56} \\
\hline Aposent. pensões & \multicolumn{2}{|c|}{0,6095} & \multicolumn{2}{|c|}{0,1374} & \multicolumn{2}{|c|}{23,22} \\
\hline Aluguéis & \multicolumn{2}{|c|}{0,7800} & \multicolumn{2}{|c|}{0,0270} & \multicolumn{2}{|c|}{4,56} \\
\hline Pensão alimentícia & \multicolumn{2}{|c|}{0,6054} & \multicolumn{2}{|c|}{0,0075} & \multicolumn{2}{|c|}{1,27} \\
\hline Renda mín. & \multicolumn{2}{|c|}{0,1711} & \multicolumn{2}{|c|}{0,0006} & \multicolumn{2}{|c|}{0,10} \\
\hline Outros rend. & \multicolumn{2}{|c|}{0,7030} & \multicolumn{2}{|c|}{0,0118} & & \\
\hline Gini global & & & & & & \\
\hline
\end{tabular}

Fonte: dados da pesquisa. 
Ainda com relação à Tabela 17, serão analisadas as razões de concentração, procurando evidenciar as diferenças entre as mesorregiões mineiras. No primeiro momento discute-se apenas as razões de concentração individualmente, mas depois procura-se verificar as relações existentes entre o nível de desenvolvimento com as razões de concentração das parcelas do rendimento.

Nota-se que os componentes do rendimento domiciliar per capita, nas mesorregiões, nem sempre apresentam um resultado comum na contribuição para a desigualdade, isto é, em algumas mesorregiões a razão de concentração de uma determinada parcela do rendimento domiciliar per capita é maior do que o índice de Gini dessa mesorregião, e em outras mesorregiões o mesmo componente do rendimento domiciliar per capita tem uma razão de concentração menor do que o índice de Gini da região.

Observa-se que "pensão alimentícia, mesada e doação" está contribuindo para aumentar a desigualdade nas mesorregiões Norte de Minas, RMBH, Oeste de Minas e Zona da Mata, pois a sua razão de concentração é maior do que o índice de Gini da mesorregião. Nas demais mesorregiões acontece o oposto.

No que se refere à parcela do índice de Gini associada a aposentadorias e pensões, destacam-se valores mais elevados para a razão de concentração na RMBH, Sul/Sudoeste de Minas, Campo das Vertentes e Zona da Mata. Apenas nessas mesorregiões a razão de concentração das aposentadorias e pensões é superior ao índice de Gini.

O rendimento do trabalho tem razão de concentração menor do que o índice de Gini no Triângulo Mineiro/Alto Paranaíba, RMBH, Oeste de Minas, Sul/Sudoeste, Campos das Vertentes e Zona da Mata. Nas demais mesorregiões, a razão de concentração é maior do que o Gini global. Cabe observar que, nesta decomposição do índice de Gini, a maior parte da desigualdade nas mesorregiões provém do rendimento do trabalho principal. Na mesorregião Noroeste de Minas 84,66\% da desigualdade é gerada pelo rendimento do trabalho principal.

Outros componentes do rendimento, como demais trabalhos, aluguéis e outros rendimentos apresentam uma razão de concentração maior do que o índice de Gini nas 
doze mesorregiões mineiras. Por fim, renda mínima/bolsa escola/seguro desemprego é o único componente que têm uma razão de concentração menor do que o índice de Gini em todas as mesorregiões.

Apesar da pequena participação ${ }^{16}$ do componente "renda mínima, bolsa e escola e seguro desemprego" na renda domiciliar per capita (em Minas Gerais essa participação é $0,36 \%$ ) é importante analisar com mais detalhe sua razão de concentração.

Renda mínima, bolsa escola e seguro desemprego são gastos públicos sociais dos governos. Tradicionalmente, atribui-se ao setor público três funções básicas: garantir a estabilidade e o crescimento econômico, promover eficiência na alocação de recursos e promover equidade na distribuição de oportunidades e de acesso a bens meritórios, contribuindo para melhorar a distribuição de renda. O gasto público social é o instrumento central dos governos no desempenho dessa última função. Em outras palavras deseja-se dizer que os dois objetivos fundamentais do gasto social são: o primeiro é oferecer segurança ao indivíduo contra situações de risco, como por exemplo, o seguro-desemprego no caso da perda do emprego pelo indivíduo. O segundo é combater a pobreza e promover maior equidade na distribuição dos recursos da sociedade. Os programas de transferência direta de renda tais como bolsa escola e renda mínima são exemplos de programas com esse segundo objetivo (Brasil, 2003).

Os baixos valores para as razões de concentração do componente "renda mínima, bolsa escola e seguro desemprego" nas mesorregiões mineiras ajudam, em parte, a comprovar a afirmativa acima. Nota-se que as razões de concentração apresentam valores muito menores do que o Gini da mesorregião, ou seja, essa parcela do rendimento contribui claramente para diminuir a desigualdade. Isso acontece principalmente pela presença dos rendimentos de renda mínima e bolsa escola, pois eles estão focalizados diretamente nas famílias pobres. O Vale do Jequitinhonha destaca-se pela razão de concentração negativa para esse componente, indicando que nessa mesorregião essa parcela do rendimento é maior para os relativamente pobres, fazendo a curva de concentração ficar acima da linha de perfeita igualdade.

16 Tabela 16. 
Como renda mínima, bolsa escola e seguro desemprego estão incluídos em uma única categoria, não dá para separar a contribuição de cada uma dessas parcelas para a desigualdade. Mas se fosse possível separar os rendimentos de renda mínima e bolsa escola dos rendimentos do seguro desemprego, provavelmente a razão de concentração do primeiro tipo de rendimento seria sempre negativa, uma vez que eles são típicos de domicílios relativamente pobres. Já a respeito do rendimento "seguro desemprego" pode-se dizer que a respectiva curva de concentração permanece abaixo da linha de perfeita igualdade, principalmente pelo fato de que para recebê-lo não é condição necessária ser pobre. O conjunto desses dois rendimentos apresenta, em Minas Gerais, uma razão de concentração pequena, mas positiva.

À medida que esses programas de transferência de renda forem expandidos para um maior número de beneficiários potenciais, o efeito esperado é que a razão de concentração desse componente contribua cada vez mais para diminuir a desigualdade. Como a participação desse componente é pequena, esses programas ainda podem ser expandidos dentro do estado mineiro, principalmente nas regiões menos desenvolvidas, pois nessas localidades o número de pessoas pobres é bastante crítico, como é exposto na seção 4.4 .

Através da correlação simples busca-se determinar à associação entre o nível de desenvolvimento, medido pelo IDH-M, e as razões de concentração de cada parcela do rendimento, nas mesorregiões. A Tabela 18 mostra o coeficiente de correlação. Dos sete componentes analisados, somente as razões de concentração do trabalho principal, dos demais trabalhos, aluguéis e outros rendimentos apresentam uma associação estatisticamente significativa com o nível de desenvolvimento das mesorregiões. 
Tabela 18. Correlação simples entre o IDH-M e a razão de concentração das mesorregiões mineiras, em 2000 e probabilidade caudal do teste da hipótese de ausência de correlação.

\begin{tabular}{lcr}
\hline Razões de concentração & $\begin{array}{c}\text { Coeficiente de correlação } \\
\text { com o IDH-M }\end{array}$ & $\begin{array}{r}\text { Probabilidade } \\
\text { caudal do teste }\end{array}$ \\
\hline Trabalho principal & $-0,769$ & 0,0034 \\
Demais trabalhos & 0,925 & $<0,0001$ \\
Aposent. pensões & 0,113 & 0,7265 \\
Aluguéis & $-0,736$ & 0,0063 \\
Pensão alimentícia & $-0,245$ & 0,4435 \\
Renda mín. & 0,082 & 0,7977 \\
Outros rend. & 0,661 & 0,0192 \\
\hline
\end{tabular}

Fonte: dados da pesquisa.

Nota-se, na tabela, que a razão de concentração do rendimento do trabalho principal aumenta à medida que o nível o desenvolvimento das mesorregiões diminui. Comparando a razão de concentração do rendimento trabalho principal das mesorregiões menos desenvolvidas com as mais desenvolvidas, quatro das seis mesorregiões menos desenvolvidas têm a razão de concentração do componente "trabalho principal" da renda domiciliar per capita maior do que o índice de Gini da mesorregião, ou seja, nessas mesorregiões a participação desse componente na desigualdade é maior do que sua participação no rendimento total, contribuindo assim para aumentar a desigualdade dentro da mesorregião. Por outro lado, nas mesorregiões mais desenvolvidas (Triângulo Mineiro/Alto Paranaíba, RMBH, Oeste de Minas, Sul /Sudoeste de Minas e Campo das Vertentes) esse componente tem uma razão de concentração menor do que o índice de Gini. Assim, nas mesorregiões mais desenvolvidas a contribuição para a desigualdade do rendimento proveniente do trabalho principal é menor do que sua participação no rendimento total.

A razão de concentração do rendimento de aluguéis também tem uma correlação negativa com a variável que mede o nível de desenvolvimento da região. Já as razões de concentração do rendimento dos demais trabalhos e outros rendimentos possuem correlação positiva com o IDH-M. 
Mesmo não havendo associação entre as razões de concentração do componente "aposentadorias e pensões" com o nível de desenvolvimento das mesorregiões, é importante chamar atenção para o fato de que algumas mesorregiões menos desenvolvidas do estado (Noroeste, Norte, Jequitinhonha, Vale do Mucuri e Vale do Rio Doce) apresentam razões de concentração referentes a essa parcela bem menores do que os índices de Gini das mesorregiões.

Uma possível explicação para esse fato é que as razões de concentração de "aposentadorias e pensões" nessas mesorregiões são relativamente baixas devido à presença de um grande número de aposentadorias rurais. A Tabelas 27 do apêndice mostra que nessas mesorregiões menos desenvolvidas há um maior número de pessoas vivendo na zona rural com rendimentos provenientes de aposentadorias e pensões do que nas demais mesorregiões.

A divisão dos rendimentos de aposentadorias e pensões em estratos (Tabelas 28 a 40 do apêndice) indica que a maioria das aposentadorias e pensões pagas nessas mesorregiões correspondem a 1 salário mínimo ( $\mathrm{R} \$ 151,00$ ). Enquanto, em Minas Gerais como um todo 53,39\% das pessoas aposentadas ou pensionistas recebem rendas de aposentadorias ou pensões no valor de 1 salário mínimo, nas mesorregiões Noroeste, Norte, Jequitinhonha, Vale do Mucuri e Vale do Rio Doce esses valores chegam a $74,63 \%, 60,06 \%, 61,73 \%, 67,09 \%$ e 59,56\% respectivamente. É importante ressaltar que a proporção de pessoas com aposentadorias e pensões superiores a $\mathrm{R} \$ 755,00$ é pequena nessas mesorregiões. Em Minas Gerais $11,87 \%$ das pessoas estão em estratos de aposentadorias e pensões superiores a $\mathrm{R} \$ 755,00$. Já nessas mesorregiões (Noroeste, Norte, Jequitinhonha, Vale do Mucuri e Vale do Rio Doce) há respectivamente 3,74\%, $3,95 \%, 2,85 \%, 3,96 \%$ e $9,97 \%$ pessoas recebendo aposentadorias e pensões dentro desse intervalo.

De acordo com os dados da amostra do censo, em Minas Gerais, as aposentadorias e pensões representam 17,18\% do rendimento total declarado.

Na Tabela 19 são contabilizados 2.174.826 aposentados e pensionistas em Minas Gerais. Nota-se certa concentração na mesorregião Metropolitana de Belo Horizonte, com uma participação de 30,39\% do total. O rendimento médio das aposentadorias e 
pensões pagas no estado de Minas Gerais é R\$ 391,50. Na RMBH o valor médio das aposentadorias e pensões ( $\mathrm{R} \$$ 531,38) está muito acima da média do estado. Nas mesorregiões Noroeste, Norte, Jequitinhonha e Vale do Mucuri esses valores não ultrapassam $\mathrm{R} \$ 250,00$. As demais mesorregiões têm um rendimento médio girando em torno de $\mathrm{R} \$ 350,00$.

Tabela 19. Número de pessoas com rendimento positivo para aposentadorias e pensões na amostra, $\mathrm{n}^{\mathrm{o}}$ de pessoas com rendimento positivo para aposentadoria e pensões na população, a participação percentual de aposentados e pensionistas $\left(\%_{\mathrm{A}}\right)$, participação de aposentados e pensionistas na população das mesorregiões $\left(\%_{\mathrm{B}}\right)$ e o valor médio das aposentadorias e pensões pagas, em 2000 .

\begin{tabular}{|c|c|c|c|c|c|}
\hline \multirow{2}{*}{$\begin{array}{c}\text { Estado e } \\
\text { mesorregiões }\end{array}$} & \multirow{2}{*}{$\begin{array}{c}\mathrm{N}^{\mathrm{o}} \text { de pessoas } \\
\text { aposent. ou pens. } \\
\text { na amostra }\end{array}$} & \multicolumn{3}{|c|}{$\begin{array}{l}\text { População de pessoas aposent. } \\
\text { ou pensionistas. }\end{array}$} & \multirow[t]{2}{*}{ Valor médio } \\
\hline & & $\mathrm{N}^{\mathrm{O}}$ & ${ }^{1} \%_{\mathrm{A}}$ & ${ }^{2} \%_{\mathrm{B}}$ & \\
\hline Minas Gerais & 276.864 & 2.174 .826 & 100 & 12,28 & 391,50 \\
\hline Noroeste de Minas & 3.794 & 30.029 & 1,38 & 9,18 & 225,58 \\
\hline Norte de Minas & 20.595 & 153.816 & 7,07 & 10,43 & 235,71 \\
\hline Jequitinhonha & 11.030 & 73.647 & 3,39 & 10,98 & 213,92 \\
\hline Vale do Mucuri & 6.327 & 43.966 & 2,02 & 11,66 & 240,85 \\
\hline \multicolumn{6}{|l|}{ Triângulo Mineiro/ Alto } \\
\hline Paranaíba & 23.841 & 205.830 & 9,46 & 11,11 & 356,34 \\
\hline Central Mineira & 6.384 & 47.620 & 2,19 & 12,63 & 305,26 \\
\hline RMBH & 72.984 & 660.930 & 30,39 & 11,96 & 531,38 \\
\hline Vale do Rio Doce & 27.737 & 199.714 & 9,18 & 13,14 & 317,41 \\
\hline Oeste de Minas & 13.577 & 107.998 & 4,97 & 12,97 & 325,13 \\
\hline Sul/ Sudoeste de Minas & 38.225 & 274.779 & 12,63 & 12,31 & 360,87 \\
\hline Campo das Vertentes & 10.352 & 75.333 & 3,46 & 14,85 & 386,50 \\
\hline Zona da Mata & 42.018 & 301.162 & 13,85 & 14,94 & 385,86 \\
\hline
\end{tabular}

Fonte: dados da pesquisa

$1 \%_{\mathrm{A}}$ é a participação de cada mesorregião no total de aposentados e pensionistas do Estado.

${ }^{2} \%_{\mathrm{B}}$ é a participação de aposentados e pensionistas na população da mesorregião. 
Conclui-se que o rendimento de aposentadorias e pensões contribui para reduzir a desigualdade nas mesorregiões em que há maior concentração de valores desse rendimento iguais a 1 salário mínimo, e poucos valores elevados, como ocorre em várias mesorregiões menos desenvolvidas. Já em mesorregiões onde grande número de aposentadorias e pensões iguais a 1 salário mínimo coexiste com um número substancial de valores elevados desse tipo de rendimento, ele chega a contribuir para aumentar a desigualdade total. Cabe destacar a $\mathrm{RMBH}$, onde a razão de concentração de aposentadorias e pensões $(0,616)$ supera o elevado valor do índice de Gini da mesorregião $(0,613)$.

Para melhor compreensão da decomposição do índice de Gini, a Figura 7 mostra as curvas de concentração para os componentes do rendimento domiciliar per capita para Minas Gerais no ano 2000.

A curva preta é a curva de Lorenz da distribuição do rendimento domiciliar per capita. Essa curva é uma média ponderada das curvas de concentração das parcelas do rendimento domiciliar. Se a curva de concentração de uma parcela do rendimento ficar sempre abaixo da curva de Lorenz, essa parcela está contribuindo para aumentar a desigualdade da distribuição do rendimento domiciliar per capita.

Conforme exposto anteriormente, as razões de concentração do trabalho principal e de aposentadorias e pensões em Minas Gerais são apenas ligeiramente menores do que o índice de Gini. Através das curvas de concentração também é possível verificar essa aproximação de valores das três medidas. Nota-se, no gráfico, que as curvas de concentração para o trabalho principal (n.1) e aposentadorias e pensões (n.3) são praticamente coincidentes com a curva de Lorenz. Mas, observa-se que a curva de concentração do trabalho principal encontra-se mais afastada da linha de perfeita igualdade do que a curva de concentração de aposentadorias e pensões. Isso significa que a parcela do rendimento do trabalho principal está contribuindo mais para a desigualdade do rendimento domiciliar per capita do que a parcela do rendimento de aposentadorias e pensões.

Porém, alguns trabalhos de abrangência nacional, usando dados da PNAD, mostram na análise da decomposição do Gini que a parcela do rendimento de 
aposentadorias e pensões também pode estar contribuindo para aumentar a desigualdade de renda. Cita-se como exemplo Ferreira (2003) e Hoffmann (2003).

O primeiro autor, utilizando dados da PNAD de 2001, mostra que no Brasil a curva de concentração para aposentadorias e pensões encontra-se abaixo da curva de Lorenz e contribui mais para a desigualdade de renda do que o rendimento do trabalho principal.

O segundo autor, para analisar a contribuição das parcelas do rendimento para a desigualdade de renda do Brasil em 2001, divide o rendimento de todos os trabalhos em 3 três parcelas referentes ao rendimento do trabalho de empregados, empregadores e de contra própria, mostrando que a parcela do rendimento de aposentadorias e pensões tem razão de concentração ligeiramente maior do que o índice de Gini e substancialmente maior do que a razão de concentração do rendimento do trabalho de empregados.

Fazendo essa mesma análise para Minas Gerais, com os dados do censo, nota-se que a razão de concentração de aposentadorias e pensões $(C=0,588$ Tabela 17) é um pouco menor do que o índice de Gini $(0,601)$ e bem maior do que a razão de concentração do rendimento do trabalho assalariado $(C=0,503)$. Neste caso, a curva de concentração de aposentadorias e pensões encontra-se acima da curva de Lorenz, mas, mais afastada da linha de perfeita igualdade do que o rendimento do trabalho de empregado.

Uma justificativa para a diferença de resultados no que se refere à posição relativa da curva de concentração de aposentadorias e pensões e da curva de Lorenz é a mudança da base de dados. Na seção 4.7 são discutidos alguns possíveis motivos que influenciam os resultados da distribuição da renda de acordo com a base de dados utilizada.

A curva de concentração para aposentadorias e pensões (n.3) apresenta um “pequeno degrau" ao redor do $55^{\circ}$ percentil da distribuição do rendimento domiciliar per capita. Isso se deve ao grande número de aposentadorias e pensões iguais ao salário mínimo. 
As curvas de concentração para demais trabalhos (n.2), aluguéis (n.4) e outros rendimentos (n.7) são as que se encontram mais afastadas da curva de Lorenz, mostrando que essas três parcelas do rendimento são as que mais contribuem para aumentar a desigualdade no estado mineiro.

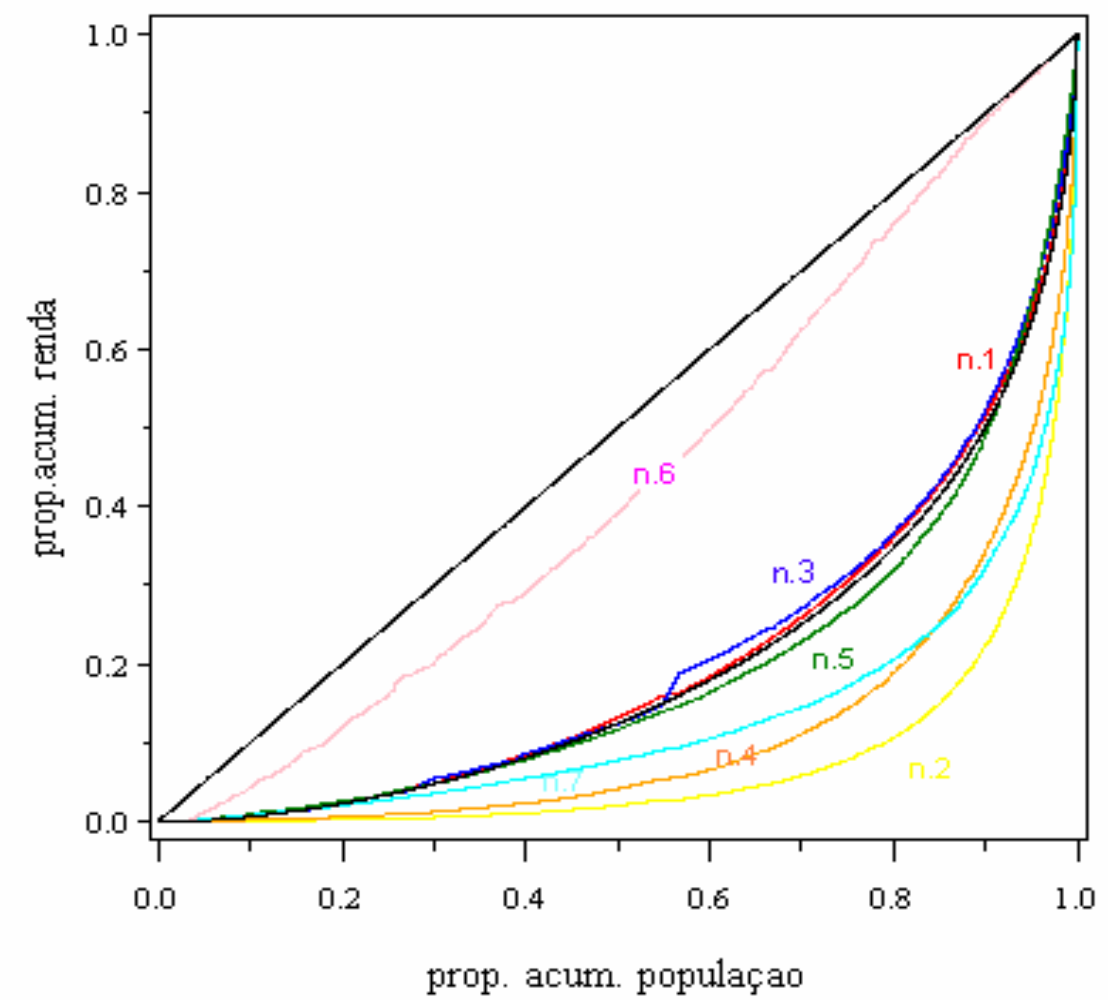

Figura 7 - As curvas de concentração para os componentes do rendimento domiciliar per capita, em Minas Gerais, 2000.

Fonte: dados da pesquisa.

Nota: n.1 trabalho principal; n.2 demais trabalhos; n.3 aposentadorias e pensões ; n.4 aluguel; n.5 pensão alimentícia, mesada, doação; n.6 renda min, bolsa-esc, seguro-desempro; n.7 outros rendimentos.

\subsection{A pobreza}

Como o nível de vida de uma pessoa é condicionado, basicamente, pela sua renda per capita, a renda domiciliar per capita é a variável usada para a obtenção das medidas de pobreza. Cabe lembrar que foi adotada uma linha de pobreza de $\mathrm{R} \$ 76,00$. 
Pela Tabela 20 observa-se que quase $30 \%$ da população mineira vive abaixo da linha de pobreza estabelecida. Nas mesorregiões Norte de Minas, Vale do Mucuri e Jequitinhonha o número de pessoas vivendo abaixo da linha de pobreza é ainda mais crítico, pois mais da metade da população encontra-se nessa situação.

A razão de insuficiência de renda (I) em Minas Gerais é 0,438 , indicando que a renda média dos pobres está 43,8\% abaixo da linha de pobreza. Nas mesorregiões Triângulo Mineiro/Alto Paranaíba, Oeste de Minas e Sul/Sudoeste de Minas a razão de insuficiência de renda gira em torno de 35\%, sendo esses valores os menores do estado. A razão de insuficiência de renda nas mesorregiões menos desenvolvidas é superior a $50 \%$.

Tabela 20. Número de pessoas pobres na população, a proporção de pessoas pobres, índice de Foster, Greer e Thorbecke (FGT) e a razão de insuficiência (I) da renda domiciliar per capita, adotando uma linha de pobreza com valor real igual a $\mathrm{R} \$ 76,00$, de acordo com a amostra do censo de 2000.

\begin{tabular}{lcccc}
\hline \multicolumn{1}{c}{$\begin{array}{c}\text { Estado } \\
\text { Mesorregiões }\end{array}$} & $\begin{array}{c}\mathrm{N}^{\mathrm{o}} \text { de pessoas pobres } \\
\text { na população }\end{array}$ & $\begin{array}{c}\text { Proporção de } \\
\text { pessoas pobres }\end{array}$ & FGT & I \\
\hline Minas Gerais & 5.255 .478 & 0,297 & 0,085 & 0,438 \\
Noroeste & 119.360 & 0,365 & 0,106 & 0,437 \\
Norte de Minas & 845.638 & 0,573 & 0,218 & 0,535 \\
Jequitinhonha & 419.529 & 0,625 & 0,232 & 0,532 \\
Vale do Mucuri & 208.035 & 0,552 & 0,186 & 0,503 \\
Triângulo/ Alto Paranaíba & 323.176 & 0,174 & 0,037 & 0,350 \\
Central Mineira & 116.037 & 0,308 & 0,070 & 0,377 \\
RMBH & 1.247 .189 & 0,226 & 0,061 & 0,417 \\
Vale do Rio Doce & 602.989 & 0,397 & 0,120 & 0,460 \\
Oeste de Minas & 162.448 & 0,195 & 0,039 & 0,341 \\
Sul/ Sudoeste & 448.563 & 0,201 & 0,040 & 0,347 \\
Campo das Vertentes & 154.845 & 0,305 & 0,070 & 0,386 \\
Zona da Mata & 607.665 & 0,302 & 0,075 & 0,404 \\
\hline
\end{tabular}

Fonte: dados da pesquisa.

O índice de Foster, Greer e Torbecke atinge o seu valor máximo (igual a 1) em situação extrema em que toda a população tenha rendimento igual a zero. Nota-se, pela tabela, que o valor máximo ocorre na mesorregião do Vale Jequitinhonha $(0,232)$. O Triângulo Mineiro/ Alto Paranaíba é a mesorregião com menor valor para esse índice. 
Segundo Costa \& Carneiro (2002), um programa de combate a pobreza em Minas Gerais, desenvolvido no plano estadual, com as graves restrições fiscais que se impõem hoje aos Estados terá que forçosamente, pelo menos de início, estabelecer prioridades em termos de público e regiões, ou seja, deve ser focalizado.

As medidas de pobreza apresentadas acima mostram que os núcleos de pobreza mineira estão concentrados basicamente nas mesorregiões Norte, Vale do Mucuri e Jequitinhonha. Sendo assim, se há necessidade de focalização, essas três mesorregiões devem merecer atenção especial nos programas de combate a pobreza. Por outro lado, verifica-se que quase $1 / 4$ dos pobres de Minas Gerais estão na RMBH. O controle à pobreza deve ser focalizado nos domicílios pobres, não devendo se limita a determinada regiões.

Não é objetivo desse trabalho analisar as políticas públicas de combate à pobreza do estado mineiro. Mas uma vez que na amostra do censo são pesquisados rendimentos pagos por programas oficiais de auxilio tais como renda mínima, bolsa escola, seguro desemprego e outros, é interessante mostrar o número de beneficiários desses tipos de rendimento que, geralmente, são destinados a famílias pobres, com exceção do seguro desemprego, que pode estar ou não vinculado a condição de pobreza.

Como não é possível saber pelos dados a qual programa a família ou individuo está ligado, supõe-se que rendimentos da categoria renda mínima, bolsa escola e seguro desemprego superiores a $\mathrm{R}$ \$ 151,00 (1 salário mínimo) são fornecidos pelo programa de seguro desemprego. Isso porquê pelas regras e objetivos de alguns programas de transferência direta de renda sabe-se que os seus valores são inferiores a 1 salário mínimo.

"Os programas assistências voltados para as crianças e os adolescentes são em geral condicionais, envolvendo ações socioeducativas, tal como o Bolsa Escola e o Programa de Erradicação do Trabalho Infantil (PETI), ambos vinculados à frequiência escolar. Além de suplementação da renda familiar, o programa Bolsa Escola tem o objetivo de aumentar a frequiência das crianças, aperfeiçoando, deste modo, os resultados do ensino. O Governo paga, para famílias com renda per capita igual ou inferior a meio salário 
mínimo, R \$ 15,00 por mês para cada filho e ou dependente com idade de 6 a 15 anos matriculados e freqüentando a escola no Ensino Fundamental (até um máximo de R\$ 45,00 por família)” (Brasil, 2003, p.30).

Depois de excluir o rendimento renda mínima, bolsa escola e seguro desemprego superior à $\mathrm{R} \$ 151,00$, considera-se que o restante dos rendimentos são transferências diretas de renda para as famílias pobres. ${ }^{17}$ A Tabela 41 do apêndice mostra o número de pessoas consideradas pobres que tem como componente de sua renda domiciliar per capita este tipo de rendimento. De acordo com a tabela, 32,69\% dos beneficiários estão na RMBH, seguindo pelo Vale do Jequitinhonha com uma participação de $17,46 \%$ e Norte de Minas tendo 6,75\%. O Vale do Mucuri tem uma participação pouco expressiva desses recursos com 1,15\%. A razão entre esse número de pessoas pobres beneficiárias da população e a população total de pobres é um indicador que mostra a abrangência dos programas e o quanto eles ainda podem ser expandidos. Pela tabela 41 nota-se que apenas o Vale do Jequitinhonha consegue atender $5 \%$ de sua população pobre com benefícios de auxílio governamental.

\subsection{A distribuição do rendimento das pessoas ocupadas}

Tendo em vista o ajuste das equações de rendimento apresentadas na próxima seção, considera-se para análise da distribuição de renda apenas as pessoas economicamente ativas com rendimento positivo de todos os trabalhos. Contudo, antes de iniciar a analise cabe mencionar que algumas observações são excluídas da amostra, conforme justificativas apresentadas abaixo.

- Na PNAD, o tempo semanal de trabalho está limitado em 98 horas semanais, mas, na amostra do censo não há um limite máximo estabelecido. Procurando estabelecer um intervalo para essa variável, é levado em consideração que um tempo semanal de trabalho superior a 99 horas significa uma carga horária diária de aproximadamente 14 horas ou mais por dia durante sete dias. Assim, é tomada a decisão de excluir as

\footnotetext{
${ }^{17}$ São excluídas 86.926 pessoas consideradas pobres que tem como componente da renda domiciliar per capita, o rendimento renda mínima, bolsa escola e seguro desemprego superior a $\mathrm{R} \$ 151,00$.
} 
pessoas que declararam número de horas trabalhadas habitualmente em todos os trabalhos superior a 99 horas ou inferior a 10 horas .

- Na amostra do censo há 295 pessoas que disseram possuir idade acima de 100 anos. Desse total 57 enquadram-se na categoria de pessoas ocupadas com rendimento positivo. Essas pessoas também são excluídas da amostra.

- No rendimento de todos os trabalhos há aqueles considerados extremamente elevados (valor de R \$ 100.000,00 ou mais). Há 39 pessoas que declararam receber esse valor de rendimento, sendo elas também excluídas da amostra.

- Na variável anos de estudo, além dos anos seqüenciais de estudo, há uma categoria para as pessoas que freqüentaram cursos de alfabetização de adultos. Contudo, devido à dificuldade em estabelecer uma correspondência dos anos de estudo para um curso de alfabetização de adultos, essa categoria é excluída.

Também são excluídas as pessoas sem informação de escolaridade, cor, tempo semanal de trabalho, as envolvidas em atividades mal especificadas, as que possuem uma relação com o responsável pela família de individual em domicílio coletivo e aquelas cuja posição na ocupação enquadra-se nas categorias de aprendiz ou estagiário sem remuneração, não remunerado em ajuda a membro do domicílio ou trabalhador na produção para autoconsumo.

As pessoas que apresentam pelo menos uma das características acima são excluídas da amostra da distribuição do rendimento de todos os trabalhos das pessoas ocupadas. Cabe reconhecer que há uma certa arbitrariedade nessas exclusões, mas como a amostra utilizada é muito grande, isso não afeta a validade dos resultados.

A Tabela 21 mostra a quantidade de pessoas ocupadas em Minas Gerais e nas doze mesorregiões mineiras, já excluindo as 39 pessoas que declaram ter rendimento de todos os trabalhos no valor de $\mathrm{R} \$ 100.000,00$ ou mais. Na amostra do censo há 925.970 pessoas ocupadas. Mas após essa exclusão o número de pessoas na amostra cai para 925.931. A PEA com rendimento positivo é de 862.017 pessoas, correspondendo a uma população de 7.153.150 pessoas. Contudo, depois de impor todas as restrições a amostra contém 830.198 observações, representando uma população de 6.517 .343 pessoas ocupadas para a análise da distribuição do rendimento de todos os trabalhos. 
Tabela 21. Pessoas ocupadas em Minas Gerais e nas 12 mesorregiões com declaração do rendimento ${ }^{1}$ de todos os trabalhos: Tamanho da amostra e da população, percentual sem rendimento e número de pessoas com rendimento positivo, em 2000 .

\begin{tabular}{lrrrrr}
\hline \multirow{2}{*}{$\begin{array}{c}\text { Estados e } \\
\text { mesorregiões }\end{array}$} & \multicolumn{2}{c}{ Pessoas na amostra } & \multicolumn{2}{c}{ Pessoas na população } \\
\cline { 2 - 6 } & $\begin{array}{c}\text { Com } \\
\text { declaração } \\
\text { de rdmto }\end{array}$ & $\begin{array}{c}\text { Com rdmto } \\
\text { positivo }\end{array}$ & $\begin{array}{c}\text { Com } \\
\text { declaração } \\
\text { de rdmto }\end{array}$ & $\begin{array}{c}\text { \% sem } \\
\text { rdmto }\end{array}$ & $\begin{array}{c}\text { Com rdmto } \\
\text { positivo }\end{array}$ \\
\hline Minas Gerais & 925.931 & 862.017 & 7.153 .150 & 5,33 & 6.771 .575 \\
Noroeste & 16.817 & 15.504 & 129.178 & 6,42 & 120.883 \\
Norte & 70.779 & 58.438 & 510.565 & 14,28 & 437.635 \\
Jequitinhonha & 37.482 & 29.323 & 238.659 & 18,83 & 193.731 \\
Vale do Mucuri & 20.670 & 17.477 & 135.112 & 11,79 & 119.183 \\
Triângulo & & & & & \\
Mineiro/Alto & & & & & \\
Paranaíba & 97.821 & 94.878 & 819.242 & 2,58 & 798.114 \\
Central & 21.388 & 20.573 & 155.778 & 3,18 & 150.823 \\
RMBH & 244.559 & 237.349 & 2.225 .969 & 2,45 & 2.171 .410 \\
Rio Doce & 76.930 & 69.396 & 556.851 & 7,89 & 512.914 \\
Oeste & 47.638 & 46.061 & 372.380 & 2,83 & 361.851 \\
Sul e Sudoeste & 144.312 & 137.368 & 993.832 & 3,96 & 954.441 \\
Campo das & & & & & \\
Vertentes & 27.898 & 23.395 & 194.379 & 4,19 & 186.233 \\
Zona da Mata & 119.637 & 109.255 & 821.206 & 6,42 & 764.359 \\
\hline
\end{tabular}

Fonte: dados da pesquisa.

${ }^{1}$ Excluindo 39 que se declararam ocupadas, com rendimento de todos os trabalho no valor de $\mathrm{R} \$ 100.000,00$ ou mais.

A Tabela 22 mostra as medidas de posição e desigualdade da distribuição do rendimento de todos os trabalhos das pessoas ocupadas, em Minas Gerais e nas doze mesorregiões mineiras analisadas. Nessa tabela acrescenta-se o L de Theil, cujo cálculo foi possível devido à exclusão prévia das pessoas com rendimento igual a zero.

No período analisado, verifica-se que o rendimento médio mineiro corresponde a 3,7 salários mínimos e o rendimento mediano é igual a 1,6 salários mínimos. Como o $75^{\circ}$ percentil $(\mathrm{R} \$ 425,00)$ é menor do que o rendimento médio, conclui-se que mais de três quartos da população ocupada com rendimento recebe menos do que a média. 
Os resultados apontam grandes diferenças regionais. Verifica-se que o rendimento médio de todos os trabalhos na $\mathrm{RMBH}(\mathrm{R} \$ 687,37)$ é 2,35 maior do que o rendimento médio no Vale do Jequitinhonha.

O índice de Gini varia de 0,534 (Vale do Jequitinhonha) a 0,604 (Noroeste de Minas). Comparando com os índices de Gini apresentados na Tabela 13 (referente ao rendimento domiciliar per capita), verifica-se que os índices de Gini da Tabela 22 apresentam menor dispersão.

As mesorregiões Norte, Triângulo/Alto Paranaíba, Central e RMBH possuem os índices de Gini e o $L$ de Theil menores do que de Minas Gerais como um todo. Contudo, o $T$ de Theil dessas mesorregiões é maior do que o valor encontrado para o estado. Isso porquê o $T$ de Theil é mais sensível a modificações nas rendas dos relativamente ricos, enquanto o L de Theil é mais sensível a modificações entre os pobres. O índice de Gini, por sua vez, é particularmente sensível a modificações nas rendas próximas da moda ou da mediana da distribuição (Hoffmann, 2001d).

Verifica-se que, na maioria das mesorregiões, o primeiro quartil (ou $25^{\circ}$ percentil) da distribuição do rendimento das pessoas economicamente ativas com rendimento é de $\mathrm{R} \$ 151,00$ (valor do salário mínimo do período analisado). Isso significa que nessas regiões $25 \%$ da população ganha $\mathrm{R} \$ 151,00$ ou menos, e $75 \%$ ganha pelo menos R\$ 151,00. Somente em duas mesorregiões (RMBH e Triângulo Mineiro e Alto Paranaíba) o primeiro quartil da distribuição das pessoas economicamente ativas com rendimento é R\$200,00.

Vários indicadores mostram a grande desigualdade da distribuição. Em todas as mesorregiões os $10 \%$ mais ricos ficam com mais de $45 \%$ da renda total. Na maioria das mesorregiões (com exceção do Vale do Mucuri) a participação do $1 \%$ mais rico na renda total supera a participação da metade mais pobre da população.

Nas comparações regionais nota-se que grande parte das mesorregiões menos desenvolvidas apresenta o índice de Gini inferior ao índice do Estado, diferentemente do que ocorre na análise da distribuição do rendimento domiciliar per capita. Somente as mesorregiões menos desenvolvidas do Vale do Mucuri, Vale do Rio Doce e Noroeste de Minas têm o índice de Gini superior ao do Estado. Quanto às mesorregiões mais 
desenvolvidas, há tanto aquelas com o índice de Gini inferior ao do Estado quanto aquelas com o índice superior ao do Estado. Assim, não é possível estabelecer uma relação entre essa medida de desigualdade e o desenvolvimento das mesorregiões.

Tabela 22. Principais características da distribuição do rendimento de todos os trabalhos de pessoas ocupadas (somente pessoas com rendimento positivo, utilizadas na estimação das equações de rendimento), em Minas Gerais e nas 12 mesorregiões mineiras, de acordo com dos dados da amostra do censo de 2000.

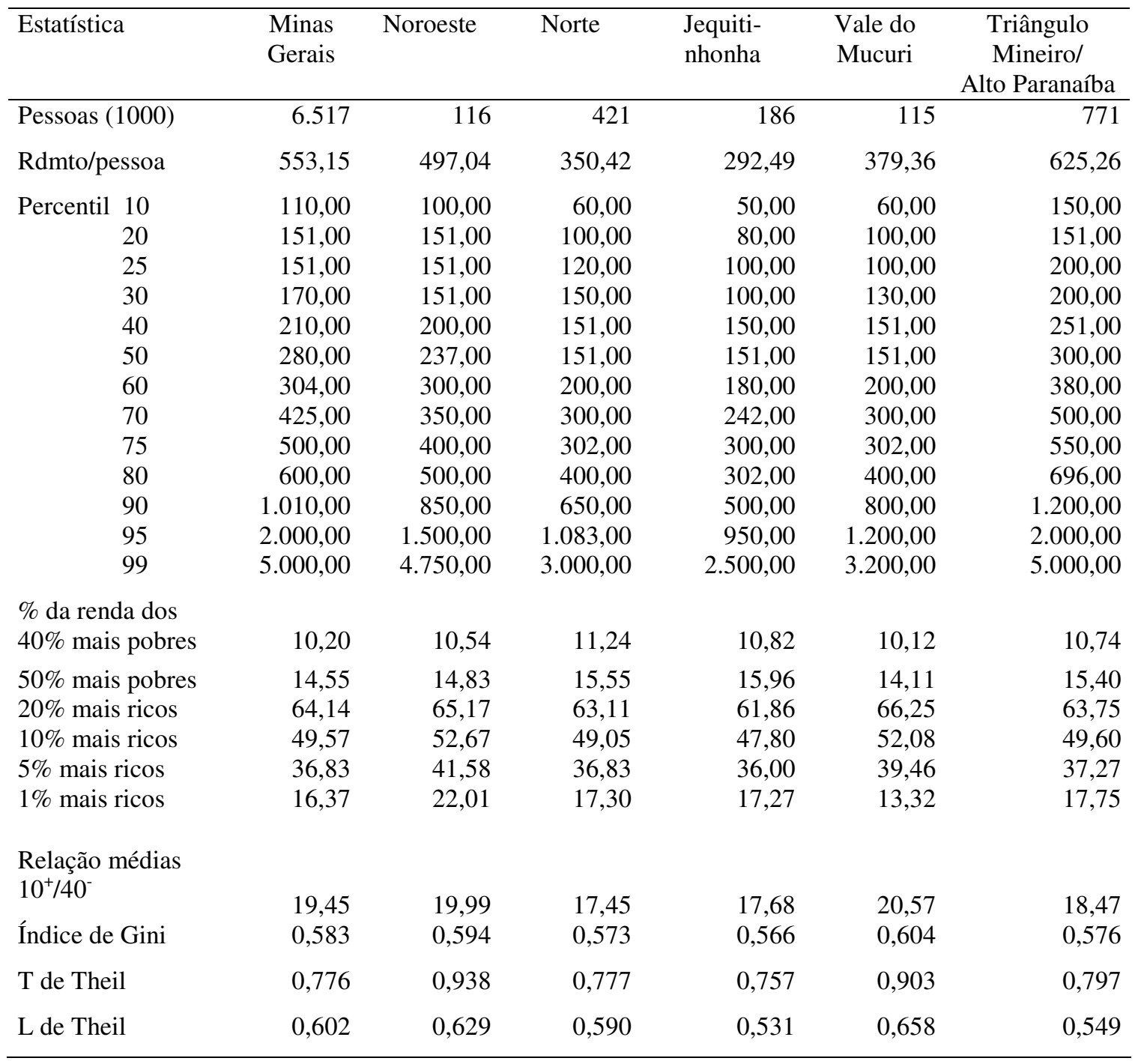


Tabela 22. Principais características da distribuição do rendimento de todos os trabalhos de pessoas ocupadas (somente pessoas com rendimento positivo, utilizadas na estimação das equações de rendimento), em Minas Gerais e nas 12 mesorregiões mineiras, de acordo com dos dados da amostra do censo de 2000 .

\begin{tabular}{|c|c|c|c|c|c|c|c|}
\hline Estatística & Central & RMBH & $\begin{array}{l}\text { Vale do } \\
\text { Rio } \\
\text { Doce }\end{array}$ & Oeste & $\begin{array}{c}\text { Sul e } \\
\text { Sudoeste }\end{array}$ & $\begin{array}{l}\text { Campo das } \\
\text { Vertentes }\end{array}$ & $\begin{array}{c}\text { Zona da } \\
\text { Mata }\end{array}$ \\
\hline Pessoas (1000) & 144 & 2.077 & 494 & 350 & 922 & 180 & 739 \\
\hline Rdmto/pessoa & 451,66 & 687,37 & 464,52 & 473,47 & 534,76 & 461,23 & 479,96 \\
\hline $\begin{array}{r}\text { Percentil } 10 \\
20 \\
25 \\
30 \\
40 \\
50 \\
60 \\
70 \\
75 \\
80 \\
90 \\
95 \\
99\end{array}$ & $\begin{array}{r}100,00 \\
151,00 \\
151,00 \\
151,00 \\
195,00 \\
226,00 \\
300,00 \\
336,00 \\
400,00 \\
470,00 \\
800,00 \\
1.300,00 \\
4.000,00\end{array}$ & $\begin{array}{r}151,00 \\
167,00 \\
200,00 \\
213,00 \\
270,00 \\
302,00 \\
400,00 \\
538,00 \\
630,00 \\
800,00 \\
1500,00 \\
2.500,00 \\
5.800,00\end{array}$ & $\begin{array}{r}90,00 \\
150,00 \\
151,00 \\
151,00 \\
170,00 \\
200,00 \\
280,00 \\
354,00 \\
422,00 \\
500,00 \\
1.000,00 \\
1.500,00 \\
4.000,00\end{array}$ & $\begin{array}{r}140,00 \\
151,00 \\
151,00 \\
180,00 \\
220,00 \\
260,00 \\
300,00 \\
400,00 \\
450,00 \\
500,00 \\
9.000,00 \\
1500,00 \\
4.000,00\end{array}$ & $\begin{array}{r}150,00 \\
151,00 \\
160,00 \\
197,00 \\
225,00 \\
300,00 \\
303,00 \\
400,00 \\
500,00 \\
590,00 \\
1.000,00 \\
1.700,00 \\
5.000,00\end{array}$ & $\begin{array}{r}100,00 \\
151,00 \\
151,00 \\
151,00 \\
180,00 \\
225,00 \\
300,00 \\
360,00 \\
430,00 \\
500,00 \\
900,00 \\
1.500,00 \\
4.000,00\end{array}$ & $\begin{array}{r}100,00 \\
151,00 \\
151,00 \\
151,00 \\
200,00 \\
226,00 \\
300,00 \\
379,00 \\
450,00 \\
500,00 \\
1.000,00 \\
1.50000 \\
4.000,00\end{array}$ \\
\hline $\begin{array}{l}\% \text { da renda dos } \\
40 \% \text { mais pobres } \\
50 \% \text { mais pobres } \\
20 \% \text { mais ricos } \\
10 \% \text { mais ricos } \\
5 \% \text { mais ricos } \\
1 \% \text { mais ricos }\end{array}$ & $\begin{array}{l}13,82 \\
16,28 \\
62,37 \\
49,36 \\
38,38 \\
19,89\end{array}$ & $\begin{array}{l}10,03 \\
14,35 \\
63,95 \\
48,52 \\
35,25 \\
14,69\end{array}$ & $\begin{array}{l}10,23 \\
14,32 \\
64,56 \\
49,53 \\
36,41 \\
16,02\end{array}$ & $\begin{array}{l}12,46 \\
17,47 \\
59,77 \\
46,17 \\
34,70 \\
16,47\end{array}$ & $\begin{array}{l}11,47 \\
16,20 \\
62,26 \\
48,34 \\
36,71 \\
16,95\end{array}$ & $\begin{array}{l}11,26 \\
15,61 \\
62,62 \\
48,11 \\
35,52 \\
14,93\end{array}$ & $\begin{array}{l}10,98 \\
15,31 \\
63,36 \\
48,78 \\
36,26 \\
15,86\end{array}$ \\
\hline $\begin{array}{l}\text { Relação médias } \\
10^{+} / 40^{-}\end{array}$ & $\begin{array}{l}17,01 \\
0,563\end{array}$ & $\begin{array}{l}19,34 \\
0,581\end{array}$ & $\begin{array}{l}19,37 \\
0,586\end{array}$ & $\begin{array}{l}14,82 \\
0,534\end{array}$ & $\begin{array}{l}16,85 \\
0,559\end{array}$ & $\begin{array}{l}17,08 \\
0,563\end{array}$ & $\begin{array}{l}17,78 \\
0,571\end{array}$ \\
\hline $\mathrm{T}$ de Theil & 0,835 & 0,731 & 0,772 & 0,693 & 0,749 & 0,707 & 0,742 \\
\hline L de Theil & 0,557 & 0,594 & 0,538 & 0,494 & 0,542 & 0,553 & 0,571 \\
\hline
\end{tabular}

Fonte: dados da pesquisa. 


\subsection{As equações de rendimento}

As grandes diferenças de rendimento no mercado de trabalho contribuem para a desigualdade de renda entre pessoas e regiões. Essa seção tem como objetivo expor o efeito de diversos fatores na determinação do rendimento das pessoas ocupadas, averiguando se o efeito da variável escolaridade está associado ao nível de desenvolvimento das mesorregiões.

Após impor as restrições citadas na seção anterior, ficando com uma amostra de 830.198 observações, são ajustadas três equações de rendimento para as pessoas ocupadas. No primeiro modelo não se considera a variável explicativa "posição na ocupação" e a variável escolaridade é tratada como uma variável contínua. O segundo modelo inclui a variável posição na ocupação. O terceiro modelo difere do segundo ao considerar variáveis binárias para a escolaridade.

A Tabela 23 apresenta os coeficientes das equações de rendimento ajustadas. Ela também informa, quando a variável é binária, a diferença percentual entre o rendimento esperado na categoria tomada como base e o rendimento da categoria para a qual aquela variável binária assume valor 1, já descontados os efeitos das demais variáveis explanatórias incluídas na equação de regressão. No caso da variável contínua escolaridade, é dada a taxa de retorno, ou seja, o acréscimo percentual no rendimento esperado produzido por cada ano adicional de estudo.

Essa diferença percentual entre os rendimentos estimados da categoria considerada e da categoria tomada como base é obtido por meio do cálculo: $100[\exp (b)-1] \%$. Por exemplo, se o coeficiente para binária de situação "rural" for $b$, então o rendimento esperado das pessoas com domicílio rural supera o rendimento esperado das pessoas com domicílio urbano em $100[\exp (b)-1] \%$, já considerados os efeitos das demais variáveis explanatórias incluídas na equação de regressão. No caso da variável escolaridade como variável contínua, é usada a mesma fórmula, mas calcula-se, nesse caso, a taxa de retorno por um ano adicional de estudo.

Todos os coeficientes dos três modelos são estatisticamente diferentes de zero ao nível de significância de $1 \%$. Cabe reconhecer que o grande número de observações da 
amostra utilizada facilita a obtenção de coeficientes estatisticamente significativos. Observa-se que o coeficiente de determinação $\left(\mathrm{R}^{2}\right)$ para os três modelos ajustados é $46,28 \%, 48,25 \%$ e $50,14 \%$. Embora os valores dos coeficientes de determinação $\left(\mathrm{R}^{2}\right)$ pareçam baixos, isso é típico em equações de rendimento, pois os rendimentos das pessoas dependem de elementos aleatórios e de características pessoais (como ambição, tino comercial, capacidade empresarial, etc.) cuja mensuração é praticamente impossível (Hoffmann, 2000).

Os principais comentários a respeito dos coeficientes estimados na Tabela 23 são:

- Em todos os três modelos estimados, o coeficiente para sexo feminino indica que depois de considerados os efeitos das demais variáveis explanatórias incluídas na regressão, o rendimento esperado das mulheres é cerca de $25 \%$ mais baixo que o dos homens em Minas Gerais. É importante dizer que a diferença é menor quando não se desconta o efeito das demais variáveis, sendo que a média geométrica dos rendimentos das mulheres mineiras é aproximadamente $21 \%$ menor do que a média geométrica dos rendimentos dos homens ocupados em Minas Gerais para os três modelos;

- Verifica-se que a idade associada ao máximo rendimento esperado é 55 anos no primeiro modelo, 54 anos no segundo modelo e 52 anos no terceiro modelo;

- Em qualquer um dos três modelos, se o indivíduo ocupa a posição de membro responsável pela família, os seus ganhos monetários são aproximadamente 17\% a mais do que um indivíduo que não ocupa essa condição familiar;

- A variável posição na ocupação mostra que os empregadores ganham $118 \%$ a mais do que os empregados.

- O rendimento esperado das pessoas que não vivem na RMBH é mais baixo do que daquelas que vivem. Nas mesorregiões menos desenvolvidas, como Vale do Mucuri, Jequitinhonha e Norte de Minas a renda esperada é quase 30\% menor do que a renda na $\mathrm{RMBH}$, mantendo as demais características constantes. 
O último comentário a ser feito da Tabela 23 é a respeito da variável escolaridade. Devido ao grau de importância dessa variável na explicação dos rendimentos é importante discuti-la mais detalhadamente.

Os coeficientes para escolaridade nas equações estimadas no primeiro e segundo modelo mostram que em Minas Gerais um ano adicional de estudo contribui para que o indivíduo tenha um acréscimo de rendimento de $12,99 \%$ e 12,39\%, respectivamente. Nesse caso os dois primeiros modelos apresentados consideram que a escolaridade tem retornos constantes por anos adicionais de estudo. Contudo, nem sempre os estudos consideram que a taxa de retorno da educação seja constante.

Existe uma série de trabalhos empíricos com o propósito de esclarecer a natureza da relação entre educação e salários. No âmbito das proposições utilizadas para testar essas relações, existe uma conhecida como "efeito diploma". De acordo com essa proposição, a graduação de curso fornece evidências adicionais de maior capacidade ou potencial produtivo que uma simples seqüência de anos de estudo, de modo que os salários aumentam mais rapidamente com os anos extras de educação associados à concessão de certificados (Ramos et al., 1996).

No terceiro modelo o efeito da educação é captado por meio de variáveis binárias, que permitem estimar os retornos específicos a cada nível educacional, sendo possível identificar os ganhos de rendimento diretamente associados à obtenção de um diploma. Nota-se que os coeficientes para os anos de estudo que correspondem à conclusão do ensino fundamental ( 8 anos de estudo), ensino médio (11 ou 12 anos de estudo) e curso superior (15 anos ou mais de estudo) aumentam mais rapidamente do que nos anos seqüenciais de estudo. Cita-se como exemplo, os valores dos coeficientes estimados para 9, 10 e 11 anos de estudos que são respectivamente: 0,6573; 0,7177 e 1,0285. Observa-se que de 9 para 10 anos de estudos o acréscimo no rendimento é de 6,23\%; já o indivíduo que chega a 11 anos de estudo ou completa o ensino médio, tem um acréscimo de 36,45\% no rendimento em relação ao indivíduo que tem somente 10 anos de estudo. Verifica-se que os resultados apresentados confirmam a proposição do "efeito diploma" na população ocupada mineira. 
Outro conceito também discutido nos trabalhos sobre o assunto, considerando a taxa de retorno à educação não constante, é o "threshold effect" (efeito limiar). $\mathrm{O}$ "threshold effect" surge na literatura de economia do trabalho, e refere-se à nãolinearidade no retorno da função educação, com uma mudança de declividade na função educação depois de um certo nível de escolaridade (Dias et. al, 2003). Em outras palavras isso significa que as economias dos países, de acordo com o seu estágio de desenvolvimento e paradigma tecnológico exigem dos trabalhadores um determinado nível de conhecimento no processo produtivo. Por exemplo, atualmente as economias modernas vivem um padrão tecnológico que exige da mão de obra conhecimentos que a torne capaz de operar máquinas automatizadas e computadores.

O gráfico da Figura 8 mostra os coeficientes estimados pelos anos adicionais de estudo dos indivíduos e a poligonal estimada conforme o modelo da Tabela 42. Nota-se que a partir de 10 anos de escolaridade há um salto brusco na declividade da função, ou seja, até 10 anos de estudo os indivíduos têm um retorno no rendimento hora praticamente constante e baixo pelos anos adicionais de estudo, acima desse intervalo os anos adicionais de estudo representam acréscimos de rendimentos bem mais elevados. 


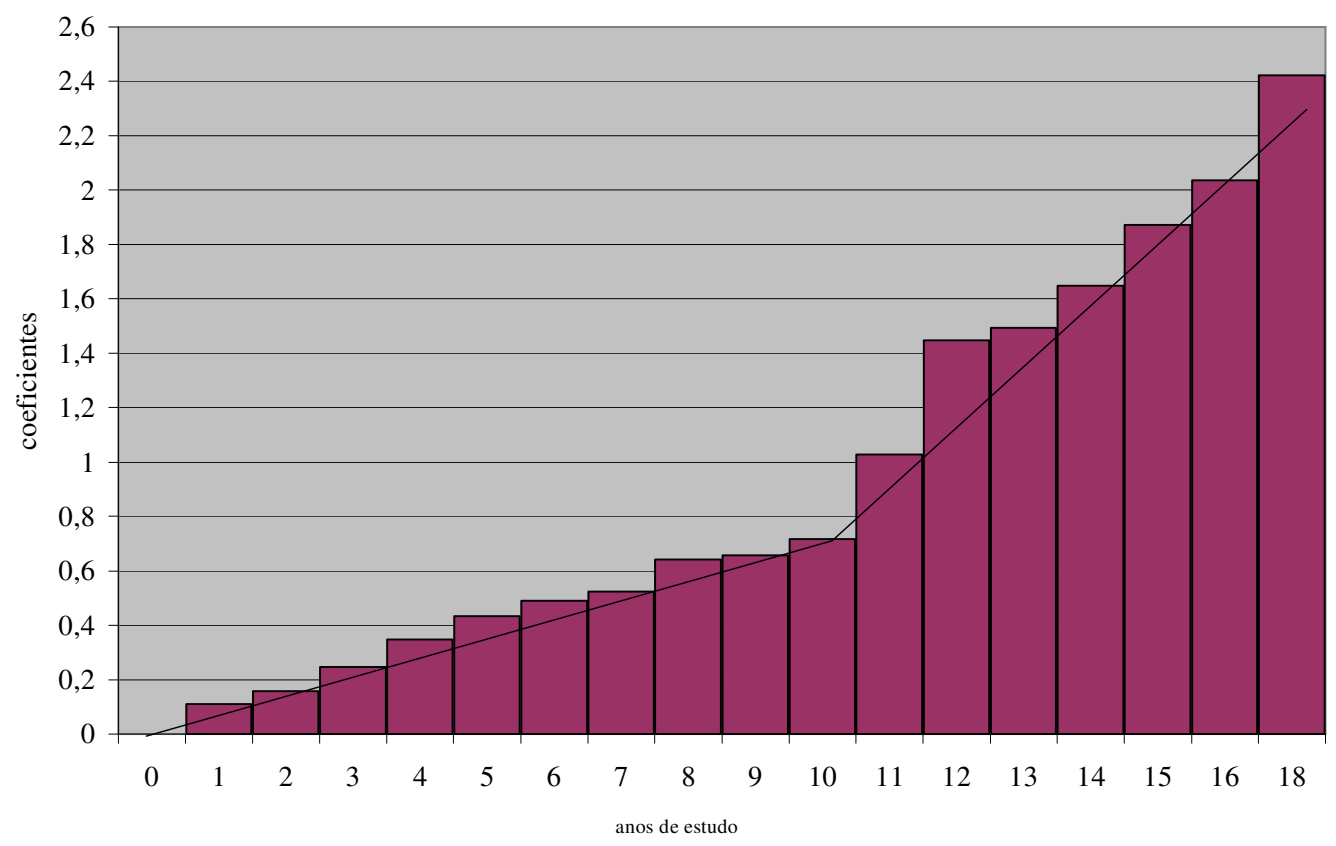

Figura 8 - Coeficientes estimados para as variáveis binárias "anos de estudo" e o "threshold effect".

Fonte: dados da pesquisa.

Com o objetivo de captar a mudança na taxa de retorno da educação a partir dos 10 anos de escolaridade, foi estimada uma equação de rendimento adicional. O resultado obtido na equação estimada mostra que a taxa de retorno pelos anos adicionais de estudo até os 10 anos de escolaridade é de 8,09\% e para as pessoas que ultrapassam 10 anos de escolaridade essa taxa de retorno sobe para 14,37\%. Na Tabela 42 em apêndice estão os coeficientes estimados, considerando "threshold effect". 
Tabela 23. Equações de rendimento para pessoas ocupadas em Minas Gerais, considerando o rendimento de todos os trabalhos, de acordo com os dados da amostra do censo de 2000.

\begin{tabular}{|c|c|c|c|c|c|c|}
\hline \multirow[t]{2}{*}{ Variável } & \multicolumn{2}{|c|}{ Modelo 1} & \multicolumn{2}{|c|}{ Modelo 2} & \multicolumn{2}{|c|}{ Modelo 3} \\
\hline & $\begin{array}{c}\text { Coefici- } \\
\text { ente }\end{array}$ & $\begin{array}{l}\% \text { renda } \\
\text { esperada }\end{array}$ & $\begin{array}{l}\text { Coefici- } \\
\text { ente }\end{array}$ & $\begin{array}{l}\% \text { renda } \\
\text { esperada }\end{array}$ & $\begin{array}{c}\text { Coefici- } \\
\text { ente }\end{array}$ & $\begin{array}{r}\% \text { renda } \\
\text { esperada }\end{array}$ \\
\hline Constante & $-1,7638$ & - & $-1,7254$ & - & $-1,4110$ & - \\
\hline Sexo feminino & $-0,2952$ & $-25,56$ & $-0,2709$ & $-23,73$ & $-0,2762$ & $-24,13$ \\
\hline Idade/10 & 0,7085 & - & 0,6929 & - & 0,6154 & - \\
\hline$(\text { idade } / 10)^{2}$ & $-0,0641$ & - & $-0,0645$ & - & $-0,0590$ & - \\
\hline Escolaridade & 0,1221 & 12,99 & 0,1168 & 12,39 & Nota 2 & Nota 3 \\
\hline Cor: Preta & $-0,1836$ & $-16,77$ & $-0,1551$ & $-14,37$ & $-0,1524$ & $-14,13$ \\
\hline Amarela & 0,1293 & 13,80 & 0,1045 & 11,02 & 0,0683 & 7,05 \\
\hline Parda & $-0,1423$ & $-13,26$ & $-0,1232$ & $-11,59$ & $-0,1127$ & $-10,66$ \\
\hline Indígena & $-0,1080$ & $-10,24$ & $-0,0922$ & $-8,81$ & $-0,0800$ & $-7,68$ \\
\hline Pessoa de refer. na fam. & 0,1577 & 17,08 & 0,1480 & 15,95 & 0,1490 & 16,07 \\
\hline Domicílio rural & $-0,1099$ & $-10,41$ & $-0,1110$ & $-10,51$ & $-0,1317$ & $-12,33$ \\
\hline Posição na ocupação: & & & & & & \\
\hline Conta própria & - & - & 0,0839 & 8,75 & 0,0988 & 10,38 \\
\hline Empregador & - & - & 0,7794 & 118,02 & 0,7767 & 117,43 \\
\hline Setor: indústria & 0,1385 & 14,85 & 0,1438 & 15,47 & 0,1920 & 10,38 \\
\hline Serviços & 0,1403 & 15,06 & 0,1438 & 15,47 & 0,1872 & 20,57 \\
\hline Mesorregiões $^{1}$ : I & $-0,1483$ & $-13,78$ & $-0,1568$ & $-14,51$ & $-0,1505$ & $-13,97$ \\
\hline II & $-0,3223$ & $-27,55$ & $-0,3289$ & $-28,03$ & $-0,3362$ & $-28,55$ \\
\hline III & $-0,3224$ & $-27,56$ & $-0,3314$ & $-28,21$ & $-0,3522$ & $-29,69$ \\
\hline IV & $-0,2873$ & $-24,97$ & $-0,2970$ & $-25,70$ & $-0,3072$ & $-26,45$ \\
\hline $\mathrm{V}$ & $-0,0622$ & $-6,03$ & $-0,0637$ & $-6,17$ & $-0,0557$ & $-5,42$ \\
\hline VI & $-0,2154$ & $-19,38$ & $-0,2209$ & $-19,82$ & $-0,2170$ & $-17,36$ \\
\hline VII & $-0,1885$ & $-17,18$ & $-0,1923$ & $-17,49$ & $-0,1907$ & $-17,36$ \\
\hline VIII & $-0,1380$ & $-12,88$ & $-0,1407$ & $-13,13$ & $-0,1323$ & $-12,39$ \\
\hline IX & $-0,0533$ & $-5,19$ & $-0,0535$ & $-5,21$ & $-0,0503$ & $-4,91$ \\
\hline $\mathrm{X}$ & $-0,2610$ & $-22,97$ & $-0,2615$ & $-23,01$ & $-0,2605$ & $-22,93$ \\
\hline XI & $-0,1814$ & $-16,59$ & $-0,1856$ & $-16,94$ & $-0,1848$ & $-16,87$ \\
\hline Número de observações & 830.198 & - & 830.198 & - & 830.198 & - \\
\hline $\mathrm{R}^{2}$ & 0,4628 & - & 0,4825 & - & 0,5014 & - \\
\hline $\mathrm{F}$ & 31.091 & - & 30.955 & - & 20.359 & - \\
\hline
\end{tabular}

Fonte: dados da pesquisa.

${ }^{1}$ I. Noroeste, II. Norte, III. Jequitinhonha, IV. Vale do Mucuri, V. Triângulo Mineiro/Alto Paranaíba, VI. Central, VII. Vale do Rio Doce, VIII. Oeste, IX. Sul/Sudoeste, X. Campo das Vertentes e XII. Zona da Mata.

${ }^{2}$ Os coeficientes das variáveis binárias para escolaridade com 1, 2, 3, 4, 5, 6, 7, 8, 9, 10, 11 ,12, $1314,15,16$ e 17 ou mais anos de estudo são respectivamente: 0,$1094 ; 0,1563 ; 0,2469$; 0,$3471 ; 0,4337 ; 0,4900 ; 0,5244 ; 0,6420 ; 0,6573 ; 0,7177 ; 1,0285 ; 1,4465 ; 1,4937 ; 1,6484$; 1,$8716 ; 2,0363$ e 2,4218 .

${ }^{3}$ Os acréscimos percentuais associados às binárias para escolaridade são, respectivamente, $11,56 \%, 16,92 \%, 28,01 \%, 41,50 \%, 54,30 \%, 63,23 \%, 68,94 \%, 90,03 \%, 92,96 \%, 104,97 \%$, $179,69 \%, 324,82 \%, \quad 345,35 \%, 419,87 \% ; 549,87 \% ; 666,22 \%$ e $1026,61 \%$. 
A Tabela 24 mostra a contribuição marginal de cada fator para a soma de quadrados da regressão, isto é, o aumento ocorrido na parte explicada das variações do logaritmo do rendimento das pessoas ocupadas por meio da introdução da respectiva variável, depois que todas as demais variáveis estejam incluídas no modelo.

Verifica-se que em todos os três modelos o principal condicionante do rendimento é a escolaridade, que apresenta a maior contribuição marginal. Muitos estudos argumentam que o efeito da variável educação está superestimado nos modelos, pois os dados disponíveis para o estudo da distribuição de renda não distinguem os rendimentos associados ao capital físico, que certamente faz uma grande diferença para a desigualdade de renda no país e em Minas Gerais.

Ao incluir nos modelos 2 e 3 a variável posição na ocupação, o objetivo foi ter uma proxy para a posse do capital físico. Segundo Langoni, citado por Corrêa (1996), admitindo que diferenças no acesso à propriedade estão relacionadas com a posição na ocupação, pode-se usar essa variável como uma proxy para capital físico. Entretanto, mesmo com a inclusão da variável posição na ocupação, a educação ainda se destaca como o fator condicionante que apresenta maior contribuição marginal.

Hoffmann (2000) diz que a variável posição na ocupação não reflete adequadamente a propriedade do capital, nas equações estimadas para a economia de maneira geral. Mas ao analisar separadamente o setor agrícola, a variável posição na ocupação passa a ser a principal variável para a determinação dos rendimentos. $\mathrm{O}$ autor escreve:

“...o coeficiente de educação está mais superestimado nos setores urbanos porque aí a variável posição na ocupação não reflete a propriedade de capital, como ocorre na agricultura, onde o empregador é, tipicamente, o proprietário de um sítio ou de uma fazenda” (Hoffmann, 2000, p.104).

No apêndice a Tabela 43 mostra as equações de rendimento estimadas para os setores agrícola, indústria e serviços de Minas Gerais. No setor agrícola a variável posição na ocupação se destaca como o fator mais importante, apresentando a maior contribuição marginal para a soma de quadrados da regressão $(22,14 \%)$, enquanto a educação corresponde a 14,87\%. Na indústria e no serviços a escolaridade continua 
sendo o principal condicionante do rendimento, tendo uma contribuição de $38,62 \%$ na indústria e 46,74\% no setor de serviços.

Tabela 24. A contribuição marginal de cada fator para a soma dos quadrados de regressão das equações de rendimento ajustadas.

\begin{tabular}{lccc}
\hline \multicolumn{1}{c}{ Fator } & $\begin{array}{c}\text { Modelo 1 } \\
(\%)\end{array}$ & $\begin{array}{c}\text { Modelo 2 } \\
(\%)\end{array}$ & $\begin{array}{c}\text { Modelo 3 } \\
(\%)\end{array}$ \\
\hline Sexo & 3,34 & 2,65 & 2,65 \\
Idade/10 & 15,85 & 12,67 & 7,87 \\
Escolaridade & 45,90 & 39,46 & 41,74 \\
Cor & 1,15 & 0,81 & 0,68 \\
Pess. de refer. na fam ${ }^{1}$ & 0,90 & 0,76 & 0,74 \\
Domicilio rural & 0,24 & 0,23 & 0,31 \\
Setor & 0,41 & 0,41 & 0,68 \\
Posição na ocupação & - & 4,08 & 3,09 \\
Mesorregião & 2,44 & 2,45 & 2,46 \\
\hline
\end{tabular}

Fonte: dados da pesquisa.

${ }^{1}$ pessoa de referência na família.

A Tabela 25 apresenta novas equações de rendimento, incluindo a interação entre mesorregiões e escolaridade, para analisar como o efeito da escolaridade varia entre regiões. A interação estatisticamente significativa entre escolaridade e as mesorregiões mineiras mostra que o acréscimo no logaritmo do rendimento por hora a favor dos que têm anos adicionais de estudo difere de uma mesorregião para outra.

No modelo 1, o coeficiente de educação na região Noroeste de Minas é mais baixo do que na região tomada como base $(\mathrm{RMBH})$, a diferença sendo igual a $-0,0283$. A taxa de retorno por um ano adicional de estudo na região base (RMBH) é de 14,45\%, ao passo que no Noroeste é $11,37 \% .^{18}$ Seguindo essa mesma regra, nas demais mesorregiões o acréscimo no rendimento devido a um ano adicional de escolaridade é de: Norte de Minas (13,02\%), Jequitinhonha (12,94\%), Vale do Mucuri (13,34\%), Triângulo Mineiro/Alto Paranaíba (11,83\%), Central Mineira (11,20\%), Vale do Rio

18 O cálculo consiste em somar o coeficiente da escolaridade com o coeficiente de interação da mesorregião $(0,13500-0,0283=0,1067)$, depois se obtém a taxa de retorno pela fórmula $100[\exp (b)-1] \%$. 
Doce (13,33\%), Oeste de Minas (11,40\%), Sul/Sudoeste de Minas (11,06\%), Campo das Vertentes $(13,17 \%)$ e Zona da Mata $(12,78 \%)$.

No modelo 2, com a inclusão da variável posição na ocupação, ocorrem pequenas modificações nos coeficientes estimados e a taxa de retorno da educação nas mesorregiões passa a ser: Noroeste $(10,68 \%)$ Norte de Minas (2,55\%), Jequitinhonha (12,51\%), Vale do Mucuri (12,73\%), Triângulo Mineiro/Alto Paranaíba (11,17\%), Central Mineira (10,57\%), Vale do Rio Doce (13,93\%), Oeste de Minas (12,78\%), Sul/Sudoeste de Minas (10,67\%), Campo das Vertentes (10,27\%) e Zona da Mata $(12,61 \%)$.

Em ambos os modelos, os resultados da interação mostram que o logaritmo do rendimento por hora das pessoas ocupadas em Minas Gerais por anos adicionais de estudo difere de uma mesorregião para outra. Necessita-se, ainda, investigar se essas diferenças na taxa de retorno da educação entre mesorregiões estão relacionadas com o nível de desenvolvimento das mesmas. Para isso são empregadas análises de correlação simples e regresssão. Além de selecionar as variáveis IDH-M e taxa de retorno da educação para a análise, também são escolhidas as variáveis renda média das pessoas ocupadas e a participação do setor de serviços nas mesorregiões. A maior participação do setor de serviços na economia mineira, geralmente, ocorre nas mesorregiões mais dinâmicas economicamente, assim, pode considerar essa participação como um indicador de desenvolvimento do mercado de trabalho, daí a explicação para a escolha da variável.

Nas mesorregiões mineiras a participação do setor de serviços é de 51,89\% no Noroeste de Minas, 53,78\% no Norte, 47,71\% no Jequitinhonha, 55,77\% no Vale do Mucuri, 60,90\% no Triângulo Mineiro/Alto Paranaíba, 54,82\% na Central Mineira, $70,28 \%$ na $\mathrm{RMBH}, 55,71 \%$ no Vale do Rio Doce, $50,42 \%$ no Oeste de Minas, 47,65\% no Sul/Sudoeste de Minas, 57,02\% em Campo das Vertentes e 55,34\% na Zona da Mata. 
Tabela 25. Equações de rendimento para pessoas ocupadas em Minas Gerais, considerando o rendimento de todos os trabalhos, incluindo variáveis de interações, de acordo com a amostra do censo de 2000.

\begin{tabular}{|c|c|c|}
\hline \multirow[t]{2}{*}{ Variáveis } & \multicolumn{2}{|c|}{ Coeficientes para } \\
\hline & Modelo 1 & Modelo 2 \\
\hline Constante & $-1,8806$ & $-1,8481$ \\
\hline Sexo feminino & $-0,2952$ & $-0,2705$ \\
\hline Idade/10 & 0,7077 & 0,6916 \\
\hline$(\text { idade/10) })^{2}$ & $-0,0642$ & $-0,0646$ \\
\hline Escolaridade & 0,1350 & 0,1304 \\
\hline Cor: Preta & $-0,1797$ & $-0,1504$ \\
\hline Amarela & 0,1357 & 0,1111 \\
\hline Parda & $-0,1377$ & $-0,1181$ \\
\hline Indígena & $-0,1020$ & $-0,0857$ \\
\hline Pessoa de refer. Na fam. & 0,1587 & 0,1489 \\
\hline Domicílio rural & $-0,1099$ & $-0,1111$ \\
\hline Posição na ocupação: Conta própria & - & 0,0877 \\
\hline Empregador & - & 0,7856 \\
\hline Setor :Indústria & 0,1559 & 0,1621 \\
\hline Serviços & 0,1577 & 0,1621 \\
\hline Mesorregião ${ }^{1}$ : I & 0,0438 & 0,0461 \\
\hline II & $-0,2188$ & $-0,2266$ \\
\hline III & $-0,2140$ & $-0,2250$ \\
\hline IV & $-0,1992$ & $-0,2030$ \\
\hline V & 0,1166 & 0,1243 \\
\hline VI & 0,0118 & $-0,0100$ \\
\hline VII & $-0,1029$ & $-0,1050$ \\
\hline VIII & 0,0603 & 0,0716 \\
\hline IX & 0,1648 & 0,1815 \\
\hline $\mathrm{X}$ & $-0,1667$ & $-0,1649$ \\
\hline XI & $-0,0642$ & $-0,0627$ \\
\hline Interação: esc. x mesorregião: I & $-0,0273$ & $-0,0289$ \\
\hline II & $-0,0126$ & $-0,0122$ \\
\hline III & $-0,0133$ & $-0,0125$ \\
\hline IV & $-0,0098$ & $-0,0106$ \\
\hline $\mathrm{V}$ & $-0,0232$ & $-0,0244$ \\
\hline VI & $-0,0288$ & $-0,0299$ \\
\hline VII & $-0,0099$ & $-0,0101$ \\
\hline VIII & $-0,0270$ & $-0,0290$ \\
\hline IX & $-0,0301$ & $-0,0325$ \\
\hline $\mathrm{X}$ & $-0,0113$ & $-0,0115$ \\
\hline XI & $-0,0147$ & $-0,0154$ \\
\hline $\mathrm{R}^{2}$ & 0,4651 & 0,4851 \\
\hline $\mathrm{F}$ & 21.227 & 21.725 \\
\hline
\end{tabular}

Fonte: dados da pesquisa.

Nota: ${ }^{1}$ I. Noroeste, II. Norte, III. Jequitinhonha, IV. Vale do Mucuri, V. Triângulo Mineiro/Alto Paranaíba, VI. Central, VII. Vale do Rio Doce, VIII. Oeste, IX. Sul/Sudoeste, X. Campo das Vertentes e XII. Zona da Mata. 
A Tabela 44 em apêndice mostra que na análise de correlação simples a taxa de retorno da educação está apenas estatisticamente correlacionada com a variável participação do setor de serviços nas mesorregiões. Também é ajustada uma equação tendo como variável dependente a taxa de retorno a educação (TRE) e as variáveis explicativas renda média $(\mu)$ das pessoas ocupadas e a participação do setor de serviços nas mesorregiões (PSER). O valor do coeficiente de determinação para a equação é $83,85 \%$ e o teste $\mathrm{F}$ é 29,55 . A equação estimada é (o teste $t$ entre parênteses):

$$
\text { TRE }=3,5694-0,0082 \mu+0,2244 \text { PSER }
$$

Embora não tenha sido obtida uma relação funcional entre a taxa de retorno da educação e o nível de desenvolvimento da mesorregião medido pelo IDH-M, observa-se que a taxa de retorno da educação está positivamente relacionada com a participação do setor de serviços nas mesorregiões mineiras. Em outras palavras isso significa que nas mesorregiões em que a participação do setor de serviços é maior, os indivíduos são melhor remunerados pelos seus anos adicionais de estudo. 


\subsection{Comparações da amostra do censo com os dados da PNAD de 2001}

Um dos objetivos propostos é fazer comparações de resultados entre a base de dados principal (amostra do censo) com a PNAD. Como nos anos censitários o IBGE não realiza PNAD, as comparações serão feitas com a PNAD de 2001. Já foi mencionado que os resultados das curvas de concentração do trabalho principal e de aposentadorias e pensões diferem de acordo com a base de dados usada. Como não é viável repetir todos os cálculos já feitos com os dados da PNAD, é apresentada, a seguir, a distribuição do rendimento domiciliar per capita de Minas Gerais em 2001.

De acordo com a PNAD de 2001, a amostra dos domicílios particulares permanentes em Minas Gerais, exclusive as pessoas cuja condição no domicílio é “pensionista, empregado doméstico e parente de empregado doméstico" é de 9.979, enquanto a amostra do censo de 2000, dadas as mesmas condições, inclui uma amostra 601.120 domicílios particulares permanentes.

No tratamento dos dados, chama a atenção o fato de que na PNAD de 2001 as observações com valores mais elevados para a renda domiciliar per capita são: $\mathrm{R} \$ 7.000,00 ; \mathrm{R} \$ 7.800,00 ; \mathrm{R} \$ 9.7000,00$ e $\mathrm{R} \$ 9.733,00$. Na amostra do censo os valores mais altos para a renda domiciliar per capita são: R\$ 145.106,00; R\$ 150.500,00, $\mathrm{R} \$ 164.450,00$ e R\$173.833,00. Após a exclusão dos domicílios com rendimentos de $\mathrm{R} \$ 100.000,00$ ou mais, os maiores valores observados passam a ser de $\mathrm{R} \$ 76.000,00$; $\mathrm{R} \$ 80.000,00$ (repetido três vezes) e $\mathrm{R} \$ 82.000,00$.

Nota-se, na Tabela 26, que as medidas de desigualdade e rendimento médio em Minas Gerais, de acordo com a PNAD de 2001, são menores do que as apresentadas pela amostra do censo. Segundo as estimativas do IBGE, em 2001 o PIB per capita mineiro correspondeu a $\mathrm{R} \$ 6.261,00$; transformando esse valor anual para mensal temos um PIB per capita de $\mathrm{R} \$ 521,75$. A renda domiciliar per capita média, de acordo com a PNAD de 2001 foi de $\mathrm{R} \$ 263,16$. A relação entre as duas variáveis é de 0,5. Já foi mostrada na seção 4.1 que essa mesma relação, considerando a renda domiciliar per capita da amostra do censo é de 0,55 . Nota-se que essa última relação está mais próxima de um do 
que a primeira, mostrando que a renda está um pouco menos subdeclarada na amostra do censo do que na PNAD.

Tabela 26. Principais características da distribuição do rendimento domiciliar per capita em Minas Gerais, de acordo com dados da PNAD de 2001 e da amostra do censo 2000 .

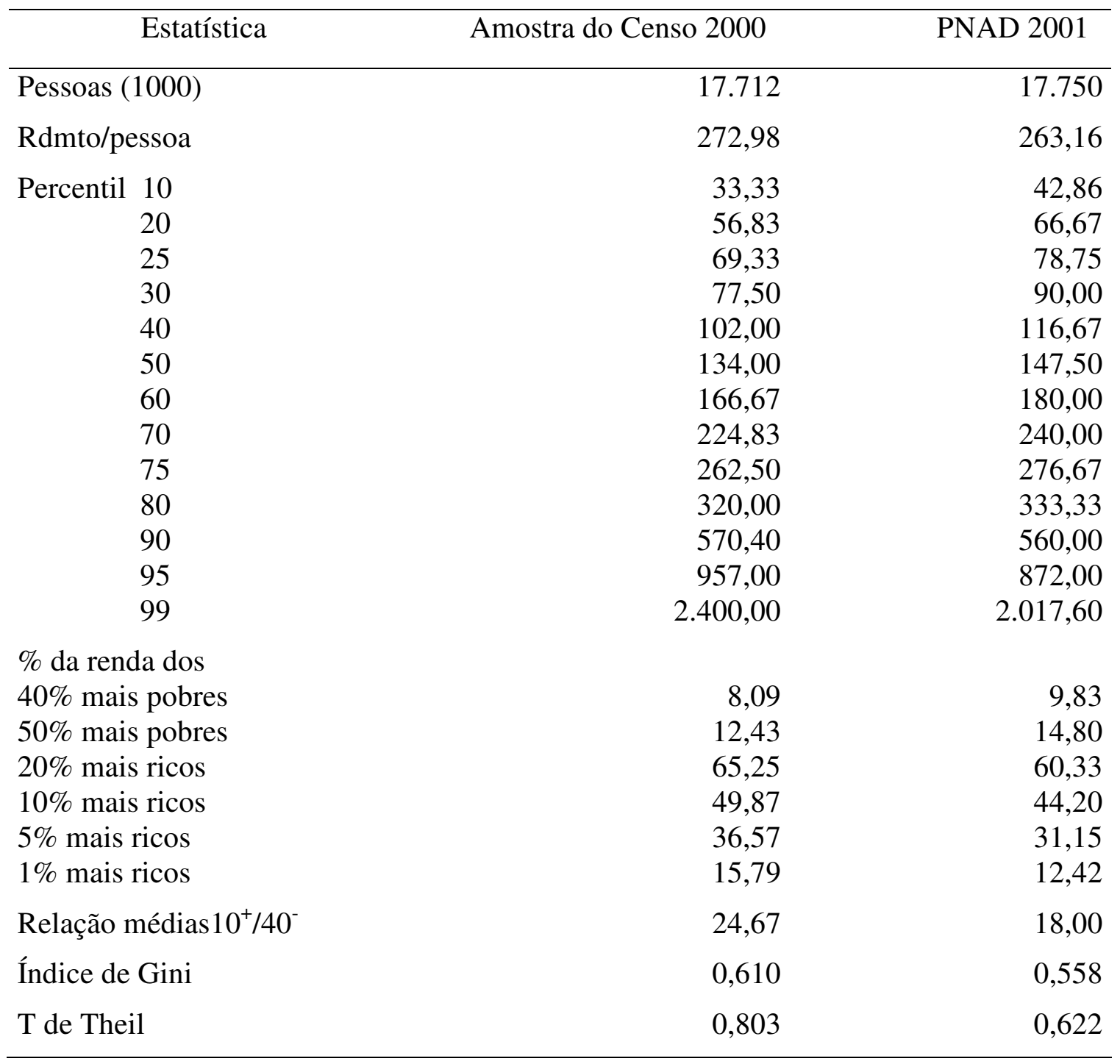

Fonte: dados da pesquisa.

1 Exclusive domicílios com pessoas com rendimento declarado no valor de $\mathrm{R} \$ 100.000,00$ ou mais. 
Acredita-se que as diferenças de resultados entre PNAD e censo, no que se refere à distribuição de renda, sejam, pelo menos em parte, decorrentes do fato de a amostra do censo ter um número muito maior de observações, ajudando a captar melhor os rendimentos extremamente elevados. Sendo assim, no censo o nível de subdeclaração dos rendimentos é menor e as medidas de desigualdade e posição central são maiores. Nas curvas de concentração, a explicação encontrada é que aposentadorias e pensões, como são geralmente rendimentos oficiais, tendem a ser menos subdeclarados em ambos os dados. Entretanto, o rendimento total é mais subdeclarado na PNAD do que na amostra do censo. Sendo assim, há uma maior subdeclaração do rendimento domiciliar per capita na PNAD. Isso faz com que a curva de Lorenz usando dados da PNAD fique mais à esquerda, em termos gráficos, do que a curva de Lorenz para o rendimento domiciliar per capita na amostra do censo. Assim, no primeiro caso a curva de concentração para aposentadorias e pensões fica um pouco abaixo da curva de Lorenz e no segundo caso fica um pouco acima da curva de Lorenz. 


\section{CONCLUSÕES}

O presente trabalho analisa a desigualdade de renda e a pobreza em Minas Gerais no ano 2000, tendo como contexto o nível de desenvolvimento das regiões mineiras.

De acordo com a metodologia empregada pelo IBGE, o estado mineiro é formado por 12 mesorregiões: Noroeste de Minas, Norte de Minas, Jequitinhonha, Vale do Mucuri, Triângulo Mineiro/Alto do Paranaíba, Central Mineira, Metropolitana de Belo Horizonte (sede da capital mineira), Vale do Rio Doce, Oeste de Minas, Sul/Sudoeste de Minas, Campo das Vertentes e Zona da Mata.

O nível de desenvolvimento das mesorregiões mineiras é medido pelo Índice de Desenvolvimento Humano Municipal (IDH-M), sendo ele composto por 3 outros índices (longevidade, renda e educação).

Os maiores valores para o IDH-M encontram-se nas mesorregiões Triângulo Mineiro/Alto Paranaíba, Região Metropolitana de Belo Horizonte (RMBH), Oeste de Minas, Sul/Sudoeste de Minas, Campo das Vertentes. Enquanto, os menores valores encontram-se nas mesorregiões Jequitinhonha, Vale do Mucuri, Norte de Minas, Vale do Rio Doce, Central Mineira, Noroeste de Minas e Zona da Mata. O primeiro grupo é classificado como as mesorregiões mais desenvolvidas do estado e o segundo grupo as menos desenvolvidas.

No estudo, dois tipos de distribuição são avaliadas: do rendimento domiciliar per capita, analisando o bem-estar da população mineira, e do rendimento das pessoas ocupadas, analisando o mercado de trabalho mineiro.

Na análise da distribuição do rendimento domiciliar per capita, observa-se que à medida que o grau de desenvolvimento das mesorregiões se eleva, maiores são os valores para a renda domiciliar per capita média, mostrando o grau de associação entre 
esses dois indicadores. Em situações extremas, tem-se o Vale do Jequitinhonha com a pior renda domiciliar per capita média e o pior IDH-M e, por outro lado, o Triângulo Mineiro/Alto Paranaíba com o melhor IDH-M mineiro e a segunda maior renda domiciliar per capita média do estado.

Verifica-se que a desigualdade da renda tende a ser menor nas mesorregiões mais desenvolvidas do que nas mesorregiões menos desenvolvidas, uma vez que as medidas de desigualdade das mesorregiões Vale do Mucuri, Norte de Minas, Jequitinhonha e Noroeste de Minas são as mais elevadas de Minas Gerais. Contudo, há uma exceção, a $\mathrm{RMBH}$, que mesmo sendo uma das mais desenvolvidas do Estado, apresenta uma das maiores medidas de desigualdade. Essa peculiaridade da RMBH, provavelmente, acontece pela presença da capital mineira, Belo Horizonte, que por ser um grande centro polarizador, tende a incluir os mais ricos do estado, sem deixar de incluir grande número de pobres. Entretanto, é importante ressaltar que mesmo nas mesorregiões que apresentam as menores medidas de desigualdade do estado, elas ainda são elevadas para os padrões internacionais.

O rendimento domiciliar per capita é divido em 7 componentes de componentes de rendimento: rendimento do trabalho principal; demais trabalhos; aposentadorias e pensões; aluguéis; pensão alimentícia, mesada, doação; renda mínima, bolsa escola, seguro desemprego; e outros rendimentos.O rendimento do trabalho principal é o componente de maior participação na renda domiciliar per capita em todas as mesorregiões, seguido pelo rendimento de aposentadorias e pensões.

Por meio da decomposição do índice de Gini é possível conhecer a contribuição das 7 parcelas do rendimento para a desigualdade de renda em Minas Gerais e nas mesorregiões mineiras.

Em Minas Gerais como um todo, os componentes do trabalho principal, aposentadorias e pensões e renda mínima/bolsa escola/seguro desemprego são menos concentrados do que o rendimento total. Contudo, é importante destacar que as aposentadorias e pensões, e trabalho principal são apenas ligeiramente menos concentrados do que o rendimento total. 
$\mathrm{Na}$ análise regional, observa-se que 3 parcelas do rendimento (pensão alimentícia, mesada, doação; aposentadorias e pensões; trabalho principal) encontram-se menos concentradas do que o rendimento total em algumas mesorregiões e mais concentradas que o rendimento total em outras mesorregiões. Demais trabalhos, aluguéis e outros rendimentos estão mais concentrados do que o rendimento total em todas as mesorregiões mineiras. Renda mínima/bolsa escola/seguro desemprego é o único componente que está menos concentrado do que o rendimento total nas 12 mesorregiões.

Dos 7 componentes do rendimento analisados nas mesorregiões, 3 merecem ser destacados: rendimento do trabalho principal, rendimentos de aposentadorias e pensões e renda mínima/bolsa escola e seguro desemprego, os dois primeiros pela participação considerável no rendimento domiciliar e o último por serem gastos sociais do governo.

Quanto ao rendimento do trabalho principal, constata-se que há uma associação negativa entre a sua razão de concentração e o nível de desenvolvimento das mesorregiões.

$\mathrm{Na}$ análise da parcela do rendimento proveniente de aposentadorias e pensões não se verifica relação dessa parcela com o nível de desenvolvimento das mesorregiões medido pelo IDH-M. Mas deve-se destacar que as 3 mesorregiões menos desenvolvida de Minas Gerais (Vale do Mucuri, Norte e Jequitinhonha) tem o rendimento de aposentadorias e pensões substancialmente menos concentrado do que o rendimento total domiciliar comparativamente com as demais mesorregiões. Mostra-se que isso decorre da concentração de aposentadorias e pensões iguais a 1 salário mínimo, provavelmente aposentadorias e pensões rurais, e poucas aposentadorias e pensões elevadas.

O rendimento renda mínima/bolsa escola e seguro desemprego possui a menor participação no rendimento domiciliar per capita, mas pela sua natureza de gasto social, é analisado mais detalhadamente. Este rendimento é o que mais contribui para diminuir a desigualdade de renda em todas as mesorregiões mineiras. Geralmente, esses rendimentos são de baixo valor, mas é um importante instrumento no combate à pobreza e à desigualdade de renda no médio prazo, dada a dificuldade de realizar reformas estruturais no modelo distributivo brasileiro. Os resultados na mensuração da pobreza 
mostram que, pelo menos em 2000, ainda existia uma grande população potencial para o recebimento desses benefícios.

Apesar da pequena participação das mesorregiões Vale do Mucuri, Jequitinhonha e Norte de Minas na população mineira, é preocupante a situação dessas mesorregiões, uma vez que metade da população dessas mesorregiões vivem em situação de pobreza. Além da desigualdade de renda ser elevada nessas mesorregiões, um grande contingente da população enfrenta uma situação de extrema pobreza. Os dados mostram que nessas mesorregiões a proporção de pessoas que vivem em domicílios com renda igual a zero é relativamente alta se comparando com as demais mesorregiões. Por outro lado, apesar da RMBH ser uma das mais desenvolvidas do estado, nela encontra-se concentrada quase 1/4 da população pobre de Minas Gerais. Isso mostra que é preciso busca, no plano estadual, políticas públicas que contemplem toda as regiões.

$\mathrm{Na}$ segunda parte do trabalho, é analisada a distribuição do rendimento das pessoas ocupadas. Observa-se que as medidas de desigualdade da distribuição do rendimento das pessoas ocupadas são relativamente menores do que as medidas de desigualdade apresentadas na análise da distribuição do rendimento domiciliar per capita. Isso acontece principalmente pelo fato de que na distribuição das pessoas ocupadas são excluídos os rendimentos iguais a zero. Já na análise do rendimento domiciliar per capita são contabilizadas as pessoas que vivem em domicílios sem nenhum rendimento.

Não foi possível estabelecer uma relação entre o nível de desenvolvimento das mesorregiões, medido pelo IDH-M, e a desigualdade de renda das pessoas ocupadas. Mesmo assim, os resultados mostram disparidades regionais na desigualdade de renda.

Aprofundando a análise do rendimento das pessoas ocupadas, foram estudados alguns dos condicionantes do rendimento por hora das pessoas ocupadas. Nota-se que a educação é o principal determinante da desigualdade de rendimentos no mercado de trabalho mineiro. Mas, quando a economia mineira é separada em setores de atividade (agrícola, indústria e serviços), no setor agrícola a variável posição na ocupação passa a ser o fator mais importante na explicação da desigualdade do rendimento hora. 
Outro fator que também afeta o rendimento das pessoas ocupadas em Minas Gerais é a região geográfica em que a pessoa reside. Os rendimentos pagos na RMBH são superiores comparativamente aos rendimentos pagos nas demais mesorregiões. Novamente, a presença da capital mineira nessa mesorregião a diferencia das demais. Além disso, outras variáveis como idade, sexo, cor, etc também estão influenciando o rendimento por hora no estado de Minas Gerais.

Devido à grande importância da escolaridade na determinação dos rendimentos, esse fator é analisado sob diferentes ângulos. Primeiro mostra-se que a taxa de retorno da educação não é constante em todos os níveis de escolaridade. Em anos de estudo que o individuo obtém diplomas de conclusão de curso o acréscimo é maior do que nos demais anos. Segundo, também é colocado que devido ao "threshold effect" há um aumento considerável na taxa de retorno da educação para os indivíduos que ultrapassam 10 anos de escolaridade. Por fim, é verificado se a educação sofre influência do desenvolvimento das mesorregiões. Apesar de haver diferenças entre mesorregiões na taxa de retorno da educação, não se constata a existência de uma relação monotônica entre essa taxa e o nível de desenvolvimento da mesorregião, medido pelo IDH-M. Mas se a participação do setor de serviços for considerada um indicador de desenvolvimento do mercado de trabalho, verifica-se que há uma relação positiva entre a taxa de retorno da educação e essa variável.

Em suma, os resultados apresentados, permitem aprofundar o conhecimento da distribuição da renda e da pobreza do Estado de Minas Gerais, identificando em nível regional as diferenças de desigualdade de renda, mostrando que esse problema atinge todas as regiões. 


\section{REFERÊNCIAS BIBLIOGRÁFICAS}

ABREU, J.F.; AMORIM FILHO, O.B.; RIGOTTI, J.I.R.; TORRES, M.E.L. Tipologia das regiões. In: BANCO DE DESENVOLVIMENTO DE MINAS GERAIS (BDMG) (Org.). Minas Gerais do século XXI. Belo Horizonte, 2002. v.2, cap.6, p.252-296.

ANÚARIO ESTATÍSTICO DE MINAS GERAIS - 2000, v.9, 2001. 582p.

BANCO DE DESENVOLVIMENTO DE MINAS GERAIS (BDMG). DEPARTAMENTO DE PLANEJAMENTO, PROGRAMA E ESTUDOS ECONOMICOS DO BDMG (DPE). Minas Gerais do século XXI. Belo Horizonte, 2002. v.1, cap.5, p.227-243: Minas Gerais no país e no mundo.

BARROS, R.P. de B.; MENDONÇA, R.S. Os determinantes da desigualdade no Brasil. Rio de Janeiro: IPEA, jul.1995. 63p. (Texto para discussão, 377)

BARROS, R.P. de B.; FOGUEL, M.N. Focalização dos gastos públicos sociais e erradicação da pobreza no Brasil. In: HENRIQUES, R. (Org.). Desigualdade e pobreza no Brasil. Rio de Janeiro: IPEA, 2000. p.719-739.

BARROS, R.P. de B.; HENRIQUES, R.; MENDONÇA, R. A estabilidade inaceitável: desigualdade e pobreza no Brasil. In: HENRIQUES, R. (Org.). Desigualdade e pobreza no Brasil. Rio de Janeiro: IPEA, 2000. p.21-47. 
BONELLI, R. Distribuição de renda no Brasil. Rio de Janeiro: IPEA, jan. 1993. 32p. (Texto para discussão, 288)

BRASIL. Ministério da Fazenda. Secretária de Política Econômica. Gasto social do governo central: 2001 e 2000. Brasília, nov. 2003. 47p.

DIAS, J.; MCDERMOTT, J. Aggregate threshold effects and the importance of human capital in economic development. In: ENCONTRO BRASILEIRO DE ECONOMETRIA, 25., Porto Seguro. 2003, Anais. Rio de Janeiro: SBE, 2003. p.550-569.

COELHO, A.M.; CORSEUIL, C.H. Diferenciais salariais no Brasil: um breve panorama. Rio de Janeiro: IPEA, ago. 2002. 26p. (Texto para discussão, 898)

CORRÊA, A.J. Distribuição de renda e pobreza na agricultura brasileira. Piracicaba: Editora UNIMEP, 1998. 260p.

COSTA, B.L.D.; CARNEIRO, C.B.L. Sugestões para política estadual de combate a pobreza persistente. In: BANCO DE DESENVOLVIMENTO DE MINAS GERAIS (BDMG) (Org.). Minas Gerais do século XXI. Belo Horizonte, 2002. v.2, cap.3, p.171-195.

FERREIRA, M.S. Rede de cidades em Minas Gerais a partir da realocação da indústria Paulista. Nova Economia, p.9-69, 1996. Número especial.

FERREIRA, F.H.G. Os determinantes da desigualdade de renda no Brasil: luta de classes ou heterogeneidade educacional. In: HENRIQUES, R. (Org.). Desigualdade e pobreza no Brasil. Rio de Janeiro: IPEA, 2000. p.131-158. 
FERREIRA, C.R. Participação das aposentadorias e pensões na desigualdade da distribuição da renda no Brasil. Piracicaba, 2003. 135p. Tese (Doutorado) - Escola Superior de “Agricultura Luiz de Queiroz,” Universidade de São Paulo.

FEDERAÇÃO DAS INDÚSTRIAS DO ESTADO DE MINAS GERAIS (FIEMG). Balanço da economia mineira e brasileira em 2002. Belo Horizonte, 2002. http://www.fiemg.com.br (01 jul. 2003)

FURTADO, C. Formação econômica do Brasil. 6.ed. São Paulo: Editora Nacional, 1967. 292p.

GREMAUD, A.P.; VASCONCELLOS, M.A.S. de; TONETO JUNIOR, R. Economia brasileira contemporânea. 4.ed. São Paulo: Editora Altas, 2002. 626p.

HOFFMANN, R. Distribuição de renda: medidas de desigualdade e pobreza. São Paulo: EDUSP, 1998a. 275p.

HOFFMANN, R. Desigualdade e pobreza no Brasil no período 1979/97 e a influência da inflação e do salário mínimo. Economia e Sociedade, n.11, p.199-221, dez. 1998 b.

HOFFMANN, R. Mensuração da desigualdade e pobreza no Brasil. In: HENRIQUES, R. (Org.). Desigualdade e pobreza no Brasil. Rio de Janeiro: IPEA, 2000. p.81-107.

HOFFMANN, R. Distribuição da renda no Brasil em 1999 (compact disc). In: CONGRESSO BRASILEIRO DE ECONOMIA E SOCIOLOGIA RURAL, 39., Recife, 2001. Anais. Brasília: SOBER, 2001a. 
HOFFMANN, R. Income distribution in Brazil and the regional and sectoral contrasts. In: GUILHOTO, J.J.M; HEWINGS, G.J.D. Structure and strutural change in brazilian economy. Aldershot: Ashgate, 2001b. p.85-106.

HOFFMANN, R. Distribuição de renda e crescimento econômico. Estudos Avançados, v.15, n.41, p.67-76, 2001c.

HOFFMANN, R. Distribuição da renda no Brasil: poucos com muito e muitos com muito pouco. In: DOWBOR, L.; KILSZTAJN, S. (Org.). Economia social no Brasil. São Paulo: SENAC, 2001d. p.43-69.

HOFFMANN, R. Posse da terra, renda e condições de vida na agricultura brasileira (compact disc). In: CONGRESSO BRASILEIRO DE ECONOMIA E SOCIOLOGIA RURAL, 40., Passo Fundo, 2002. Anais. Brasília: SOBER, jul. 2002a.

HOFFMANN, R. A distribuição da renda no Brasil no período 1992-2001. Economia e Sociedade, v.11, n.2, p.213-235, jul./dez. 2002b.

HOFFMANN, R. A contribuição das aposentadorias e do rendimento agrícola para a desigualdade do rendimento domiciliar per capita no Brasil. In: BENECKE, D.W.; NASCIMENTO, R. (Org.). Política social preventiva: desafio para o Brasil. Rio de Janeiro: Konrad Adenauer Stiftung, 2003. p.79-199.

INSTITUTO BRASILEIRO DE GEOGRAFIA E ESTATISTICA (IBGE). Pesquisa nacional por amostra de domicílios 1999: notas metodológicas (compact disc). Rio de Janeiro: IBGE, 2001a. 
INSTITUTO BRASILEIRO DE GEOGRAFIA E ESTATISTICA (IBGE). Censo Demográfico 2000: resultados do universo. Rio de Janeiro, $2001 \mathrm{~b}$. http://www.ibge.gov.br (01 jun. 2003)

INSTITUTO BRASILEIRO DE GEOGRAFIA E ESTATISTICA (IBGE). Contas regionais do Brasil - 2000. Rio de Janeiro, 2001c. http://www.ibge.gov.br (01 jun. 2003)

INSTITUTO BRASILEIRO DE GEOGRAFIA E ESTATISTICA (IBGE). Censo demográfico 2000: documentação dos microdados da amostra do censo (compact disc). Rio de Janeiro, 2002a.

INSTITUTO BRASILEIRO DE GEOGRAFIA E ESTATISTICA (IBGE). Pesquisa nacional por amostra de domicílios 2001 (compact disc). Rio de Janeiro, 2002b.

LANGONI, C.G. Distribuição da renda e desenvolvimento econômico do Brasil. Rio de Janeiro: Editora Expressão e Cultura, 1973. 312p.

KAGEYMA, A.; HOFFMANN R. Determinantes da renda e condições das famílias agrícolas no Brasil. Economia, v.1, n.2, p.147-183, 2000.

MINAS GERAIS (Estado). Programa integrado de uso da tecnologia de Geopressamento pelos órgãos do Estado de Minas Gerais: mapas http://www.geominas.gov.br (01 jun. 2003)

MOREIRA E MOREIRA, R. Estudo exploratório dos fatores que afetam a distribuição da renda nas microrregiões homogêneas no Brasil. Piracicaba, 1992. 150p. Dissertação (M.S) - Escola Superior de Agricultura "Luiz de Queiroz", Universidade de São Paulo. 
NEY, M.G.; HOFFMANN, R. O efeito da posse da terra na renda dos agricultores por conta própria e empregadores (compact disc). In: CONGRESSO BRASILEIRO DE ECONOMIA E SOCIOLOGIA RURAL, 40., Passo Fundo, 2002. Anais. Brasília: SOBER, jul. 2002.

QUEIROZ, B.L. Diferenciais regionais de salários nas microrregiões mineiras. Belo Horizonte, 2001. 191p. Dissertação (M.S) - Faculdade de Ciências Econômicas, Universidade Federal de Minas Gerais.

PRATES, F.M.; MACHADO, E.N. da M.; BATITUCCI, E.C.; ARAUJO, M.B. As condições de vida. In: BANCO DE DESENVOLVIMENTO DE MINAS GERAIS (BDMG) (Org.). Minas Gerais do século XXI. Belo Horizonte, 2002a. v.1, cap.3, p.139-179.

PRATES, F.M; MACHADO, E.N. da M.; BATITUCCI, E.C.; HADDAD, P.R. As transformações em curso In: BANCO DE DESENVOLVIMENTO DE MINAS GERAIS (BDMG) (Org.). Minas Gerais do século XXI. Belo Horizonte, 2002b. v.1, cap.2, p.61-134.

PROGRAMA DAS NAÇÕES UNIDAS PARA DESENOVOLVIMENTO (PNUD). Relatório de desenvolvimento humano 2002. Brasília, 2002. http://www. pnud. org.br (01 jul. 2003)

PROGRAMA DAS NAÇÕES UNIDAS PARA O DESENVOLVIMENTO (PNUD); FUNDAÇÃO JOAO PINHEIRO (FJP); INSTITUTO DE ECONOMIA APLICADA (IPEA). Atlas de desenvolvimento humano do Brasil (software). Rio de Janeiro, set. 2003. 
RAMOS, L.; VIEIRA, M.L. A relação entre educação e salários no Brasil. In: INSTITUTO DE ECONOMIA APLICADA (IPEA). A economia brasileira em perspectiva. Rio de Janeiro, 1996. v.2, p.493-510.

RAMOS, L.R.A.; REIS, J.G.A. Distribuição da renda: aspectos teóricos e o debate no Brasil. In: GIAMBIAGI, F.; CAMARGO, J.M. Distribuição de renda no Brasil. São Paulo: Paz e Terra, 1991. 237p.

RAMOS, L.; VIEIRA M.L. Desigualdade de rendimento no Brasil nas década de 80 e 90: evolução dos principais determinantes. Rio de Janeiro: IPEA, 2001. 22p. (Texto para discussão, 803)

ROCHA, S. Pobreza no Brasil: o que há de novo no limiar do século XXI ? Economia, v.1, n.2, p.73-106, jan./jun. 2001.

ROCHA, S. A investigação do rendimento na PNAD: comentários e sugestões à pesquisa nos anos 2000. Rio de Janeiro: IPEA, ago. 2002. 19p. (Texto para discussão, 899)

SANTANA, J.A. A influência da migração no processo de envelhecimento populacional das regiões de planejamento do Estado de Minas Gerias. Belo Horizonte, 2002. 111p. Dissertação (M.S) - Faculdade de Ciências Econômicas, Universidade Federal de Minas Gerais.

SANTOS, F.B.T. dos. A construção econômica recente. In: BANCO DE DESENVOLVIMENTO DE MINAS GERAIS (BDMG) (Org.). Minas Gerais do século XXI. Belo Horizonte, 2002. v.1, cap.1, p.15-56. 
APÊNDICE 
Tabela 27. Número de pessoas na amostra e na população com rendimento positivo para aposentadorias e pensões que residem na zona rural das mesorregiões e a sua participação, em 2000.

\begin{tabular}{lcccc}
\hline \multicolumn{1}{c}{ Mesorregião } & $\begin{array}{c}\mathrm{N}^{\mathrm{o}} \text { de aposent. e } \\
\text { pens. urbanos na } \\
\text { população }^{1}\end{array}$ & $\begin{array}{c}\mathrm{N}^{\mathbf{0}} \text { de aposent. } \\
\text { e pens. rurais } \\
\text { na população }\end{array}$ & $\begin{array}{c}\text { Participação para } \\
\text { aposent. e pens. } \\
\text { urbanos (\%) }\end{array}$ & $\begin{array}{c}\text { Participação } \\
\text { para aposent. e } \\
\text { pens. rurais } \\
(\%)\end{array}$ \\
\hline Noroeste & 23.117 & 6.912 & 76,98 & 23,02 \\
Norte de Minas & 97.293 & 56.522 & 63,25 & 36,75 \\
Jequitinhonha & 43.390 & 30.257 & 58,92 & 41,08 \\
Vale do Mucuri & 29.914 & 14.053 & 68,04 & 31,96 \\
Triângulo/ Alto & & & & \\
Paranaíba & 188.726 & 17.104 & 91,69 & 8,31 \\
Central Mineira & 40.849 & 6.771 & 85,78 & 14,22 \\
RMBH & 617.042 & 43.883 & 93,96 & 6,64 \\
Vale do Rio Doce & 152.816 & 46.897 & 76,52 & 23,48 \\
Oeste de Minas & 92.299 & 15.699 & 85,46 & 14,54 \\
Sul/Sudoeste & 225.617 & 49.162 & 82,11 & 17,89 \\
Campo das & & & & \\
Vertentes & 63.933 & 11.400 & 84,87 & 15,13 \\
Zona da Mata & 243.465 & 57.697 & 80,84 & 19,16 \\
\hline
\end{tabular}

Fonte: dados da pesquisa.

${ }^{1}$ aposent.$=$ aposentados e pens. $=$ pensionistas

Tabela 28. Distribuição dos domicílios e das pessoas em estratos de rendimento de aposentadorias e pensões em Minas Gerais, em 2000.

\begin{tabular}{lrrrrr}
\hline \multicolumn{1}{c}{ Estratos } & \multicolumn{2}{c}{ Amostra } & \multicolumn{2}{c}{ População } & \multirow{2}{*}{$\begin{array}{c}\text { Rdmto } \\
\text { médio }\end{array}$} \\
\cline { 2 - 5 } & \multicolumn{1}{c}{$\mathrm{N}^{\mathrm{O}}$} & $\%$ & $\mathrm{~N}^{\mathrm{O}}$ & $\%$ & \\
\hline Entre 0 e 151 & 25.785 & 9,31 & 184.685 & 8,49 & 128,13 \\
Igual a 151 & 156.742 & 56,61 & 1.161 .210 & 53,39 & 151,00 \\
Mais de 151 a 302 & 29.944 & 10,82 & 251.868 & 11,58 & 244,74 \\
Mais de 302 a 453 & 16.040 & 5,79 & 139.703 & 6,42 & 387,05 \\
Mais de 453 a 755 & 20.163 & 7,28 & 179.066 & 8,23 & 592,45 \\
Mais de 755 a 1510 & 19.216 & 6,94 & 175.060 & 8,05 & 1025,42 \\
Mais de 1510 a 3020 & 6.418 & 2,32 & 58.787 & 2,70 & $2.162,82$ \\
Mais de 3020 a 10.000 & 2.484 & 0,90 & 23.788 & 1,09 & $4.860,00$ \\
Mais de 10.000 & 72 & 0,03 & 659 & 0,03 & 12.707 \\
Total & 276.864 & 100 & 2.174 .826 & 100 & - \\
\hline
\end{tabular}

Fonte: dados da pesquisa. 
Tabela 29. Distribuição dos domicílios e das pessoas em estratos de rendimento de aposentadorias e pensões no Noroeste de Minas, em 2000.

\begin{tabular}{lrrrrr}
\hline \multicolumn{1}{c}{ Estratos } & \multicolumn{2}{c}{ Amostra } & \multicolumn{2}{c}{ População } & \multicolumn{2}{c}{ Rdmto } \\
\cline { 2 - 5 } & $\mathrm{N}^{\mathrm{o}}$ & $\%$ & $\mathrm{~N}^{\mathrm{o}}$ & $\%$ & \multicolumn{1}{c}{ médio } \\
\hline Entre 0 e 151 & 313 & 8,25 & 2.278 & 7,58 & 119,67 \\
Igual a 151 & 2.861 & 75,41 & 22.409 & 74,63 & 151,00 \\
Mais de 151 a 302 & 245 & 6,46 & 2.082 & 6,93 & 240,74 \\
Mais de 302 a 453 & 118 & 3,11 & 976 & 3,25 & 379,02 \\
Mais de 453 a 755 & 134 & 3,53 & 1.160 & 3,86 & 579,70 \\
Mais de 755 a 1510 & 87 & 2,29 & 814 & 2,71 & $1.022,89$ \\
Mais de 1510 a 3020 & 30 & 0,79 & 255 & 0,85 & $2.027,00$ \\
Mais de 3020 a 10.000 & 6 & 0,16 & 55 & 0,18 & $4.044,22$ \\
Mais de 10.000 & - & - & - & - & - \\
Total & 3.794 & 100 & 30.029 & 100 & - \\
\hline
\end{tabular}

Fonte: dados da pesquisa.

Tabela 30. Distribuição dos domicílios e das pessoas em estratos de rendimento de aposentadorias e pensões no Norte de Minas, em 2000.

\begin{tabular}{lrrrrr}
\hline \multicolumn{1}{c}{ Estratos } & \multicolumn{2}{c}{ Amostra } & \multicolumn{2}{c}{ População } & \multicolumn{1}{c}{ Rdmto } \\
\cline { 2 - 5 } & \multicolumn{1}{c}{$\mathrm{N}^{\mathrm{o}}$} & $\%$ & $\mathrm{~N}^{\mathrm{O}}$ & $\%$ & \multicolumn{1}{c}{ médio } \\
\hline Entre 0 e 151 & 4.950 & 24,03 & 35.267 & 22,93 & 141,86 \\
Igual a 151 & 12.671 & 61,52 & 92.388 & 60,06 & 151 \\
Mais de 151 a 302 & 1.152 & 5,59 & 9.493 & 6,17 & 249,62 \\
Mais de 302 a 453 & 541 & 2,63 & 4.758 & 3,09 & 386,34 \\
Mais de 453 a 755 & 632 & 3,07 & 5.815 & 3,78 & 579,01 \\
Mais de 755 a 1510 & 434 & 2,11 & 4.052 & 2,63 & $1.038,2$ \\
Mais de 1510 a 3020 & 162 & 0,79 & 1.530 & 0,99 & $2.074,64$ \\
Mais de 3020 a 10.000 & 53 & 0,26 & 513 & 0,33 & $4.573,92$ \\
Mais de 10.000 & - & - & - & - & - \\
Total & 20.595 & 100 & 153.816 & 100 & - \\
\hline
\end{tabular}

Fonte: dados da pesquisa. 
Tabela 31. Distribuição dos domicílios e das pessoas em estratos de rendimento de aposentadorias e pensões no Vale do Jequitinhonha, em 2000.

\begin{tabular}{lrrrrr}
\hline \multicolumn{1}{c}{ Estratos } & \multicolumn{2}{c}{ Amostra } & \multicolumn{2}{c}{ População } & \multicolumn{1}{c}{ Rdmto } \\
\cline { 2 - 5 } & $\mathrm{N}^{\mathrm{O}}$ & $\%$ & $\mathrm{~N}^{\mathrm{O}}$ & $\%$ & \multicolumn{1}{c}{ médio } \\
\hline Entre 0 e 151 & 2.529 & 22,93 & 17.679 & 24,01 & 142,37 \\
Igual a 151 & 7.086 & 64,24 & 45.459 & 61,73 & 151,00 \\
Mais de 151 a 302 & 701 & 6,36 & 4.825 & 6,55 & 255,87 \\
Mais de 302 a 453 & 257 & 2,33 & 1.892 & 2,57 & 384,79 \\
Mais de 453 a 755 & 214 & 1,94 & 1.687 & 2,29 & 568,39 \\
Mais de 755 a 1510 & 165 & 1,50 & 1.387 & 1,88 & $1.053,41$ \\
Mais de 1510 a 3020 & 60 & 0,54 & 563 & 0,76 & $2.110,7$ \\
Mais de 3020 a 10.000 & 16 & 0,15 & 137 & 0,19 & $4.403,53$ \\
Mais de 10.000 & 2 & 0,02 & 18 & 0,02 & $11.000,00$ \\
Total & 11.030 & 100 & 73.647 & 100 & - \\
\hline
\end{tabular}

Fonte: dados da pesquisa.

Tabela 32. Distribuição dos domicílios e das pessoas em estratos de rendimento de aposentadorias e pensões no Vale do Mucuri, em 2000.

\begin{tabular}{lcrrrr}
\hline \multicolumn{1}{c}{ Estratos } & \multicolumn{2}{c}{ Amostra } & \multicolumn{2}{c}{ População } & Rndmto \\
\cline { 2 - 5 } & $\mathrm{N}^{\mathrm{o}}$ & $\%$ & $\mathrm{~N}^{\mathrm{o}}$ & $\%$ & \multicolumn{1}{c}{ médio } \\
\hline Entre 0 e 151 & 1.082 & 17,10 & 6.713 & 15,27 & 137,00 \\
Igual a 151 & 4.279 & 67,63 & 29.495 & 67,09 & 151,00 \\
Mais de 151 a 302 & 395 & 6,24 & 2.925 & 6,65 & 245,6 \\
Mais de 302 a 453 & 186 & 2,94 & 1.493 & 3,40 & 384,16 \\
Mais de 453 a 755 & 192 & 3,03 & 1.599 & 3,64 & 577,04 \\
Mais de 755 a 1510 & 124 & 1,96 & 1.068 & 2,43 & $1.037,15$ \\
Mais de 1510 a 3020 & 57 & 0,90 & 555 & 1,26 & $2.169,77$ \\
Mais de 3020 a 10.000 & 12 & 0,19 & 118 & 0,27 & $5.823,4$ \\
Mais de 10.000 & - & - & - & - & - \\
Total & 6.327 & 100 & 43.966 & 100 & - \\
\hline
\end{tabular}

Fonte: dados da pesquisa. 
Tabela 33. Distribuição dos domicílios e das pessoas em estratos de rendimento de aposentadorias e pensões no Triângulo Mineiro/Alto Paranaíba, em 2000.

\begin{tabular}{lrrrrr}
\hline \multicolumn{1}{c}{ Estratos } & \multicolumn{2}{c}{ Amostra } & \multicolumn{2}{c}{ População } & \multicolumn{2}{c}{$\begin{array}{c}\text { Rdmto } \\
\text { médio }\end{array}$} \\
\cline { 2 - 5 } & \multicolumn{1}{c}{$\mathrm{N}^{\mathbf{0}}$} & $\%$ & $\mathrm{~N}^{\mathbf{0}}$ & $\%$ & \\
\cline { 2 - 5 } Entre 0 e 151 & 1.567 & 6,57 & 12.820 & 6,57 & 117,53 \\
Igual a 151 & 14.203 & 59,57 & 118.791 & 59,57 & 151,00 \\
Mais de 151 a 302 & 2.760 & 11,58 & 24.687 & 11,58 & 240,00 \\
Mais de 302 a 453 & 1.436 & 6,02 & 12.947 & 6,02 & 387,71 \\
Mais de 453 a 755 & 1.648 & 6,91 & 15.388 & 6,91 & 591,86 \\
Mais de 755 a 1510 & 1.543 & 6,47 & 14.597 & 6,47 & $1.018,21$ \\
Mais de 1510 a 3020 & 512 & 2,15 & 4.838 & 2,15 & $2.140,96$ \\
Mais de 3020 a 10.000 & 167 & 0,70 & 1.721 & 0,70 & $4.698,07$ \\
Mais de 10.000 & 5 & 0,02 & 42 & 0,02 & $12.574,54$ \\
Total & 23.841 & 100 & 205.831 & 100 & - \\
\hline
\end{tabular}

Fonte: dados da pesquisa.

Tabela 34. Distribuição dos domicílios e das pessoas em estratos de rendimento de aposentadorias e pensões na Central Mineira, em 2000.

\begin{tabular}{lcrrrr}
\hline \multicolumn{1}{c}{ Estratos } & \multicolumn{2}{c}{ Amostra } & \multicolumn{2}{c}{ População } & \multicolumn{1}{c}{ Rdmto } \\
\cline { 2 - 5 } & $\mathrm{N}^{\mathrm{o}}$ & $\%$ & $\mathrm{~N}^{\mathrm{o}}$ & $\%$ & médio \\
\hline Entre 0 e 151 & 380 & 5,26 & 2.649 & 5,56 & 112,73 \\
Igual a 151 & 4.265 & 59,01 & 30.826 & 64,73 & 151,00 \\
Mais de 151 a 302 & 591 & 8,18 & 4.580 & 9,62 & 243,00 \\
Mais de 302 a 453 & 365 & 5,05 & 2.993 & 6,29 & 389,76 \\
Mais de 453 a 755 & 391 & 5,41 & 3.159 & 6,63 & 588,24 \\
Mais de 755 a 1510 & 265 & 3,67 & 2.311 & 4,85 & $1.035,88$ \\
Mais de 1510 a 3020 & 936 & 12,95 & 790 & 1,66 & $2.047,45$ \\
Mais de 3020 a 10.000 & 34 & 0,47 & 312 & 0,66 & $4.579,00$ \\
Mais de 10.000 & - & - & - & - & - \\
Total & 7.227 & 100 & 47.620 & 100 & - \\
\hline
\end{tabular}

Fonte: dados da pesquisa. 
Tabela 35. Distribuição dos domicílios e das pessoas em estratos de rendimento de aposentadorias e pensões na Metropolitana de Belo Horizonte, em 2000.

\begin{tabular}{lrrrrr}
\hline \multicolumn{1}{c}{ Estratos } & \multicolumn{2}{c}{ Amostra } & \multicolumn{2}{c}{ População } & \multirow{2}{*}{ Rdmto médio } \\
\cline { 2 - 5 } & $\mathrm{N}^{\mathrm{O}}$ & $\%$ & $\mathrm{~N}^{\mathrm{o}}$ & $\%$ & \\
\hline Entre 0 e 151 & 3.910 & 5,36 & 32.949 & 4,99 & 114,20 \\
Igual a 151 & 32.217 & 44,14 & 277.647 & 42,01 & 151,00 \\
Mais de 151 a 302 & 10.364 & 14,20 & 95.600 & 14,46 & 241,63 \\
Mais de 302 a 453 & 5.916 & 8,11 & 56.134 & 8,49 & 386,15 \\
Mais de 453 a 755 & 8.128 & 11,14 & 77.063 & 11,66 & 593,17 \\
Mais de 755 a 1510 & 8.218 & 11,26 & 79.900 & 12,09 & $1.024,78$ \\
Mais de 1510 a 3020 & 2.851 & 3,91 & 27.927 & 4,23 & $2.188,75$ \\
Mais de 3020 a 10.000 & 1.335 & 1,83 & 13.269 & 2,01 & $5.004,67$ \\
Mais de 10.000 & 45 & 0,06 & 441 & 0,07 & $12.750,00$ \\
Total & 72.984 & 100 & 660.928 & 100 & - \\
\hline
\end{tabular}

Fonte: dados da pesquisa.

Tabela 36. Distribuição dos domicílios e das pessoas em estratos de rendimento de aposentadorias e pensões no Vale do Rio Doce, em 2000.

\begin{tabular}{lrrrrr}
\hline \multicolumn{1}{c}{ Estratos } & \multicolumn{2}{c}{ Amostra } & \multicolumn{2}{c}{ População } & \multirow{2}{*}{ Rdmto médio } \\
\cline { 2 - 4 } & $\mathrm{N}^{\mathrm{o}}$ & $\%$ & $\mathrm{~N}^{\mathrm{o}}$ & $\%$ & \\
\hline Entre 0 e 151 & 3317 & 11,96 & 21.208 & 10,62 & 135,09 \\
Igual a 151 & 17350 & 62,55 & 118.948 & 59,56 & 151,00 \\
Mais de 151 a 302 & 2263 & 8,16 & 17.395 & 8,71 & 247,93 \\
Mais de 302 a 453 & 1046 & 3,77 & 8.730 & 4,37 & 385,59 \\
Mais de 453 a 755 & 1558 & 5,62 & 13.553 & 6,79 & 603,33 \\
Mais de 755 a 1510 & 1705 & 6,15 & 15.450 & 7,74 & 1019,57 \\
Mais de 1510 a 3020 & 409 & 1,47 & 3.606 & 1,81 & 2056,81 \\
Mais de 3020 a 10.000 & 88 & 0,32 & 812 & 0,41 & 4215,77 \\
Mais de 10.000 & 1 & 0,00 & 11 & 0,01 & $10.239,00$ \\
Total & 27737 & 100 & 199.713 & 100 & - \\
\hline
\end{tabular}

Fonte: dados da pesquisa. 
Tabela 37. Distribuição dos domicílios e das pessoas em estratos do rendimento de aposentadorias e pensões no Oeste de Minas, em 2000.

\begin{tabular}{lrrrrr}
\hline \multicolumn{1}{c}{ Estratos } & \multicolumn{2}{c}{ Amostra } & \multicolumn{2}{c}{ População } & \multirow{2}{*}{ Rdmto médio } \\
\cline { 2 - 5 } & $\mathrm{N}^{\mathrm{o}}$ & $\%$ & $\mathrm{~N}^{\mathrm{O}}$ & $\%$ & \\
\hline Entre 0 e 151 & 852 & 6,28 & 6.560 & 6,07 & 112,98 \\
Igual a 151 & 8.292 & 61,07 & 63.275 & 58,59 & 151,00 \\
Mais de 151 a 302 & 1.538 & 11,33 & 12.986 & 12,02 & 248,50 \\
Mais de 302 a 453 & 845 & 6,22 & 7.188 & 6,66 & 390,19 \\
Mais de 453 a 755 & 958 & 7,06 & 8.446 & 7,82 & 593,23 \\
Mais de 755 a 1510 & 810 & 5,97 & 7.153 & 6,62 & $1.012,70$ \\
Mais de 1510 a 3020 & 223 & 1,64 & 1.884 & 1,74 & $2.138,29$ \\
Mais de 3020 a 10.000 & 56 & 0,41 & 481 & 0,44 & $4.561,89$ \\
Mais de 10.000 & 3 & 0,02 & 25 & 0,02 & $12.417,57$ \\
Total & 13.577 & 100 & 107.998 & 100 & - \\
\hline
\end{tabular}

Fonte: dados da pesquisa.

Tabela 38. Distribuição dos domicílios e das pessoas em estratos de rendimento de aposentadorias e pensões no Sul/Sudoeste de Minas, em 2000.

\begin{tabular}{lrrrrr}
\hline \multicolumn{1}{c}{ Estratos } & \multicolumn{2}{c}{ Amostra } & \multicolumn{2}{c}{ População } & \multirow{2}{*}{ Rdmto médio } \\
\cline { 2 - 4 } & $\mathrm{N}^{\mathrm{o}}$ & $\%$ & $\mathrm{~N}^{\mathrm{O}}$ & $\%$ & \\
\hline Entre 0 e 151 & 2.889 & 7,56 & 19.909 & 7,24 & 125,56 \\
Igual a 151 & 22.590 & 59,10 & 154.014 & 56,03 & 151,00 \\
Mais de 151 a 302 & 4.140 & 10,83 & 32.072 & 11,67 & 245,25 \\
Mais de 302 a 453 & 2.270 & 5,94 & 17.890 & 6,51 & 388,52 \\
Mais de 453 a 755 & 2.740 & 7,17 & 21.991 & 8,00 & 593,86 \\
Mais de 755 a 1510 & 2.521 & 6,60 & 20.187 & 7,38 & $1.019,05$ \\
Mais de 1510 a 3020 & 811 & 2,12 & 6.531 & 2,38 & $2.152,14$ \\
Mais de 3020 a 10.000 & 257 & 0,67 & 2.130 & 0,77 & $4.766,70$ \\
Mais de 10.000 & 7 & 0,02 & 55 & 0,02 & $13.498,59$ \\
Total & 38225 & 100 & 274.779 & 100 & - \\
\hline
\end{tabular}

Fonte: dados da pesquisa. 
Tabela 39. Distribuição dos domicílios e das pessoas em estratos de rendimento de aposentadorias e pensões no Campo das Vertentes, em 2000.

\begin{tabular}{lrrrrr}
\hline \multicolumn{1}{c}{ Estratos } & \multicolumn{2}{c}{ Amostra } & \multicolumn{2}{c}{ População } & \multirow{2}{*}{ Rdmto médio } \\
\cline { 2 - 5 } & $\mathrm{N}^{\mathrm{o}}$ & $\%$ & $\mathrm{~N}^{\mathrm{O}}$ & $\%$ & \\
\hline Entre 0 e 151 & 569 & 5,50 & 4.211 & 5,59 & 109,81 \\
Igual a 151 & 6.048 & 58,42 & 40.546 & 53,82 & 151,00 \\
Mais de 151 a 302 & 1.252 & 12,09 & 9.849 & 13,07 & 248,89 \\
Mais de 302 a 453 & 703 & 6,79 & 5.746 & 7,63 & 386,72 \\
Mais de 453 a 755 & 751 & 7,25 & 6.185 & 8,21 & 590,31 \\
Mais de 755 a 1510 & 709 & 6,85 & 6.004 & 7,97 & $1.040,46$ \\
Mais de 1510 a 3020 & 238 & 2,30 & 2055 & 2,73 & $2.112,30$ \\
Mais de 3020 a 10.000 & 81 & 0,78 & 733 & 0,97 & $4.860,23$ \\
Mais de 10.000 & 1 & 0,01 & 3 & 0 & $16.000,00$ \\
Total & 10.352 & 100 & 75.332 & 100 & - \\
\hline
\end{tabular}

Fonte: dados da pesquisa.

Tabela 40. Distribuição dos domicílios e das pessoas em estratos do rendimento de aposentadorias e pensões na Zona da Mata, em 2000.

\begin{tabular}{lrrrrr}
\hline \multicolumn{1}{c}{ Estratos } & \multicolumn{2}{c}{ Amostra } & \multicolumn{2}{c}{ População } & Rdmto médio \\
\cline { 2 - 5 } & $\mathrm{N}^{\mathrm{o}}$ & $\%$ & $\mathrm{~N}^{\mathrm{o}}$ & $\%$ & \\
\hline Entre 0 e 151 & 3.427 & 8,16 & 22.443 & 7,45 & 125,32 \\
Igual a 151 & 24.880 & 59,21 & 167.413 & 55,59 & 151,00 \\
Mais de 151 a 302 & 4.543 & 10,81 & 35.373 & 11,75 & 240,97 \\
Mais de 302 a 453 & 2.357 & 5,61 & 18.954 & 6,29 & 388,07 \\
Mais de 453 a 755 & 2.817 & 6,70 & 23.020 & 7,64 & 590,39 \\
Mais de 755 a 1510 & 2.635 & 6,27 & 22.137 & 7,35 & $1.036,79$ \\
Mais de 1510 a 3020 & 972 & 2,31 & 8.252 & 2,74 & $2.195,50$ \\
Mais de 3020 a 10.000 & 379 & 0,90 & 3.505 & 1,16 & $4.705,71$ \\
Mais de 10.000 & 8 & 0,02 & 63 & 0,02 & $12.673,00$ \\
Total & 42.018 & 100 & 301.160 & 100 & - \\
\hline
\end{tabular}

Fonte: dados da pesquisa. 
Tabela 41. Número de pessoas beneficiárias do rendimento renda mínima, bolsa escola seguro desemprego de valor $\leq \mathrm{R} \$ 151,00$ e que residem em domicílios com renda domiciliar per capita $\leq \mathrm{R} \$ 76,00$, conforme dados da amostra do censo de 2000.

\begin{tabular}{lccccc}
\hline \multicolumn{1}{c}{$\begin{array}{c}\text { Estado } \\
\text { Mesorregiões }\end{array}$} & $\begin{array}{c}\text { Pessoas } \\
\text { beneficiárias } \\
\text { na amostra }\end{array}$ & \multicolumn{2}{c}{$\begin{array}{c}\text { Pessoas beneficiárias } \\
\text { na população (a) }\end{array}$} & $\begin{array}{c}\mathrm{N}^{\mathrm{o}} \text { de pessoas } \\
\text { pobres }\end{array}$ & $\left(\begin{array}{c}\mathrm{a} \\
\text { n }\end{array}\right.$ \\
\cline { 3 - 4 } & & & $\%$ & & \\
Minas Gerais & 17.432 & 121.082 & 100 & 5.255 .478 & 2,30 \\
Noroeste & 332 & 3001 & 2,48 & 119.360 & 2,51 \\
Norte de Minas & 1312 & 8190 & 6,76 & 845.638 & 0,97 \\
Jequitinhonha & 3893 & 21146 & 17,46 & 419.529 & 5,04 \\
Vale do Mucuri & 219 & 1393 & 1,15 & 208.035 & 0,67 \\
Triângulo/ Alto & & & & & \\
Paranaíba & 443 & 3879 & 3,20 & 323.176 & 1,20 \\
Central Mineira & 243 & 1618 & 1,34 & 116.037 & 1,39 \\
RMBH & 4506 & 39577 & 32,69 & 1.247 .189 & 3,17 \\
Vale do Rio Doce & 2167 & 14355 & 11,86 & 602.989 & 2,38 \\
Oeste de Minas & 648 & 5157 & 4,26 & 162.448 & 3,17 \\
Sul/ Sudoeste & 819 & 5994 & 4,95 & 448.563 & 1,34 \\
Campo das & & & & 154.845 & \\
Vertentes & 375 & 2686 & 2,22 & & 1,73 \\
Zona da Mata & 2475 & 14086 & 11,63 & 607.665 & 2,32 \\
\hline
\end{tabular}

Fonte: dados da pesquisa. 
Tabela 42. Equações de rendimento para pessoas ocupadas em Minas Gerais, considerando o rendimento de todos os trabalhos, incluindo o "threshold effect", de acordo com a amostra do censo de 2000.

\begin{tabular}{|c|c|c|}
\hline Variáveis & Coeficientes & $\%$ renda esperada \\
\hline Constante & $-1,4124$ & - \\
\hline Sexo feminino & $-0,2741$ & $-23,97$ \\
\hline Idade/10 & 0,6271 & - \\
\hline$(\text { idade } / 10)^{2}$ & $-0,0603$ & - \\
\hline Escolaridade (até 10 anos) & 0,0778 & 8,09 \\
\hline Escolaridade (acima de 10 anos) & 0,1343 & 14,37 \\
\hline Cor: Preta & $-0,1552$ & $-14,38$ \\
\hline Amarela & 0,0986 & 10,36 \\
\hline Parda & $-0,0692$ & $-6,69$ \\
\hline Indígena & $-0,1143$ & $-10,80$ \\
\hline Pessoa de refer. na fam. & 0,1483 & 15,99 \\
\hline Domicílio rural & $-0,1315$ & $-12,32$ \\
\hline \multicolumn{3}{|l|}{ Posição na ocupação: } \\
\hline Conta própria & 0,0986 & 10,36 \\
\hline Empregador & 0,7791 & 117,95 \\
\hline Setor: Indústria & 0,1931 & 21,30 \\
\hline Serviços & 0,1886 & 20,75 \\
\hline Mesorregiões ${ }^{1}:$ I & $-0,1506$ & $-13,98$ \\
\hline II & $-0,3381$ & $-28,69$ \\
\hline III & $-0,3551$ & $-29,89$ \\
\hline IV & $-0,3100$ & $-26,66$ \\
\hline $\mathrm{V}$ & $-0,0563$ & $-5,47$ \\
\hline VI & $-0,2165$ & $-19,47$ \\
\hline VII & $-0,1918$ & $-17,45$ \\
\hline VIII & $-0,1319$ & $-12,36$ \\
\hline IX & $-0,0501$ & $-4,89$ \\
\hline $\mathrm{X}$ & $-0,2594$ & $-22,85$ \\
\hline XI & $-0,1841$ & $-16,81$ \\
\hline Número de observações & 830.198 & - \\
\hline $\mathrm{R}^{2}$ & 0,5001 & - \\
\hline $\mathrm{F}$ & 31.949 & - \\
\hline
\end{tabular}

Fonte: dados da pesquisa.

1 I. Noroeste, II. Norte, III. Jequitinhonha, IV. Vale do Mucuri, V. Triângulo Mineiro/Alto Paranaíba, VI. Central, VII. Vale do Rio Doce, VIII. Oeste, IX. Sul/Sudoeste, X. Campo das Vertentes e XII. Zona da Mata. 
Tabela 43. Equações de rendimento para pessoas ocupadas em Minas Gerais, considerando o rendimento de todos os trabalhos, conforme setor de ocupação, de acordo com a amostra do censo de 2000.

\begin{tabular}{|c|c|c|c|}
\hline \multirow{2}{*}{ Variáveis } & \multicolumn{3}{|c|}{ Coeficientes para } \\
\hline & Agrícola & Indústria & Serviço \\
\hline Constante & $-0,8122$ & $-1,4022$ & $-1,9419$ \\
\hline Sexo feminino & $-0,1029$ & $-0,2987$ & $-0,2559$ \\
\hline Idade/10 & 0,2055 & 0,6779 & 0,8361 \\
\hline$(\text { idade/10) })^{2}$ & $-0,0175$ & 0,0661 & $-0,0786$ \\
\hline Escolaridade & 0,0667 & 0,0988 & 0,1261 \\
\hline Cor: Preta & $-0,1119$ & $-0,1455$ & $-0,1726$ \\
\hline Amarela & 0,1667 & 0,2368 & 0,0405 \\
\hline Parda & $-0,0743$ & $-0,1150$ & $-0,1372$ \\
\hline Indígena & $-0,0568$ & $-0,1236$ & $-0,0805$ \\
\hline Pessoa de refer. na fam. & 0,1697 & 0,1968 & 0,1389 \\
\hline Domicílio rural & $-0,1207$ & $-0,1407$ & $-0,0745$ \\
\hline Posição na ocupação: & & & \\
\hline Conta própria & 0,1699 & $-0,0198$ & 0,6654 \\
\hline Empregador & 1,4817 & 0,0988 & 0,1326 \\
\hline Mesorregiões $^{1}$ : I & 0,1832 & $-0,1954$ & $-0,1997$ \\
\hline II & $-0,1572$ & $-0,3620$ & $-0,3193$ \\
\hline III & $-0,1646$ & $-0,4156$ & $-0,3235$ \\
\hline IV & $-0,1528$ & $-0,3448$ & $-0,2794$ \\
\hline $\mathrm{V}$ & 0,3033 & $-0,0741$ & $-0,0998$ \\
\hline VI & 0,0859 & $-0,2226$ & $-0,2490$ \\
\hline VII & $-0,0655$ & $-0,1147$ & $-0,2015$ \\
\hline VIII & 0,1011 & $-0,0919$ & $-0,1808$ \\
\hline IX & 0,2646 & $-0,0548$ & $-0,1070$ \\
\hline $\mathrm{X}$ & $-0,0744$ & $-0,2611$ & $-0,2574$ \\
\hline XI & 0,0069 & $-0,1750$ & $-0,1946$ \\
\hline Observações & 195.486 & 179.949 & 454.763 \\
\hline $\mathrm{R}^{2}$ & 0,3027 & 0,4144 & 0,5106 \\
\hline $\mathrm{F}$ & 3.688 & 5.535 & 20.629 \\
\hline
\end{tabular}

Fonte: dados da pesquisa.

1 I. Noroeste, II. Norte, III. Jequitinhonha, IV. Vale do Mucuri, V. Triângulo Mineiro/Alto Paranaíba, VI. Central, VII. Vale do Rio Doce, VIII. Oeste, IX. Sul e Sudoeste, X. Campo das Vertentes e XII. Zona da Mata. 
Tabela 44. Correlação simples entre a taxa de retorno da educação, o IDH-M, renda média das pessoas ocupadas e participação do setor de serviços nas mesorregiões mineiras e probabilidade caudal do teste de hipótese de ausência de correlação, em 2000.

\begin{tabular}{lcc}
\hline & $\begin{array}{c}\text { Taxa de retorno da } \\
\text { educação }\end{array}$ & $\begin{array}{c}\text { Probabilidade caudal } \\
\text { teste }\end{array}$ \\
\hline IDH -M & $-0,005$ & 0,1601 \\
Renda média das pessoas ocupadas & 0,433 & 0,9881 \\
Participação do setor de serviços & 0,836 & 0,0007 \\
\hline
\end{tabular}

Fonte: dados da pesquisa. 